\title{
12 Sonstige Beschwerden und Erkrankungen
}

12.1 Diabetes mellitus

12.1.1 Rangverschiebung in der Statistik

12.1.2 Vermeintlich klassische Symptome

12.1.3 Verändertes Problembewußtsein

12.1.4 Diät

12.1.5 Diabeteskost: Zur Psychologie bei Arzt und Patient

12.1.6 Selbstkontrolle - Arztkontrolle

12.2 Uncharakteristische Kopfschmerzen, Migräne

12.2.1 Situationshypothese

12.2.2 Fällestatistik

12.2.3 Klassifizierung von Symptomen

12.2.4 Intuition und Programmierte Diagnostik

12.2.5 Praktisches Vorgehen

12.3 Varizen

12.3.1 Überlappung der Fachgebiete

12.3.2 Patientenklage und Selbstmaßnahmen

12.3.3 Thrombophlebitis-Bilder

12.3.4 Phlebothrombose-Bilder

12.3.5 Beinkrämpfe

12.3.6 Arterielle Verschlußkrankheit, Extremitätenembolien

12.4 Schlafstörungen/Schlaflosigkeit (Agrypnie)

12.4.1 Tips zur Patientenführung

12.5 Bilder von Masern, Röteln, Varizellen, Mumps, Scharlach

Die in den Kapiteln B 1-11 vorgenommene Aufteilung läßt für das verbliebene Kapitel 12 einen völlig inhomogenen Rest „sonstiger“ Beratungsergebnisse zurück. Da in der Medizin die Krankheits- und auch Klassifizierungsbegriffe sehr verschiedener Natur sind, gibt es in allen Systematiken Restrubiken, die bunt zusammengesetzt sind.
12.5.1 Streptokokkenangina oder Scharlach?

12.5.2 Impfungen

12.6 Gewichtsveränderungen

12.6.1 Gewichtszunahme

12.6.2 Gewichtsabnahme

12.7 Fußübel und statische Beschwerden

12.7.1 Klavus

12.7.2 Kalte Füße

12.7.3 Senk- und Spreizfüße

12.7.4 Onychogryposis

12.7.5 Tarsalgien

12.7.6 Hallux valgus

12.8 Kropf und Schilddrüsenüberfunktion

12.9 Gutartige Neubildungen

12.9.1 Knoten in der Brust

12.9.2 Gynäkomastie

12.9.3 Lymphomata

12.10 Bursitis, Hygrom, Tendovaginitis, Ganglion, Epikondylitis

12.10.1 Bursitis acuta

12.10.2 Bursitis chronica

12.10.3 Hygrom

12.10.4 Tendovaginitis

12.10.5 Ganglion

12.10.6 Epikondylitis

12.11 Anämie

Thematik des Fachgesprächs

\subsection{Diabetes mellitus}

Die Furcht, zuckerkrank zu werden, ist in der Bevölkerung weit verbreitet. Manchem Laien sind vom Hörensagen schwere Spätschäden des Diabetes mellitus (C/D), z.B. Verlust des Sehvermögens oder Amputation eines Beines, bekannt.

Vielleicht wird über die Zuckerkrankheit in der Bevölkerung deswegen so viel gesprochen, weil ei- 
nerseits die Gewinnung des Ausgangsmaterials (Harn) für die Untersuchung jederzeit problem- und schmerzlos möglich ist und zudem die Analyse selbst durch Teststreifen rasch, einfach und preiswert erfolgen kann.

Aber nicht nur die schweren Spätschäden, auch vermeintliche Frühsymptome (z.B. vermehrter Durst, Hautjucken) und das Wissen um familiäre Prädisposition sind zunehmend im Gesundheitsbewußtsein der Menschen verankert.

\subsubsection{Rangverschiebung in der Statistik}

Während der Diabetes mellitus in der Statistik der 50er Jahre noch Rang 144 eingenommen hatte [31], ist er im Krankengut der späten 70er [37], der 80er [151] und der frühen 90er Jahre [237] auf Platz 15 bzw. 28 bzw. 41 vorgerückt. Die Einflüsse, die zu dieser Rangverschiebung beigetragen haben, dürfen v.a. bei den durch die Überflußgesellschaft veränderten Eßggewohnheiten und der daraus häufig resultierenden Übergewichtigkeit zu suchen sein. Dazu kommen noch Rückgang der schweren körperlichen Arbeit, Trägheit sowie steigende Lebenserwartung. Daneben spielt gewiß auch die veränderte Diagnostik des Arztes mit der viel häufigeren Anwendung von Laboranalysen eine Rolle.

Am Diabetes erkranken bekanntlich v.a. die höheren Altersgruppen und da wiederum das weibliche Geschlecht. Das bestätigen langjährige Statistiken aus dem allgemeinmedizinischen Krankengut [37]. Jeder Allgemeinarzt wird dies aus seiner Erfahrung heraus bejahen können.

Bei 59 von 82 Diagnostischen Programmen für den Hausarzt wird eine Urinuntersuchung angeraten; erfahrungsgemäß wird jedoch trotz der massenhaft durchgeführten Streifentests nur selten ein neuer Diabetes mellitus entdeckt.

Ebenso steht es mit den Gesundenuntersuchungen. Auch dort ist die Erstfeststellung eines Diabetes die ganz große Ausnahme (vgl. unten).

\subsubsection{Vermeintlich klassische Symptome}

Jeder Hausarzt veranlaßt heute im Lauf der langjährigen Betreuung seiner Patienten aus verschiedenen Gründen, oftmals auch routinemäßig, wiederholt Urin- und Blutuntersuchungen, einschließlich auch auf Glukose. Darüber hinaus werden anläßlich verschiedener Früherkennungsmaßnahmen der Kassen, der Berufsgenossenschaften und im Rahmen von Untersuchungen von Jugendlichen nach dem $\mathrm{Ar}$ beitsschutzgesetz, bei Einstellungsuntersuchungen, bei Anforderungen von Gutachten der Versicherer usw. ebenfalls Analysen auf Urinzucker vorgenommen und die Blutzuckerwerte erhoben.

Dadurch ist heute die frühe Aufdeckung eines Diabetes mellitus in der Allgemeinpraxis die Regel geworden. Als Ausnahme davon gibt es jedoch von Zeit zu Zeit einen überraschend stark positiven Harnzukkertest bzw. einen weit überhöhten Blutzuckerwert und das, obwohl der Patient diesbezüglich jahrelang unauffällig war. In solchen Fällen lenken erfahrungsgemäß nicht die vermeintlich klassische Klage ,,vermehrter Durst" in Richtung Diabetes, sondern Beratungsursachen wie ,Juckreiz in der Scheide oder auf der Eichel“, ,erneut auftretende Abszesse“, ,unerwartet schwerer Krankheitsverlauf", ,allgemeine Mattigkeit" oder "Gewichtsverlust". Gelegentlich bietet der Betroffene keine besonderen Symptome.

Krause hatte erstmals berufstheoretisch nachweisen können, wie häufig die sog. ,klassischen“ Diabetessymptome vorkommen und wie erstaunlich selten sie auf diabetischer Grundlage entstehen: „Es ist nicht alles Diabetes, was Durst hat" [136].

Bei jedem neuen Patienten, der sich bei einem Allgemeinarzt, insbesondere mit unklarer Symptomatik, vorstellt, sollte der Urin mittels Streifentest untersucht werden. Es geht dabei klarerweise nicht nur um den Diabetes, sondern auch um Nephropathien und anderes. Bei Patienten mit sog. Risikoprofil sollte auch nach einem latenten Diabetes mellitus gefahndet werden.

Spezialisten (z.B. Augenarzt, Nervenarzt, Hautarzt, Angiologe) treten bei Abklärung bestimmter, auch mit Diabetes mellitus vergesellschafteter Beratungsprobleme, an den Hausarzt heran, eine Zuckerkrankheit auszuschließen. Dabei ist die Neuentdeckung eines Diabetes mellitus erfahrungsgemäß auch hier die Ausnahme von der Regel.

\subsubsection{Verändertes Problembewußtsein}

Während der Patient bei den Konsultationen meist schon damit zufrieden ist, offensichtlich nicht an ,Zucker“ erkrankt zu sein, geht es dem Arzt heute 
darum, das Netzwerk atherogener Risikofaktoren (metabolisches Syndrom) frühzeitig zu erfassen (z.B. Adipositas - vgl. B 12.6.1; Gichtanfälle - vgl. Zusatzfragen „Hyperurikämie, Arthritis urica, Gicht“ auf S. 64; koronare Herzkrankheit - vgl. B 5.3; Hypertonie - vgl. B 5.7; Fettstoffwechselstörung - vgl. C 1.2.2; familiäre Disposition - vgl. C 1.2.2).

Durch gezielte Maßnahmen (z.B. Diabetikerschulung, Gewichtsreduktion, Änderung der Ernährungsweise, vermehrte Bewegung, Vermeidung diabetogener Medikamente) kann manchmal das Manifestwerden einer Zuckerkrankheit hinausgezögert werden.

Eine solche langzeitgerichtete Denkweise ist heute in allen ärztlichen Fachgebieten eine Selbstverständlichkeit. Die Compliance der Patienten freilich ist leider unbefriedigend.

\subsubsection{Diät}

„Diät ist die Grundlage jeder Diabetestherapie“. Dieses Prinzip besitzt weiterhin seine Gültigkeit, obwohl der Faktor Diät im Diabetesbehandlungskonzept nur einer von mehreren therapeutischen Gesichtspunkten ist (Abb. 94).

Wesentlich für die Höhe des Blutzuckers ist die Zufuhr an Kohlenhydraten. Die Mengen der anzurechnenden Kohlenhydrate werden in Deutschland und Österreich in Broteinheiten (BE) angegeben. Dadurch lassen sich die Nahrungsmittelmengen leichter abschätzen; $1 \mathrm{BE}$ besitzt dieselbe Blutzuckerwirkung wie $12 \mathrm{~g}$ Traubenzucker (=50 kcal). In der Praxis entsprechen 1 BE z.B.:

1 (hühnereigroße) Kartoffel, 1 mittelgroßer Apfel, 1/2 Brötchen, 1/2 Scheibe Brot oder 1 Glas Milch.

„Frei“", weil sie den Blutzucker kaum erhöhen, sind fast alle Gemüsesorten in üblichen Mengen, wenn sie entsprechend zubereitet wurden.

Eine realistische Kohlenhydratezumessung liegt bei Alltagsbedingungen auf Dauer nicht unter $12 \mathrm{BE}$. Ein Berechnungsbeispiel für den täglichen Energiebedarf bei 3 verschiedenen Berufen gibt Übersicht 40 .

Allen 3 Berechnungsbeispielen liegen isokalorische Kostbedingungen zugrunde, d.h. eine Gewichtsänderung findet nicht statt. Nun hatten aber die Personen in allen 3 Beispielen leichtes Übergewicht, so daß man hier pro Tagesbedarf $10 \%$ abrechnen kann, will man eine Gewichtsabnahme erreichen.
Übersicht 40. Berechnungsbeispiel für den unterschiedlichen Energiebedarf in Abhängigkeit vom Beruf [13]

\section{Sekretärin}

Größe 160 cm

Körpergewicht $66 \mathrm{~kg}$

Broca-Index 1,10

Energiebedarf pro Tag $60 \mathrm{~kg} \times 24=1440 \mathrm{kcal}$ Grund-

umsatz

+ Leistungsumsatz $(1 / 3)=440 \mathrm{kcal}$

Gesamtenergiebedarf/Tag $=1880 \mathrm{kcal}$

Mechaniker

Größe $170 \mathrm{~cm}$

Körpergewicht $80 \mathrm{~kg}$

$10 \mathrm{~kg}$ Übergewicht

Broca-Index 1,15

Sollgewicht $70 \mathrm{~kg}$

Energiebedarf pro Tag $70 \mathrm{~kg} \times 24=1680 \mathrm{kcal}$ Grundumsatz

+ Leistungsumsatz (ca. $45 \%$ ) $=760 \mathrm{kcal}$

Gesamtenergiebedarf $/ \mathrm{Tag}=2440 \mathrm{kcal}$

\section{Zimmermann}

Größe $180 \mathrm{~cm}$

Körpergewicht $92 \mathrm{~kg}$

Broca-Index 1,15

Sollgewicht $80 \mathrm{~kg}$

Energiebedarf pro Tag $80 \mathrm{~kg} \times 24=1920 \mathrm{kcal}$ Grund-

umsatz

+ Leistungsumsatz $(70 \%)=1344 \mathrm{kcal}$

Gesamtenergiebedarf/Tag $=3264 \mathrm{kcal}$

Die täglich vom Körper benötigten Energiemengen unterteilen sich in den

Grundumsatz: Das ist diejenige Energie, die der Organismus täglich zum Leben braucht (sie liegt in der Größenordnung von $24 \mathrm{kcal}$ pro kg Sollgewicht, so daß z.B. ein $60 \mathrm{~kg}$ schwerer Mensch mit ca. $1440 \mathrm{kcal}$ Grundumsatz pro Tag rechnen muß) und in den

Leistungsumsatz: Das ist der Energieanteil, der für körperliche Betätigung zusätzlich erforderlich und demzufolge abhängig ist von der Art und Dauer der körperlichen Tätigkeit (Übersicht 40).

Generell gilt, daß leichte Arbeit etwa $1 / 3$ des Grundumsatzes, mittelschwere etwa $40-50 \%$ und Schwerstarbeit 6() $70 \%$ zusätzlich an Energie benötigen.

Die Verordnung der Broteinheiten (BE) hängt ab

- vom Körpergewicht,

- vom Ausmaß der körperlichen Bewegung in Beruf und Freizeit,

- vom Alter (individuelle Diät!). 


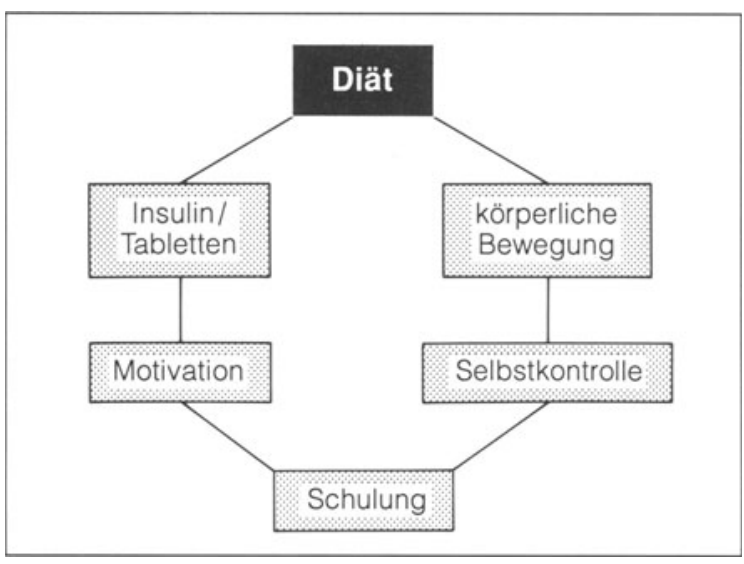

Abb. 94. Diabetesbehandlung. Aktuelles Konzept [13]

Der empfohlene Energieanteil an Kohlenhydraten in der Diabetesdiät liegt bei 40-50\% des totalen Energiebedarfs. Obwohl beim Diabetes v.a. die Kohlenhydrate in den Nahrungsmitteln interessieren, muß letztlich die Gesamtkalorienzahl in der Diätberechnung auf der Basis des gegebenen Brennwertes (Joule/J) berücksichtigt werden. Dies ist beispielsweise in Amerika ausschließlich der Fall.

Es gibt kohlenhydrathaltige Nahrungsmittel, nach denen der Blutzucker aufgrund der unterschiedlichen faserreichen Struktur

- nicht oder kaum,

- deutlich oder

- sehr schnell ansteigt (,glykämischer Index“)

(Tabelle 61).

Diskussionen gibt es seit Jahren um den Stellenwert des beliebten Nahrungsmittels Honig in der Diabetesdiät. Galt der Genuß früher als krasser Diätfehler, so ist Honig aufgrund des jetzt bekannten glykämischen Index von $87 \%$ durchaus ein Produkt, das man in der Diabetesdiät einsetzen kann [176].

Für den Diabetiker empfehlen sich 5-7 Mahlzeiten pro Tag, wobei $35 \%$ des täglichen Joule-(Kalorien-)Bedarfs mit dem ersten und zweiten Frühstück gedeckt werden sollen.

Die Kohlenhydrate auf möglichst viele Mahlzeiten zu verteilen bedeutet (im Gegensatz beispielsweise zu 3 großen Essen), daß die Insulinfreisetzung nicht jedes Mal zu stark strapaziert wird. Dadurch werden Blutzuckerschwankungen erheblich abgeschwächt.
Tabelle 61. Glykämischer Index (Gl). Maß für die Resorptionsgeschwindigkeit der Kohlenhydrate (BZ = Blutzucker) [13]

\begin{tabular}{|l|l|r|}
\hline & Lebensmittel & $\begin{array}{c}\text { GI } \\
{[\%]}\end{array}$ \\
\hline Hoher GI: & Malzzucker & 100 \\
schnelle & Traubenzucker & 100 \\
Resorption, & Karotten & 92 \\
steiler BZ- & Kartoffelbrei/Cornflakes & 80 \\
Anstieg & Bohnen (breit) & 79 \\
& Graubrot, weißer Reis & 72 \\
& Salzkartoffeln & 70 \\
& Weißbrot & 69 \\
\hline Mittlerer GI: & Müsli, brauner Reis & 66 \\
verzögerte & Bananen & 62 \\
Resorption, & Rohrzucker & 59 \\
abgeschwächter & Schrot+Korn (,All-Bran-Cereal“) & 51 \\
BZ-Anstieg & Haferbrei & 49 \\
& Spaghetti & 42 \\
\hline Niedriger Gl: & Trockenbohnen & 40 \\
langsame & Orangen & 40 \\
Resorption, & Äpfel & 39 \\
flacher BZ- & Yoghurt, Eiscrem & 36 \\
Anstieg & Milch & 34 \\
& Trockenerbsen & 33 \\
& Linsen & 29 \\
& Fruktose & 20 \\
& Sojabohnen & \\
\hline
\end{tabular}

Auch bei den diätetischen Lebensmitteln für Diabetiker gilt es, die Broteinheiten und den oft sehr hohen Fettgehalt zu beachten. So muß jeder Diabetikerzucker nach BE berechnet werden. Eine kleine Portionsschale mit Diabetikermarmelade schlägt beispielsweise bereits mit $1 \mathrm{BE} \mathrm{zu}$ Buche. Im übrigen kann der Zuckeraustauschstoff Sorbit Durchfälle verursachen.

Die Problematik der Berechnung nach Broteinheiten (BE) wird auch an dem sog. ,Diätmittel“ Diabetikerbier deutlich: Obwohl es zwar durch seinen reduzierten Kohlenhydratanteil besticht, belastet es die Gesamtenergiebilanz durch seinen Alkoholanteil nicht unerheblich.

\subsubsection{Diabeteskost: Zur Psychologie bei Arzt und Patient}

Wie viele andere chronisch Kranke (Herzkranke, Hypertoniker, Rheumatiker), fordert auch der Zukkerkranke die psychologischen und pädagogischen 
Fähigkeiten seines Hausarztes heraus. Jeder Diabetespatient ist zunächst einmal verschreckt vom Wort „Diät“. Er sieht nur noch den Verzicht auf liebgewordene Eßgewohnheiten und fühlt sich in seiner Lebensfreude wesentlich eingeschränkt. Die Einhaltung und Überwachung einer angemessenen Diät stellen daher den Kranken gleichermaßen wie den Arzt vor vielfältige Aufgaben und Probleme: Einerseits wissen die Patienten, daß eine Diät nötig ist, andererseits halten sie sich - allen Vorhaltungen zum Trotz - erfahrungsgemäß um so weniger an die ärztlichen Vorschriften, je länger sie (ohne lästige Symptome) zuckerkrank sind.

Da Diätfehler beim Diabetiker - im Gegensatz zur Gicht - bekanntlich keine Schmerzen auslösen („Diabetes tut nicht weh!“), denkt der symptomlose Patient im allgemeinen, daß es mit seiner Krankheit nicht so schlimm sei, daß er also auch mal ,sündigen“ oder die Therapie wechseln könne. Das geschieht zunächst auch ohne besondere Folgen. So schiebt er seine fälligen Kontrolluntersuchungen des Blutzukkers z.B. auf die Zeit nach der Kirschenernte hinaus, er weicht auf „Wundermittel“ (wie Sauerkrautsaft und Diabetikertee) aus oder erhöht eigenmächtig die bewußt vorgegebene Tablettenmengen, damit er ,nicht auffällt“. Aus Angst vor einer Rüge durch seinen Hausarzt hält er einige Tage vor der Kontrolle strenge Diät ein, um es nachher damit wieder weniger ernst zu nehmen. Je geringer der Leidensdruck, je vertrauter der Zustand oder je stabiler der Verlauf zu sein scheint, um so eher hört er außerdem auf nichtärztlichen Rat.

Die Zuckerkranken lassen sich - wie alle anderen Menschen auch - verführen, Dinge zu essen, von denen sie wissen, daß sie sie nicht konsumieren sollten. Dieses Problem ist jedem erfahrenen Arzt bewußt.

Der Nachholbedarf für eine effektive Patientenerziehung erklärt sich aus gewissen Handicaps bei den Ärzten: Sie können nur wenig Ärztliches delegieren und sind auch nicht darauf vorbereitet, ihre Verantwortung in Diagnostik, Therapie und Kontrolle mit den Patienten zu teilen.

Oft kann ein ausführliches Gespräch mit dem Diabetiker Vorbehalte und Ängste abbauen sowie seine richtige Einstellung zur Diät fördern. Da dem Arzt nicht selten die Zeit für eingehende Erklärungen fehlt, sollte er daher - wenn möglich - seine nichtärztlichen Mitarbeiter einsetzen.
Tabelle 62. Diagnostische Kriterien des Zuckerstoffwechsels, gültig für Glukosetoleranztest mit $100 \mathrm{~g} \mathrm{Glu-}$ kose p.o. [278]

\begin{tabular}{|c|c|c|c|c|}
\hline & \multicolumn{4}{|c|}{ Glukosekonzentration [mg/dl] } \\
\hline & & $\begin{array}{l}\text { Venöses } \\
\text { Vollblut }\end{array}$ & $\begin{array}{l}\text { Kapillar- } \\
\text { blut }\end{array}$ & $\begin{array}{l}\text { Venöses } \\
\text { Plasma }\end{array}$ \\
\hline \multirow{2}{*}{$\begin{array}{l}\text { Diabetes } \\
\text { mellitus }\end{array}$} & nüchtern & $\geq 120$ & $\geq 120$ & $>140$ \\
\hline & $\begin{array}{l}\text { und/oder } \\
2 \mathrm{~h} \text { nach } \\
\text { Glukose- } \\
\text { belastung }\end{array}$ & $\geq 180$ & $\geq 200$ & $\geq 200$ \\
\hline \multirow{2}{*}{$\begin{array}{l}\text { Patholo- } \\
\text { gische } \\
\text { Glukose- } \\
\text { toleranz }\end{array}$} & nüchtern & $<120$ & $<120$ & $<140$ \\
\hline & $\begin{array}{l}\text { und } 2 \mathrm{~h} \\
\text { nach } \\
\text { Glukose- } \\
\text { belastung }\end{array}$ & $\begin{array}{l}\geq 120- \\
<180\end{array}$ & $\begin{array}{l}\geq 140- \\
<200\end{array}$ & $\begin{array}{l}\geq 140- \\
<200\end{array}$ \\
\hline
\end{tabular}

Erfahrungsgemäß werden die Medikamente nicht immer verläßlich eingenommen oder gespritzt; etwas besser ist die Compliance der Patienten bezüglich der Diabeteskost.

\subsubsection{Selbstkontrolle - Arztkontrolle}

Normalerweise liegt der Blutzuckerspiegel zwischen 60 und höchstens $140 \mathrm{mg} \%$ (nach dem Essen). Bei normalen Blutzuckerwerten ist kein Zucker im Urin. Wenn der Blutzucker über ca. $180 \mathrm{mg} \%$ ansteigt (,Nierenschwelle“ für Zucker), tritt Zucker im Harn auf. Die diagnostischen Kriterien des Zuckerstoffwechsels sind Tabelle $62 \mathrm{zu}$ entnehmen. Von Unterzuckerung spricht man bei Blutzuckerwerten unter ca. $50 \mathrm{mg} \%$.

Die Selbstkontrolle durch den Patienten gehört zu den zentralen Lernzielen der modernen Diabetesbehandlung. Selbstkontrolle heißt aber auch, den Patienten in die Überwachung des Erkrankungsgeschehens direkt einzubeziehen und damit am Erfolg der Behandlung zu beteiligen (Tabelle 63). Der Patient bestimmt selbst

- den Urinzucker,

- den Blutzucker,

- das Azeton,

- das Körpergewicht. 


\begin{tabular}{|lll|}
\hline \multicolumn{2}{|l|}{ Tabelle 63. Selbstkontrolle:Therapieform und täglicher Aufwand (BZ = Blutzucker) [14] } \\
\hline Diabetestyp & Therapieform & Maßnahmen \\
\hline Typ-II- Diabetes & Diät & wiegen, 1 mal Urinzucker, postprandial \\
Typ-Ila-Diabetes & orale Antidiabetika & wiegen, 2 mal Urinzucker, nüchtern/postprandial \\
Typ-Illb-Diabetes & Insulin nach Sekundärversagen & wiegen, 3 mal Urinzucker, (BZ nüchtern möglich) \\
Typ-I- Diabetes stabil einstellbar Insulin & wiegen, 4 mal Urinzucker, BZ nüchtern \\
Typ-I- Diabetes instabil & Insulin & wiegen, BZ 1-4 mal tgl. je nach Insulintherapie, \\
& & Azeton bei BZ-Werten über 300 mg/dl \\
\hline
\end{tabular}

Übersicht 41. Empfehlungen zur ärztlichen Diabeteslangzeitkontrolle von Typ I und Typ II b. (Bergis 1989, pers. Mitteilung)

\section{Typ-I-Diabetes}

- Mit Selbstkontrolle:

$1 \mathrm{mal} /$ Quartal: Größe, Gewicht, Blutdruck, Urinstatus, Blutzucker spontan, Meßvergleich der selbst erhobenen Laborbefunde mit denen in der Arztpraxis, $\mathrm{HbA}_{1}$; 1 mal/Jahr: Status des Nervensystems und der $\mathrm{Au}$ gen, Lipidprogramm; Zusatzuntersuchungen bei Mikroalbuminurie, hier Nierenfunktionsprüfung!

- Ohne Selbstkontrolle:

Keine der Norm nahe Einstellung erreichbar! Vorschlagsweise alle 4 Wochen: Laborkontrolle wie oben, dazu Blutzuckertagesprofil. Dieses Vorgehen ist jedoch keine brauchbare Methode zur Insulindosisanpassung und Stoffwechselverbesserung; Spätsyndrom wahrscheinlich!

- In der Gravidität:

Ohne Selbstkontrolle Normalisierung des Blutzuckers nicht möglich! 4wöchige Protokollbesprechung zur Insulindosisanpassung, besonders zwischen 2. und 3. Trimenon.

Typ-Ilb-Diabetes

- Selbstkontrolle (Harnzuckermessung) unverzichtbar! $1 \mathrm{mal} /$ Quartal: Größe, Gewicht, Blutdruck, Urinstatus (Mikroalbuminurie?), Meßvergleich der selbst erhobenen Laborbefunde mit denen in der Arztpraxis, $\mathrm{HbA}_{1} ; 1 \mathrm{mal} / \mathrm{Jahr}$ : Status des Nervensystems und der Augen, Lipidprogramm; Zusatzuntersuchungen bei Mikroalbuminurie, hier Nierenfunktionsprüfung!

- Bei Insulintherapie: gleiche Empfehlungen wie bei Selbstkontrolle.

- Chronische Entgleisungen: Azetonmessung zur Frage der Ketoazidosegefahr.
Die Selbstkontrolle schützt vermehrt vor Hypoglykämie und langfristig vor anderen Entgleisungen. Sie ist die Basis der Dosisselbstanpassung; sie weckt mehr Verständnis für die therapeutischen Maßnahmen und führt zur Verbesserung der Einstellung. Daraus ergibt sich für den Patienten ein höheres Maß an Eigenverantwortung. Der Diabetiker ist eher bereit, mit dem Arzt vertrauensvoll zu kooperieren, er erlebt mehr Freizügigkeit in der Lebensführung und darf dank verbesserter Einstellung einer höheren Lebenserwartung sicher sein. Allerdings setzt dies eine gewisse Intelligenz des Patienten voraus.

Durch die Selbstüberwachung können v.a. die kurzen Zeitbereiche der Stoffwechselkontrolle erfaßt werden. Für die Beurteilung der Stoffwechselgüte ist jedoch die Gesamteinstellung über längere Zeit von größerer Bedeutung (Übersicht 41).

Im Kontrollbereich des Arztes hat sich daher die Bestimmung des Langzeitzuckers oder des Zuckergedächtnisses, des $\mathrm{HbA}_{1}$ (Glyko-Hb), bewährt.

Selbstkontrolle muß grundsätzlich mit Arztkontrolle kombiniert sein.

Nicht der Blutzuckerwert allein charakterisiert die Schwere der Zuckerkrankheit, sondern das Zusammentreffen mehrerer Faktoren, die schließlich zu einer Blutzuckerentgleisung führen können. In diesem Sinne gilt auch heute noch der Satz von William Osler (1849-1919):

„Es ist wichtiger zu wissen, welcher Diabetiker welche kritischen Blutzuckerwerte hat, als zu wissen, welche kritischen Blutzuckerwerte ein Diabetiker haben kann." 


\subsection{Uncharakteristische Kopfschmerzen, Migräne}

Von Uncharakteristischen Kopfschmerzen (A) spricht man in der allgemeinmedizinischen Fachsprache dann, wenn sich dafür keine äußere Ursache (z.B. Schädelprellung, Blutdruckkrise, exzessiver Alkohol- und Nikotingenuß, Überarbeitung) und auch kein sonstiger Befund (z.B. Fieber, Druckschmerz über den Nasenhöhlen, Entzündung im Bereich der Zähne, Refraktionsanomalie) finden läßt.

Als charakteristischer Kopfschmerz wird dagegen in der allgemeinmedizinischen Fachsprache die Migräne (C) bezeichnet. Typisch für die Migräne ist der einseitige Kopfschmerz, der anfallsartig, mit Geräuschempfindlichkeit, Lichtscheuheit, Übelkeit, Erbrechen, Sehstörungen usw. in wechselnder Kombination und Intensität in Erscheinung tritt.

Insgesamt betrachtet lassen sich von den Kopfschmerzfällen an der ersten ärztlichen Linie nur wenige einer Migräne zwanglos zuordnen. Es gibt Fälle von Migräne, in denen die Abgrenzung zum uncharakteristischen Kopfschmerz lange Zeit unmöglich ist.

\subsubsection{Situationshypothese}

Schematische Einteilungsversuche der Kopfschmerzen, wie sie im spezialistischen Bereich bekannt sind (z.B. vaskuläre, Spannungs-, Intoxikations-, Traktionskopfschmerzen, neuralgische Kephalgie), haben sich bisher für die Belange der Allgemeinmedizin als nur wenig brauchbar erwiesen. Dazu ist die Präsentation der diversen Kopfschmerzformen oft zu uncharakteristisch; solche (spezialistischen) Diagnosen werden normalerweise erst am Ende einer langen Kette vielfältiger diagnostischer Bemühungen formuliert. Der Allgemeinarzt dagegen ist gezwungen, rasch zu beraten und zu einer vertretbaren diagnostischen Bewertung seines Beratungsergebnisses zu kommen. Er geht also von einer Situationshypothese aus und nicht von einer Diagnose.

Die Situationshypothese findet in der Klassifizierung des Falles ihren Ausdruck. Sie ist wie folgt definiert:

- Die Situationshypothese ist das Ergebnis der bewußten statistischen und prognostischen Bewer- tung von abwartend offenbleibenden Fällen in der Allgemeinmedizin. Sie schafft die Voraussetzungen für eine vertretbare Therapie ohne Diagnosestellung [33].

\subsubsection{Fällestatistik}

Bekanntlich gibt es viele Leute, die zwar gelegentlich von Kopfschmerzen befallen sind, aber niemals einen Arzt beanspruchen.

Uncharakteristische Kopfschmerzen nahmen sowohl in den 50er [31] als auch Ende der 70er Jahre [37] sowie in den 80er Jahren [151] einen hohen Häufigkeitsrang im Krankengut ein (10 bzw. 16 bzw. 13). Frauen waren dabei öfter betroffen als Männer. In der Allgemeinpraxis kommen auf jeden Dauerkopfschmerzpatienten jährlich 2 neue Kopfschmerzfälle uncharakteristischer Art, d.h. nur jeder dritte wird zum Dauerfall.

In den allgemeinmedizinischen Statistiken sind doppelt soviele Frauen wie Männer von Migräne betroffen [37]. In den 70er Jahren nahm das Beratungsergebnis „Migräne“ Rang 146 ein, in den 80er Jahren war es Rang 119 und in den 90er Jahren [237] Rang 240. Das Verhältnis von Kopfschmerzfällen zu Migränefällen betrug in der Statistik der 70er Jahre $11,5 \%$ : $1,6 \%$.

\subsubsection{Klassifizierung von Symptomen}

Bei rund einem Viertel aller Beratungsergebnisse des Allgemeinarztes steht dominierend ein einziges Krankheitszeichen im Vordergrund (s. Abb. 2, S. 16). Hat die Diagnostik keinerlei andere nennenswerte Symptome ergeben, so wird dieses Symptom als Beratungsergebnis (BE) klassifiziert (= Symptomklassifizierung). Typische Beispiele für eine Symptomklassifizierung sind:

- Uncharakteristischer Kopfschmerz (A),

- Uncharakteristischer Schwindel (A) (vgl. B 5.8),

- Kreuzschmerzen (A/B) (vgl. B 2.4).

Neben diesem Symptom darf - das sei nochmals betont -kein nennenswertes, anderes, mit der Beratungsursache (BU) zusammenhängendes Krankheitszeichen festgestellt worden sein. 


\begin{tabular}{|l|l|}
\hline $\begin{array}{l}\text { Tabelle 64. Wesentliche Unterschiede zwischen Pro- } \\
\text { grammierter allgemeinmedizinischer Diagnostik und in- } \\
\text { dividueller, intuitiver Routine [54] }\end{array}$ \\
\hline $\begin{array}{l}\text { Programmierte allgemein- } \\
\text { medizinische Diagnostik }\end{array}$ & $\begin{array}{l}\text { Individuelle intuititve } \\
\text { Routine }\end{array}$ \\
\hline $\begin{array}{l}\text { Standardisierte Fragen } \\
\text { und standardisierte Unter- } \\
\text { suchung }\end{array}$ & $\begin{array}{l}\text { Regelmäßiges Vergessen } \\
\text { und Wiederholen derselben } \\
\text { Fragen }\end{array}$ \\
\hline $\begin{array}{l}\text { Optimum an Zeit und } \\
\text { Maximum an Information }\end{array}$ & $\begin{array}{l}\text { Minimum an Zeit bei frag- } \\
\text { würdiger Information }\end{array}$ \\
\hline $\begin{array}{l}\text { Optimale Dokumentation } \\
\text { Mangelhafte bis Null- } \\
\text { dokumentation }\end{array}$ \\
\hline $\begin{array}{l}\text { Keine Konzentration } \\
\text { auf die intuitive Produk- } \\
\text { tion wichtiger Fragen }\end{array}$ & $\begin{array}{l}\text { Höchste Konzentration auf } \\
\text { intuitive Produktion der } \\
\text { wichtigsten Fragen }\end{array}$ \\
\hline $\begin{array}{l}\text { Optimale Anwendungs- } \\
\text { möglichkeit für EDV }\end{array}$ & $\begin{array}{l}\text { EDV-mäBig nur für den } \\
\text { einzelnen Arzt verwertbar, } \\
\text { da Individuelles nicht für } \\
\text { die Allgemeinheit standar- } \\
\text { disiert werden kann }\end{array}$ \\
\hline
\end{tabular}

\subsubsection{Intuition und Programmierte Diagnostik}

Die Beratungsursache (BU) „Kopfschmerzen“ soll als Beispiel dienen, mit welchen verschiedenen diagnostischen Methoden der Allgemeinarzt an dieses Beratungsproblem herangeht oder herangehen sollte:

- Intuitive direkte Diagnostik,

- Programmierte allgemeinmedizinische Diagnostik.

Die intuitive direkte Diagnostik ist der Versuch, eine Beratungsursache (in unserem Fall Kopfschmerzen) primär, unmittelbar und intuitiv einem Krankheitsbegriff (Migräne, Sinusitis frontalis, Kater nach Alkoholabusus) zuzuordnen. Diese direkte Diagnostik ist ein absolutes Minimum, das der Allgemeinarzt nicht unterschreiten darf (vgl. B 2.2, 7.1).

Sie enthält auch stets die wichtigsten Elemente der Falsifizierung.

Die Programmierte allgemeinmedizinische Diagnostik anhand von Handlungsanweisungen ist ein allgemeinmedizinisches, spezifisches Werkzeug, mit dem der Allgemeinarzt bei seinen Problemfällen pri- mär so effektiv arbeiten kann, daß dabei das typische und atypische Häufige ebenso wie das abwendbare Gefährliche durch die Falsifizierung möglichst umfassend berücksichigt wird. Erfahrungsgemäß sind die meisten Fälle, die sich uncharakteristisch präsentieren, nach der Programmierten Diagnostik weiterhin uncharakteristisch. Dennoch bleiben bekanntlich abwendbar gefährliche Seltenheiten, wie beispielsweise ein Gehirntumor oder ein Glaukom, längere Zeit unerkannt. Der Arzt darf den unter dem Begriff „Uncharakteristische Kopfschmerzen“ offengebliebenen Fall niemals als abgeschlossen betrachten; er muß solange diagnostische Kontrollen verabreden, bis er sicher sein kann, daß es sich tatsächlich um ein harmloses Geschehen handelt.

Solange es nicht in ausreichender Menge Richtlinien gibt, wird der Allgemeinarzt gezwungen sein, bei der Masse seiner Beratungen intuitiv vorzugehen. Dabei wirken sein anerzogenes Wissen und (später) seine Berufserfahrung sowie auch der ,gesunde Menschenverstand" zusammen. Klarerweise schneidet hier der gewissenhafte, alterfahrende Arzt am besten ab [37].

Wesentliche Unterschiede zwischen Programmierter allgemeinmedizinischer Diagnostik und intuitiver direkter Diagnostik sind in Tabelle 64 dargestellt.

\subsubsection{Praktisches Vorgehen}

Eine komplette Anamnestik und Durchuntersuchung sind in der Praxis nicht realisierbar. Ebensowenig ist es möglich, jeden Kopfschmerzfall zur Abklärung der Reihe nach zum Ophthalmologen, zum Hals-Nasen-Ohrenarzt, zum Neurologen, zum Psychiater, zum Experten für bildgebende Verfahren und in andere fachärztliche Bereiche zu überweisen. Dies ist auch gar nicht erforderlich. Das Risiko zu schaden, wird für den Allgemeinarzt entscheidend dadurch herabgesetzt, daß - zumindest bei jedem neuen Fall von Uncharakteristischem Kopfschmerz - die Programmierte Diagnostik einsetzt (,KopfschmerzStandard“"Nr. 70; Übersicht 42).

Die Programmierte Diagnostik muß jedoch nicht in derselben Beratung erfolgen, wenn keine Dringlichkeit vorliegt, sondern sie kann auch auf 2 oder 3 nicht $\mathrm{zu}$ weit auseinanderliegende Konsultationen verteilt werden. 


\begin{tabular}{|c|c|}
\hline \multicolumn{2}{|c|}{$\begin{array}{l}\text { Programm } \\
\text { - für die allgemeinmedizinische Diagnostik bei Uncharakteristischen Kopfschmerzen als alleinige } \\
\text { Beratungsursache. Braun R N, West S R (1976) Modifikation von Braun R N (1989) Modifikation (1995) } \\
\text { („,Kopfschmerz-Standard“) }\end{array}$} \\
\hline $\begin{array}{l}\text { Subjektiv } \\
\text { Beratungsursache } \\
\text { erster Eindruck } \\
\text { Kopfschmerz seit } \\
\text { gleich/besser/schlechter } \\
\text { frühere Diagnostik } \\
\text { frühere Bezeichnung } \\
\text { frühere Therapie } \\
\text { jetzt seit } \\
\text { Intervalle } \\
\text { Kopfschmerzen einseitig (Lokalisation) } \\
\text { an der (den) Schläfe(n) } \\
\text { Start durch Aufregung/Unfall/Erkältung } \\
\text { täglich/jahreszeitlich auftretend/Aura } \\
\text { arbeitsunfähig } \\
\text { Dauer-, Anfallsschmerz/ } \\
\text { Begleitsymptome } \\
\text { Tageszeit des Auftretens/nachts } \\
\text { Erbrechen/Polyurie } \\
\text { drückend/hämmernd/Sonstiges } \\
\text { Intensität } \\
\text { innen/außen/lokalisiert } \\
\text { Glaukomzeichen/migräneartig } \\
\text { Schlaf/Träume } \\
\text { Appetit } \\
\text { familiäre Belastung/Allergien } \\
\text { schlechter/ausgelöst durch } \\
\text { Witterungsänderung/ } \\
\text { Wärme/Kälte/ } \\
\text { Fernsehen/Bildschirm/Lesen/Brille/Beruf/ } \\
\text { Körperhaltung!/Licht/Lärm/ } \\
\text { Anstrengung/Aufregung/StreB/Schule/ } \\
\text { Medikamente/Pille/Gifte/ } \\
\text { Menses/Schnarchen/ } \\
\text { Rauchen/Alkoholika/Kaffee/ } \\
\text { Sonstiges } \\
\text { besser durch Kaffee/Tee/Medikamente/ } \\
\text { Ruhe/Frischluft/Bewegung/Sonstiges } \\
\text { chronische Krankheiten } \\
\text { Miktion/Stuhl/Menses } \\
\text { Ängste } \\
\text { Vermutung über Ursache/Art }\end{array}$ & $\begin{array}{l}\text { Selbstbehandlung } \\
\text { Sonst noch } \\
\text { Objektiv } \\
\text { Psychisch auffällig } \\
\text { Hinweis für Organerkrankung } \\
\text { psychisch auffällig } \\
\text { Halswirbelsäule (Druck, Beweglichkeit) } \\
\text { Betastung Schädel (Trigeminus) } \\
\text { Druck auf die Augenbulbi } \\
\text { Blindgang/Intentionstremor } \\
\text { Augendruck (Vorderkammern) } \\
\text { Augenfundus } \\
\text { Sehvermögen } \\
\text { Nasen-, Rachenraum } \\
\text { Otoskopie } \\
\text { Blutdruck/Puls } \\
\text { Urin } \\
\text { BSG (BKS) } \\
\text { sonstiges Labor } \\
\text { Echo/EEG } \\
\text { Röntgen (Schädel, HWS, Zähne) } \\
\text { CT/Kernspin } \\
\text { Beratungsergebnis } \\
\text { Maßnahmen }\end{array}$ \\
\hline
\end{tabular}

Der Allgemeinarzt, der nach eigenem Gutdünken Fragen stellt und den Patienten untersucht, ist selbstverständlich ebenso bestrebt, die wichtigsten $\mathrm{Ab}$ wendbar gefährlichen Verläufe zu bedenken, bevor er eine Behandlung einleitet; nur kann er dies bei weitem nicht mit derselben Gründlichkeit tun wie mit einem Programm.

Die Überweisung in den spezialistischen Bereich geschieht heute, ohne daß dafür bindende Richtlinien existieren würden. 


\begin{tabular}{|c|c|c|c|c|c|c|c|c|c|c|}
\hline \multirow{3}{*}{$\begin{array}{l}\text { 1983-1988 } \\
\text { Rang }\end{array}$} & \multirow{3}{*}{$\begin{array}{l}1977-1980 \\
\text { Rang }\end{array}$} & \multirow{3}{*}{$\begin{array}{l}1954-1959 \\
\text { Rang }\end{array}$} & \multirow{3}{*}{$\begin{array}{l}\text { Beratungs- } \\
\text { ergebnis }\end{array}$} & \multirow{3}{*}{ Gesamtzahl } & \multirow{3}{*}{$\mathrm{m}$. } & \multirow{3}{*}{ w. } & \multicolumn{3}{|c|}{$1977-1980$} & \multirow[b]{3}{*}{$65+$} \\
\hline & & & & & & & \multicolumn{3}{|c|}{ Altersgruppen (Jahre) } & \\
\hline & & & & & & & $0-14$ & $15-44$ & $45-64$ & \\
\hline 40 & 25 & 73 & Varizen & 67 & 8 & 59 & 0 & 11 & 34 & 22 \\
\hline 37 & 30 & 46 & Thrombophlebitis & 57 & 8 & 49 & 0 & 14 & 21 & 22 \\
\hline 79 & 65 & 66 & Ulcus cruris & 29 & 11 & 18 & 0 & 3 & 15 & 11 \\
\hline 140 & 121 & - & $\begin{array}{l}\text { Arterielle Verschluß- } \\
\text { krankheiten }\end{array}$ & 15 & 10 & 5 & 0 & 0 & 6 & 9 \\
\hline 88 & 150 & 198 & Beinkrämpfe & 12 & 4 & 8 & 0 & 2 & 7 & 3 \\
\hline- & 232 & 261 & $\begin{array}{l}\text { Akuter arterieller } \\
\text { Extremitätenverschluß }\end{array}$ & 5 & 0 & 5 & 0 & 0 & 0 & 5 \\
\hline $298^{\mathrm{a}}$ & 241 & - & Raynaud-Krankheit & 5 & 3 & 2 & 1 & 0 & 2 & 2 \\
\hline 279 & $311^{a}$ & 174 & Muskelkrämpfe & 2 & 2 & 0 & 0 & 1 & 1 & 0 \\
\hline
\end{tabular}

\subsection{Varizen}

Oberflächliche Krampfadern (Varizen) (C/D) und ein „offenes Bein“ (vgl. 7.5) kann bereits der Laie ohne Schwierigkeiten erkennen. Die Verbreitung und damit auch die Bedeutung von Erkrankungen, die möglicherweise auf das Gefäßsystem hinweisen, werden daran ersichtlich, wie sehr der Allgemeinarzt im Unausgelesenen Krankengut seiner täglichen Sprechstunde damit konfrontiert wird (Tabelle 65).

Tabelle 65 belegt neben dem hohen Rang dieser Beratungsergebnisse auch die Bevorzugung des weiblichen Geschlechts. Bei allen 3 Beratungsergebnissen wird primär die intuitive direkte Diagnostik (vgl. B 12.2.4 und Tabelle 64) angewandt.

\subsection{1 Überlappung der Fachgebiete}

Was bereits bei B 3.6.2 am Beispiel des Panaritiums (Abb. 22) zur Überlappung der Fachgebiete gesagt wurde, läßt sich auch am Beispiel der Krampfadern illustrieren:

Verschiedene medizinische Spezialgebiete beanspruchen für sich die Diagnostik und Therapie der Varizenerkrankungen (z.B. die Dermatologie, innere Medizin, Chirurgie, Phlebologie, Gynäkologie). Die Krankheiten ,gehören“ jedoch allen Fächern.

Der Versuch, die ärztlichen Fachangebote gegeneinander abzugrenzen, resultiert aus pragmatisch gewählten Einteilungsprinzipien.

\subsubsection{Patientenklage und Selbstmaßnahmen}

Für den Hausarzt ist es immer wieder erstaunlich, mit welcher Geduld, Gleichgültigkeit oder Resignation (,Es hilft ohnedies nichts“) manche Betroffene oft über Jahre hinweg ausgeprägte Venenleiden hinnehmen und ertragen. Andererseits fühlen sich viele Menschen bereits durch vergleichsweise geringfügige Venenveränderungen (z.B. Besenreiser) ästhetisch berührt und suchen den Rat des Arztes.

Sehr viele Beschwerden werden vom Patienten mit einer Venenerkrankung bzw. mit einem „Krampfadernleiden“ in Verbindung gebracht, z.B. dicke Beine, anhaltendes Schweregefühl und Müdigkeit in den Beinen, abendliches Anschwellen der Knöchelpartie, Unruhe in den Beinen (besonders bei stehenden Berufen und während der Sommermonate), Knöchelschwellungen nach längeren Autoreisen oder nächtliche Wadenkrämpfe.

Dagegen kennt jeder praktizierende Arzt zahlreiche Patienten beiderlei Geschlechts, die ausgeprägte Varizenkonvolute an Ober- und/oder Unterschenkeln aufweisen und die weder darüber klagen noch sich in ihrem Schönheitsempfinden beeinträchtigt fühlen.

Häufig werden verschiedene Selbstbehandlungsmaßnahmen angewandt. Sie reichen vom Einbinden über Abreiben mit Franzbranntwein bis zur Anwendung von Salben oder Tabletten mit pflanzlichen Inhaltsstoffen; abenteuerlich muten manche Hilfs- 
mittel der Laien gegen „offene Beine“ an, z.B. Tierfette oder das Aufbinden kupferner Münzen.

\subsubsection{Thrombophlebitis-Bilder}

Bestimmte Punkte am Bein, die auf Druck schmerzhaft sind, bedeuten eine entscheidende Hilfe in der Frühdiagnostik und haben sich in jahrzehntelanger Praxis als brauchbar erwiesen (Abb. 95). Ihre Entwicklung geht den pathologischen phlebographischen Befunden voraus. Im wesentlichen handelt es sich hier um perivasale, entzündliche Infiltrate, um subfasziale und interstitielle Ödeme und um statisch bedingte Myogelosen.

$\mathrm{Ob}$ die oberflächlich gelegenen Venen auch entzündet sind, läßt sich oftmals in einfacher Weise feststellen: Die Stränge sind gerötet, leicht erhaben, infiltriert und äußerst druckschmerzhaft. Das Allgemeinbefinden des Patienten muß nicht, kann aber gestört sein.

Ausnahmsweise gestaltet sich die Diagnostik einer (oberflächlichen) Thrombophlebitis (oberflächliche Venenentzündung) (C) nicht so einfach, wenn Rötung und Infiltration fehlen und lediglich lokale Druckschmerzhaftigkeit besteht. Dies kann beispielsweise im Bereich der Kniekehle, der Wade oder des Unterarmes der Fall sein. Hier muß auch an eine Affektion benachbarter Strukturen (z.B. Meniskus, Muskeln, Sehnen) gedacht werden.

Im spezialistischen Bereich stehen verschiedene Methoden in der Diagnostik der Befundabklärung vor operativen Eingriffe an den Venen zur Verfügung.

Bei der Wahl der Therapie von Venenleiden sollte der Hausarzt jene Maßnahmen bevorzugen, die durch konsequentes Wickeln über eine Entstauung des ,dicken Beins“ (= Ödem) zu einer erheblichen Beschwerdelinderung führen können.

Sind die Klappen der Stammvarizen suffizient (negativer Trendelenburg-Test), soll man die varikösen Äste veröden; sind sie insuffizient (positiver Trendelenburg-Test), dann ist die Indikation zur Operation gegeben.

\subsubsection{Phlebothrombose-Bilder}

Während die Thrombophlebitiden im allgemeinmedizinischen Krankengut einen Rang zwischen 30 und

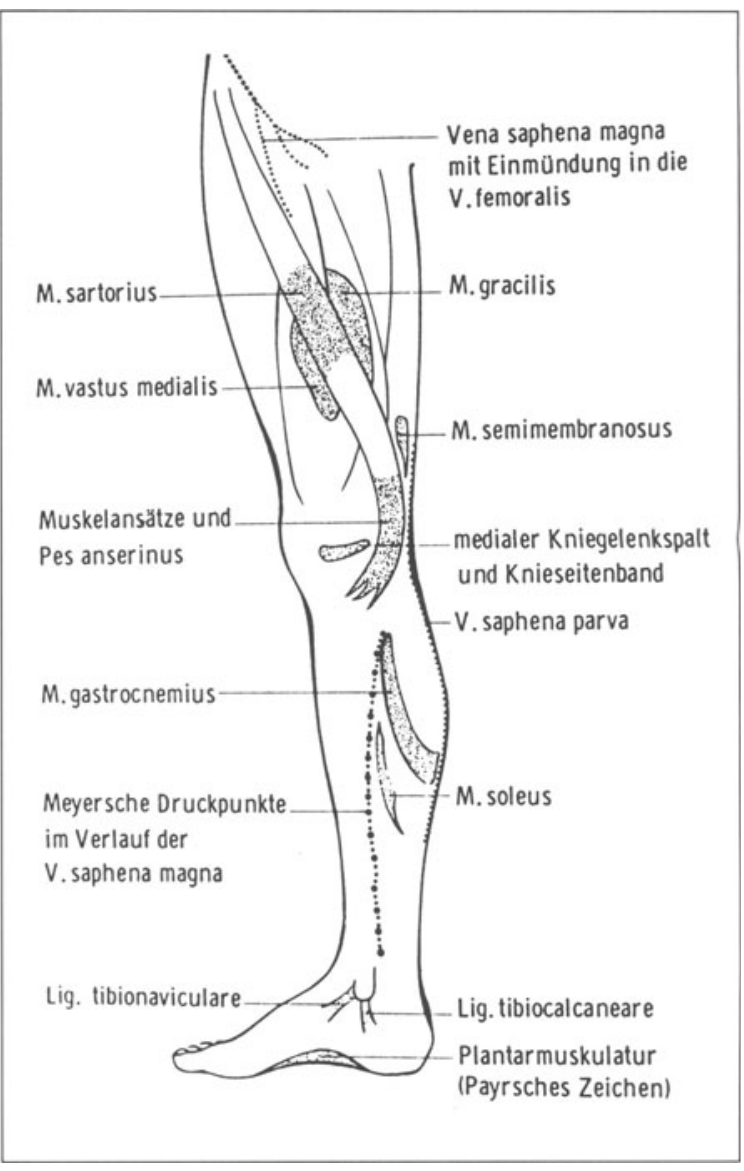

Abb. 95. Druckschmerzpunkte bei Venenthrombose und latenter, tiefer Phlebitis [101]

40 einnehmen, also relativ häufig vorkommen (Tabelle 1), sind die Phlebothrombosen (tiefe Venenentzündungen) (C) Vorkommnisse, mit denen der Allgemeinarzt in einer Durchschnittspraxis höchstens 1- oder 2 mal jährlich konfrontiert wird.

Das „Bild einer Phlebothrombose“ ist immer unter dem Aspekt eines Symptoms einer übergeordneten Erkrankungen zu sehen (Achtung: Abwendbar gefährlicher Verlauf!). Als Grundleiden kommen v.a. raumfordernde Prozesse im Bauchraum in Frage (z.B. Kolon, Pankreas, Niere, Prostata, weibliches Genitale). Aber auch Operationen, Schwangerschaft und Entbindung sowie Traumen können der Erkrankung vorausgehen, die auch nach längerer Stase bei Reisen auftritt („Thrombose des ersten Ferientages“; [97]). 
Bei Bildern, die an eine tiefe Venenentzündung denken lassen (livide Schwellungen an der unteren Extremität oder vermehrter Umfang im Vergleich zum anderen Bein oder Schmerzen an der Fußsohle), sollten unverzüglich anhand des ,Thrombose-Standards" Nr. 76 die Fragen gestellt und der Untersuchungsgang eingeschlagen werden.

\subsubsection{Beinkrämpfe}

Patienten, die von „Beinkrämpfen “ (A) geplagt sind, suchen in den meisten Fällen den Arzt wegen dieser Beschwerden nicht primär auf, sondern erwähnen eher beiläufig das oftmals die Nachtruhe störende Übel.

In der Regel wurden bereits verschiedene Hausmittel (z.B. Einreibungen mit Franzbranntwein) mit mäßigem Erfolg angewandt. Diese besonders nachts im Liegen, meist intermittierend auftretenden schmerzhaften Muskelverhärtungen, verbunden evtl. mit Par- und Dysästhesien oder Einschlafen, können Bewegungsunruhe verursachen. Ziehende Schmerzen in den Muskeln bei ,restless legs“" gehen typischerweise ohne Krämpfe einher.

Die örtliche Diagnostik deckt bei solchen uncharakteristischen Bein- und insbesondere Wadenkrämpfen in der Regel Traumen oder eine ausgeprägte Varikosis weder in der Anamnese noch beim Augenschein auf.

Bei völlig unklaren Muskelkrämpfen (Krampi) (A) empfiehlt sich die Diagnostik mittels der Handlungsanweisung Nr. 80 (,Muskelkrampf-Standard“), die in der Allgemeinmedizin selten benötigt wird.

\subsubsection{Arterielle Verschlußkrankheit, Extremitätenembolien}

Während die arterielle Verschlußkrankheit (AVK) im Krankengut der 50er Jahre noch Rang 308 eingenommen hatte (und damit nicht regelmäßig häufig war; [31]), findet sich die AVK in den Statistiken Ende der 70er Jahre und in den 80er Jahren auf Rang 121 bzw. 140 [37]. Männer sind doppelt so häufig betroffen wie Frauen (Tabelle 65). In der Statistik der Pariser Allgemeinärzte Anfang der 90er Jahre nimmt die AVK Rang 61 ein [237].

Der Hausarzt wird mit allen 4 Stadien der peripheren AVK konfrontiert, wie sie von Fontaine für die
Tabelle 66. Die 4 Stadien der peripheren arteriellen Verschlußkrankheit (AVK; sog. Makroangiopathie) nach Fontaine.

\begin{tabular}{|c|c|}
\hline Stadium & Merkmale \\
\hline I & $\begin{array}{l}\text { Beschwerdefreier Pulsausfall, apparative } \\
\text { Diagnostik ergibt Hinweise auf arterielle } \\
\text { Lumeneinengungen; subjektive Beschwerde- } \\
\text { freiheit, körperlich voll belastbar }\end{array}$ \\
\hline Ila & $\begin{array}{l}\text { Latenzschmerz, d.h. Claudicatio intermittens } \\
\text { mit Wegstrecken zwischen } 50-2000 \text { m }\end{array}$ \\
\hline $\mathrm{Ilb}$ & Beschwerdefreie Gehstrecke unter $50 \mathrm{~m}$ \\
\hline III & Ruheschmerzen, trophische Störungen obligat \\
\hline IV & Gangränbildung \\
\hline
\end{tabular}

sog. Makroangiopathie vorgeschlagen wurden (Tabelle 66).

Die programmierte Handlungsanweisung Nr. 75 („Gefäßverschluß-Standard“) ist als Richtlinie für den Allgemeinarzt gedacht, schon beim geringsten Hinweis auf eine AVK den Einzelfall am Spektrum der wichtigsten Beschwerden und Krankheitszeichen zu messen. Im Gegensatz zur Makroangiopathie ist bei der sog. Mikroangiopathie, wie sie für den Diabetes typisch ist, der periphere arterielle Pulsstatus meist regelrecht. Hinweise auf eine solche diabetische Mikroangiopathie können sein:

Retinopathie, Nephropathie, Hautulzerationen oder Neuropathie.

Akute Verschlüsse der Extremitätenarterien stellten regelmäßig häufige Ereignisse sowohl in den 50er (Rang 261; [31]) als auch in den späten 70er (Rang 219; [37]), aber nicht in den 80er Jahren dar [151]. Bei solchen meist dramatischen Fällen dreht es sich an der ersten ärztlichen Linie weniger um diffizile diagnostische Überlegungen als darum, die Betroffenen bei entsprechendem „Aussehen wie ...“ raschest einzuweisen. Charakteristisch sind für den akut peripheren arteriellen Verschluß die „6 $\mathrm{P}^{\text {“, wie }}$ sie in der angelsächsischen Literatur beschrieben sind:

- Pain (peitschenartig einsetzender Dauerschmerz),

- Pulslosigkeit,

- Palor (Blässe der Extremität distal der Verschlußlokalisation),

- Parästhesien,

- Paralysis (Lähmungen) und evtl.

- Prostration (Schock). 
Größte Eile tut not! Die operative Rekanalisation muß innerhalb von $6 \mathrm{~h}$ eingeleitet werden.

Bei vasospastischen Erkrankungen, z.B. dem Raynaud-Syndrom (D), haben sich die Kalziumantagonisten per os und Nitropräparate, oral oder topisch appliziert, zur Verminderung der Anfallshäufigkeit bewährt.

\subsection{Schlafstörungen/Schlaflosigkeit (Agrypnie)}

Beunruhigende Schlafstörungen können in jedem Lebensalter auftreten. Gewisse Formen sind typisch für einzelne Altersgruppen, wie Pavor nocturnus bei Kindern und Jugendlichen, Insomnie und Hypersomnie im mittleren und höheren Alter.

Obwohl Schafstörungen zu den häufigen Beratungsergebnissen der Allgemeinpraxis zählen (Rang 28 bzw. 16 bzw. 20 im Krankengut der 70er [37] bzw. 80er [151] bzw. frühen 90er Jahre [237], suchen die davon Betroffenen vergleichsweise nur selten allein deswegen ihren Hausarzt auf. Meist wird das Beratungsproblem obendrein nur als Rezeptwunsch präsentiert. Der Patient ist oft von falschen Vorstellungen über das Ausmaß des Schlafes geleitet. Er beklagt, daß er ,die ganze Nacht wach im Bett liege“, ,jeden Glockenschlag höre“ usw. Es handelt sich z.T. um ältere Menschen, die tagsüber zuviel schlafen, wodurch ihnen am Abend die Müdigkeit fehlt, oder die schon sehr früh ins Bett gehen (Langeweile als soziales Problem).

Der Ausdruck „Schlaflosigkeit“ (A) wird vom Laien i.allg. für jede Beeinträchtigung bezüglich der Dauer, der Tiefe oder der Erholungseigenschaften des Schlafes gebraucht. Schlaftiefe und -dauer sind jedoch individuell sehr variabel. Daher stellt sich die schwierige Frage, ob die vorgebrachten Beschwerden als abnorm zu betrachten sind [105].

Dauert die Schlafstörung länger als 2 Wochen an, ist eine Programmierte Diagnostik mit dem ,SchlafStandard" (Handlungsanweisung Nr. 71) durchzuführen, welche gleichermaßen auf körperliche und seelische Störungen ausgerichtet ist.

Der Hausarzt sollte sich hüten, vorschnell Schlafmittel - und schon gar nicht auf Dauer - zu verschreiben. So hat man z.B. erkannt, daß der weit verbreitete
Gebrauch von Benzodiazepinen als Schlafmittel mit unerwünschten Komplikationen belastet ist:

- Sie können süchtig machen.

- Nach mittellangem Gebrauch kann eine Reboundinsomnie auftreten mit dem Zwang zur Dosissteigerung.

- Aktive Metaboliten deren biologische Wirkung 36-48 $\mathrm{h}$ anhalten kann, kumulieren [105].

Als problematisch wird es heute unter folgenden Überlegungen angesehen, Barbiturate zu verwenden:

Enge therapeutische Breite, mögliches Suizidrisiko, schwierige Reanimation bei Suizidversuchen, hohes Abhängigkeitspotential und Interaktion mit anderen Arzneimitteln durch Induktion arzneimittelabbauender Enzyme in der Leber (Schwabe 1990, pers. Mitteilung).

\subsubsection{Tips zur Patientenführung}

Der rasche Griff zum Rezeptblock löst langfristig nicht das Problem der Schlafstörung. Gerade der Hausarzt sollte in der Langzeitbetreuung seiner Patienten mit Schlafstörung verschiedene Tips und Regeln zur Schlafhygiene zu vermitteln versuchen. Hier einige Beispiele (Finke in [139], [77]):

- Das Schlafdefizit ist meist geringer, als es vom Schlafgestörten vermutet wird.

- Ein entspanntes Im-Bett-Liegen ohne Schlaf besitzt durchaus erholende Wirkung.

- Mahlzeiten: abends nur leichte, evtl. frühzeitig eingenommene Mahlzeiten.

- Regelmäßigkeit: Zur gleichen Zeit zu Bett gehen und am Morgen aufstehen.

- Einschlafritual: Monotonie hilft beim Einschlafen.

- Körperliche Tätigkeit fördert Müdigkeit. Ab dem späten Nachmittag keine geistigen Spitzenleistungen, dafür Abendspaziergang.

- Kaffee, Tee und andere Stimulanzien können stören, Alkohol kann das Einschlafen erleichtern, jedoch den Schlafrhythmus beeinträchtigen.

- Lieber aufstehen, lesen, Radio hören oder fernsehen, als sich stundenlang im Bett wälzen.

- Training des vegetativen Nervensystems: warm und/oder kalt duschen.

- Schlafzimmer: Wohliges, nicht zu weiches Bett, Dunkelheit, Ruhe. 
- Das über 15-30 min ausgedehnte Mittagsschläfchen programmiert die abendliche Schlafstörung.

- Erwartungsvolles Einschlafenwollen kann die Schlafstörung verstärken. Die paradoxe Intention: „Ich will gar nicht einschlafen“ kann den Terror der Erwartungshaltung durchbrechen helfen.

- Der Patient sollte die Schlafstunden nicht nachrechnen.

- Die Aufmerksamkeit soll sich nicht auf das nächtliche Wachliegen konzentrieren, sondern auf die Bejahung des Wachseins am Tage.

- Wird Schlaf vom Organismus dringend benötigt, so setzt er sich auch gegen den Willen des Betroffenen durch.

- Eine medikamentöse Unterstützung kann durch pflanzliche Präparate erfolgen, z.B. Baldrian (Valeriana officinalis), Hopfen (Humulus lupulus), Melisse (Melissa officinalis), Passionsblume (Passiflora incarnata);

mit Zurückhaltung auch chemische Substanzen, z.B. Neuroleptika (z.B. Atosil ${ }^{\circledR}$, Melleril $^{\circledR}$, Truxal $^{\circledR}$ oder kurzfristig Tranquilizer (Benzodiazepinderivate wie Adumbran ${ }^{\circledR}$, Mogadan ${ }^{\circledR}$ ) oder sonstige Mittel wie Chloralhydrat. Cave: Barbiturate!

- Durch Medikamente ist keine kausale Therapie von Schlafstörungen möglich. Der Schlaf kann vorübergehend bestenfalls ,geborgt" werden. Nach Absetzen des Präparates muß die Schuld durch zeitweilige Schlafverminderung gleichsam zurückgezahlt werden.

\subsection{Bilder von Masern, Röteln, Varizellen, Mumps, Scharlach}

Bei disseminierten Ausschlägen, bevorzugt am Kopf und/oder am Oberkörper, mit und ohne Temperatur fordern viele besorgte Mütter ärztlichen Rat. Sie vermuten dabei häufig schon selbst, daß eine sog. „Kinderkrankheit" vorliegt. Dem liegen teils eigene Erfahrungen von anderen Fällen in der Familie, teils Berichte über ein gehäuftes Auftreten z.B. in Kindergärten, Schulen oder sonst in der Umgebung zugrunde.

Windpocken (Varizellen) (Farbtafel, S. 345 ff) präsentieren sich v.a. im ,typischen Stadium“ (,,Sternenhimmel") vergleichsweise ,charakteristisch" und ermöglichen eine direkte Diagnostik (vgl. B 7.1,
12.2.4) (wichtig sind Effloreszenzen der behaarten Kopfhaut).

Masern- und Röteln-Bilder (C) können dagegen gerade im Anfangsstadium oftmals schwer gegeneinander abzugrenzen sein.

Am besten lassen sich die Bilder der häufigen Infektionskrankheit mit und ohne Ausschlag am Höhepunkt von Epidemien erkennen (Tabelle 67).

Mitunter gehen die Erkrankungshäufigkeiten vorbei, ohne daß selbst ein erfahrener Praktiker sagen könnte, ob er es nun mit Röteln, Masern oder mit keinem von beiden zu tun gehabt hatte.

Immer wieder sieht der Hausarzt Säuglinge und Kleinkinder, die ihm wegen hohen Fiebers vorgestellt werden, aber keine sonstigen Allgemeinerscheinungen bieten. Manchmal tritt dann bei diesen kleinen Patienten am 3. (oder 4.) Tag, wenn das Kind entfiebert, ein feinfleckiger blaßrosa Ausschlag vor allem am Stamm auf, so daß die Klassifizierung „Bild eines Exanthema subitum “ (oder Pseudorubellae oder Roseola infantum) möglich ist. Das Exanthem selbst dauert meist 2 Tage.

Fieber sowie andere Allgemeinerscheinungen stehen bei Röteln-, Mumps- und Varizellen-Bilder gewöhnlich im Hintergrund.

Sind allerdings Jugendliche von Windpocken befallen, so ist teilweise mit langwierigen Verläufen zu rechnen. Erwachsene erkranken selten; hier kann der Verlauf schwer und von Komplikationen begleitet sein. Patienten mit gestörter Immunitäts- und Abwehrlage sind besonders anfällig für eine Varizellenbzw. Zostererkrankung [113].

Durch die relativ hohe Impfquote bei den Kindern (z.B. Mumps, Masern, Röteln) präsentieren sich diese insgesamt selten gewordenen Erkrankungen und deren Hauterscheinungen häufig atypisch. Damit machen sie gelegentlich auch dem Erfahrenen die Zuordnung zu Krankheitsbildern unmöglich. Stets ist zu beachten, daß uncharakteristische Fieberzustände ebenso wie allergische Exantheme (exanthematische) Kinderkrankheiten vortäuschen können. Der Jungarzt mag jedoch beruhigt sein:

Nach wenigen Praxisjahren hat er sich meist genügend Kennerschaft erworben, um aus der Erfahrung heraus weitgehend vertretbar zu urteilen.

Masern, Röteln und Mumps traten früher eher in den ersten Lebensjahren auf. Die Änderung der sozialen Gegebenheiten (z.B. Kleinfamilie) und die 
Tabelle 67. Häufige Infektionskrankheiten mit und ohne Ausschlag (ohne Berücksichtigung möglicher Effloreszenzen und deren Verteilungsmuster). Fachverband Deutscher Allgemeinärzte (FDA); Tg. Tag(e); Wo. Woche(n); Mo. Monat(e); J Jahr(e); Ex. Exanthem; HHTHämagglutinationshemmtest; ASL Antistreptolysintiter

\begin{tabular}{|c|c|c|c|}
\hline \multicolumn{2}{|l|}{ Röteln } & 8. Komplikationen ${ }^{a}$ & Embryopathie, Arthritis, ZNS \\
\hline 1. Erreger & Rubellavirus & 9. Impfzeitpunkt & ab 15. Mo. $-55 \mathrm{~J}$ \\
\hline 2. Inkubationszeit & $14-21 \mathrm{Tg}$ & 10. Aktive Immunisierung & Abgeschwächter \\
\hline 3. Infektiosität & $\begin{array}{l}1 \text { Wo. vor Ex., } \\
10 \mathrm{Tg} . \text { danach }\end{array}$ & 11. Passive Immunisierung & $\begin{array}{l}\text { Lebendimpfstoff } \\
\text { Röteln-Immunglobulin }\end{array}$ \\
\hline 4. Krankheitsdauer $^{\mathrm{a}}$ & einige $\mathrm{Tg}^{\mathrm{a}}$ & 12. Immunstatus & $\mathrm{KBR}$ und $\mathrm{HHT}$ \\
\hline 5. Fieber ${ }^{\mathrm{a}}$ & ca. $38^{\circ} \mathrm{C}$ & 13. Labor & Titer über $1: 32$ beweisend, \\
\hline 6. Exanthem/Enanthem & Ex. & & Leukopenie, IgM-AK ab 3. Tag, \\
\hline $\begin{array}{l}\text { 7. Hauptübertragungs- } \\
\text { quelle }\end{array}$ & Tröpfchen, diaplazentar & & max. Titer 2-5 Wo. nach Beginn \\
\hline \multicolumn{4}{|l|}{ Mumps } \\
\hline 1. Erreger & Mumpsvirus & 8. Komplikationen ${ }^{a}$ & Orchitis, ZNS, Epididymitis, \\
\hline 2. Inkubationszeit & $14-24 \mathrm{Tg}$ & & Pankreatitis \\
\hline 3. Infektiosität & $6 \mathrm{Tg}$. vor bis $14 \mathrm{Tg}$. nach & 9. Impfzeitpunkt & ab 15. Mo. $-55 \mathrm{~J}$. \\
\hline 4. Krankheitsdauer $^{\mathrm{a}}$ & $\begin{array}{l}\text { Parotisschwellung } \\
\text { einige } \mathrm{Tg} \text {. }\end{array}$ & 10. Aktıve Immunisıerung & $\begin{array}{l}\text { Abgeschwachter Lebend- } \\
\text { impfstoff }^{\mathrm{b}}\end{array}$ \\
\hline 5. Fieber ${ }^{\mathrm{a}}$ & subfebril bis maximal $40^{\circ} \mathrm{C}$ & 11. Passive Immunisierung & Mumpshyperimmunglobulin \\
\hline 6. Exanthem/Enanthem & Parotisausführungsgang & 12. Immunstatus & KBR \\
\hline $\begin{array}{l}\text { 7. Hauptübertragungs- } \\
\text { quelle }\end{array}$ & $\begin{array}{l}\text { geschwollen } \\
\text { Tröpfchen }\end{array}$ & 13. Labor & $\begin{array}{l}\text { Leukopenie, Serumamylase } \\
\text { erhöht, } 4 \text { facher Titeranstieg } \\
\text { bei akuter Erkrankung }\end{array}$ \\
\hline \multicolumn{4}{|l|}{ Masern } \\
\hline 1. Erreger & Masernvirus & 8. Komplikationen ${ }^{a}$ & Bakt. Bronchopneumonie \\
\hline 2. Inkubationszeit & 9-14 Tage bis Ex. & & Otitis media \\
\hline 3. Infektiosität & 7 Tg. v. Ex. bis z. Abklingen & 9. Impfzeitpunkt & ab 5. Mo. $-55 \mathrm{~J}$ \\
\hline 4. Krankheitsdauer ${ }^{\mathrm{a}}$ & Prodromalstadium 3-5 Tg. & 10. Aktive Immunisierung & Abgeschw. Lebendimpfstoff ${ }^{b}$ \\
\hline & Ex.-Stadium 4-7 Tg. & 11. Passive Immunisierung & Masernimmunglobulin \\
\hline 5. Fieber ${ }^{a}$ & $38-41^{\circ} \mathrm{C}$ & 12. Immunstatus & $\mathrm{KBR}$ und $\mathrm{HHT}$ \\
\hline 6. Exanthem/Enanthem & Ex./En. (Koplik) & 13. Labor & Leukopenie, Leukoyzytose und \\
\hline $\begin{array}{l}\text { 7. Hauptübertragungs- } \\
\text { quelle }\end{array}$ & Tröpfchen & & $\begin{array}{l}\text { Linksverschiebung bei } \\
\text { bakterieller Infektion }\end{array}$ \\
\hline \multicolumn{4}{|l|}{ Varizellen } \\
\hline 1. Erreger & Varicellavirus & 8. Komplikationen ${ }^{a}$ & ZNS \\
\hline 2. Inkubationszeit & $14-21 \mathrm{Tg}$ & 9. Impfzeitpunkt & Risikogruppen \\
\hline 3. Infektiosität & $1 \mathrm{Tg}$. vor bis $8 \mathrm{Tg}$. nach & 10. Aktive Immunisierung & In Vorbereitung \\
\hline Krankhoitcdaura ${ }^{a}$ & Ex. (bis Schorfabfall) & 11. Passive & Varicella-Zoster-Immunglobulin \\
\hline 4. Krankheitsdauer ${ }^{\mathrm{a}}$ & $\begin{array}{l}1-2 \text { Wo. (bis Schorfabfall) } \\
38-38.5^{\circ} \mathrm{C}\end{array}$ & Immunisierung & \\
\hline 5. Fieber ${ }^{a}$ & $38-38,5^{\circ} \mathrm{C}$ & 12. Immunstatus & $\mathrm{KBR}$ und $\mathrm{HHT}$ \\
\hline 6. Exanthem/Enanthem & Ex. & 13. Labor & - \\
\hline $\begin{array}{l}\text { 7. Hauptübertragungs- } \\
\text { quelle }\end{array}$ & Tröpfchen, Bläscheninhalt & & \\
\hline \multicolumn{4}{|l|}{ Pertussis } \\
\hline 1. Erreger & $\begin{array}{l}\text { Bordetella (Haemophilus) } \\
\text { pertussis }\end{array}$ & $\begin{array}{l}\text { 7. Hauptübertragungs- } \\
\text { quelle }\end{array}$ & Tröpfchen \\
\hline 2. Inkubationszeit & $7-10 \mathrm{Tg}$ & 8. Komplikationen ${ }^{\mathrm{a}}$ & Bronchopneumonie, Otitis media \\
\hline 3. Infektiosität & max. bis 2 Wo., abklingend & & Enzephalopathie \\
\hline & bis 6 Wo. $^{\mathrm{c}}$ & 9. Impfzeitpunkt & 13. Wo. $-2 \mathrm{~J}$ \\
\hline 4. Krankheitsdauer & Stad. catarrhale 1-2 Wo., Stadium & 10. Aktive Immunisierung & Inaktivierte Erreger \\
\hline & $\begin{array}{l}\text { convulsivum 3-4 Wo., Stadium } \\
\text { decrementi mind. } 3 \text { Wo. }\end{array}$ & $\begin{array}{l}\text { 11. Passive } \\
\text { Immunisierung }\end{array}$ & $\begin{array}{l}\text { Pertussisimmunglobulin } \\
\text { wertlos }\end{array}$ \\
\hline 5. Fieber & subfebril & 12. Immunstatus & KBR wertlos \\
\hline 6. Exanthem/Enanthem & - & 13. Labor & $\begin{array}{l}\text { Leukozytose (über } 10000 \text { ), } \\
\text { Lymphozytose }\end{array}$ \\
\hline
\end{tabular}




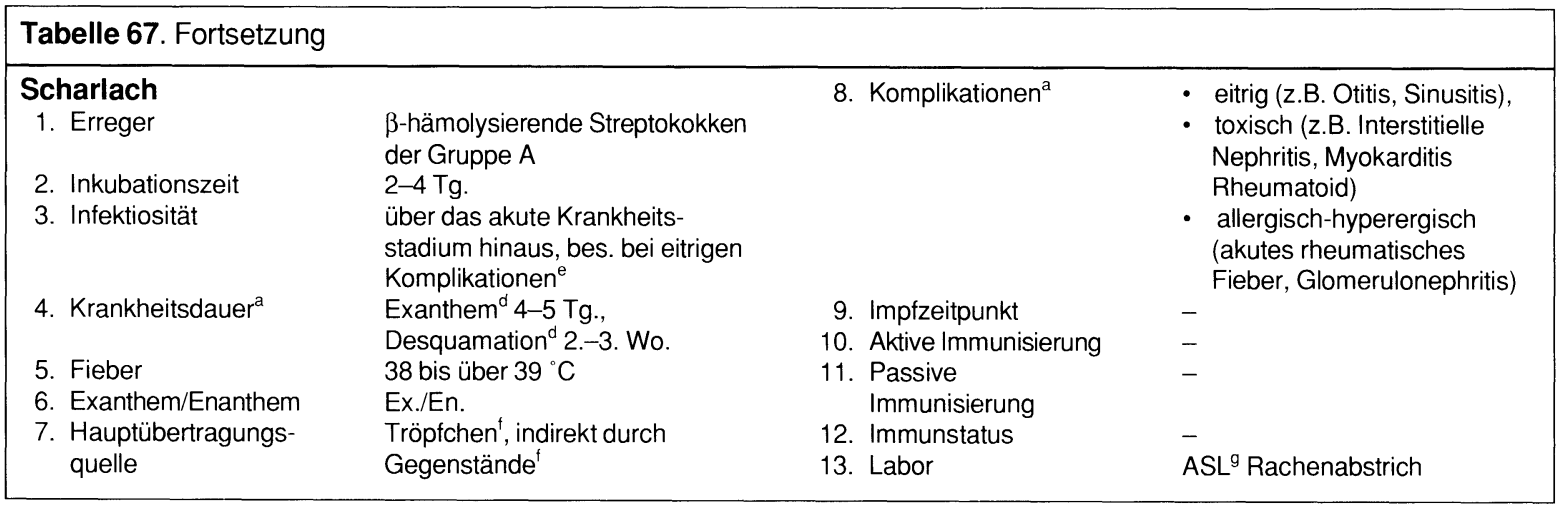

a In Abhängigkeit vom Lebensalter.

b Impfung bei geschlechtsreifen Frauen nur unter Konzeptionsschutz, Mädchen präpubertär.

${ }^{c}$ Antibiotisch behandelte Patienten sind nicht mehr ansteckend.

${ }^{d}$ Es kommen alle Übergänge vom ausgeprägten Scharlach bis zum sog. Scharlach ohne Exanthem bis zur Streptokokkenangina vor.

${ }^{\text {e }}$ Antibiotisch behandelte Patienten nach dem 2. Tag nicht mehr ansteckend.

${ }^{\dagger}$ Umgebungsprophylaxe (Geschwister und übrige Mitglieder der Wohngemeinschaft) gleichzeitig mit Oralpenizillin für 3-5 Tage (vgl. Tabelle 68). Schulbesuch frühestens ab 4. Tag nach Therapiebeginn erlaubt. Sog. zweites Kranksein: Auftreten in 3.-5. Wo. als Rezidiv oder Neuinfektion trotz vorausgegangener Behandlung möglich. Meldepflicht bei Todesfall.

${ }^{9}$ Nach frühzeitiger antibiotischer Behandlung keine sichere Immunität; bei Unbehandelten lebenslange Immunität.

Impfung sind die Gründe dafür, daß sich der Erkrankungszeitpunkt mehr und mehr gegen Ende des ersten Lebensjahrzehnts verlagert. Gleichzeitig scheinen insbesondere bei der Masern- und Mumps-, in Einzelfällen auch bei der Rötelnerkrankung, die Komplikationen zuzunehmen. Diese ,Kinderkrankheiten "verlaufen also keineswegs stets harmlos.

Bei Schwellungen und Schmerzen im Kieferwinkelbereich sprechen die Eltern und die betroffenen Erwachsenen meist schon selbst den Verdacht auf Mumps aus. Eine (exakte) Diagnose allein durch die örtliche Routine bzw. die direkte Diagnostik zu stellen, ist in der Praxis auch für einen Arzt mit großer Kennerschaft nicht möglich. Erst serologische Untersuchungsmethoden bringen die nötige diagnostische Sicherheit.

\subsubsection{Streptokokkenangina oder Scharlach?}

Halsschmerzen, Fieber sowie Rötung im Gesicht und am Stamm von Kindern werden von den Eltern zwar oft für Masern oder Röteln gehalten, der Arzt denkt hier u.a. natürlich aber auch an Scharlach. Nicht selten sind
- Erbrechen,

- stark geröteter Gaumenbogen bzw. Angina oder

- Kopfschmerzen ein weiteres Indiz.

Beweisend für eine Scharlacherkrankung ist jedoch ausschließlich die positive Kultur ( $\beta$-hämolysierende Streptokokken der Gruppe A). Schnelltests zum Nachweis des Gruppe-A-Streptokokken-Antigens aus dem Rachenabstrich sind unzuverlässig (abhängig vom Krankheitsstadium. zweifelhafte Interpretation möglich).

Von „Scharlach“(D) kann man nur dann sprechen, wenn typische Symptome, insbesondere das Exanthem sowie der positive kulturelle Erregernachweis, vorhanden sind.

Steht die Mandelentzündung innerhalb der Symptomgruppe „Halsschmerzen, Fieber, Kopfschmerzen" im Vordergrund und findet sich kein Exanthem, so erfolgt die Klassifizierung als „Angina bzw. Tonsillitis acuta $(\mathrm{C})^{\text {". }}$. Sofern im Rachenabstrich Streptokokken nachgewiesen wurden, wird eine ,Streptokokken-A-Angina (D)" klassifiziert (vgl. A 1.3).

Für den Hausarzt ist die Entscheidung, ob Scharlach vorliegt oder nicht, im Hinblick auf die Behand- 


\begin{tabular}{|c|c|c|c|c|}
\hline A-Streptokokken & $\begin{array}{l}\text { Therapie } \\
\text { ja/nein } \\
\text { Dauer } \\
\text { oral/evtl. i.m. }\end{array}$ & $\begin{array}{l}\text { Prophylaxe } \\
\text { Familie } \\
\text { a) Kleinkinder } \\
\text { b) Kinder } \\
\text { c) Erwachsene } \\
\text { Dauer/Dosis }\end{array}$ & $\begin{array}{l}\text { Prophylaxe } \\
\text { Kindergarten } \\
\text { Dauer/Dosis }\end{array}$ & $\begin{array}{l}\text { Prophylaxe } \\
\text { Schule }\end{array}$ \\
\hline $\begin{array}{l}\text { Scharlach } \\
\text { Exanthem } \\
\text { Fieber } \\
\text { Streptokokken-A- } \\
\text { Nachweis }\end{array}$ & $\begin{array}{l}\text { Ja, oral Penizillin V } \\
10 \text { Tage } \\
50000 \text { bis } 100000 \\
\text { E/kg/Tag }\end{array}$ & $\begin{array}{l}\text { a) u. b) ja, Penizillin } \\
\text { oral, } 5 \text { Tage } \\
\text { Dosis: } 50000 \\
\text { E/kg/Tag } \\
\text { c) fakultativ }\end{array}$ & $\begin{array}{l}\text { ja, Penizillin oral, } \\
\text { wenn mehrere } \\
\text { Erkrankungen; } \\
\text { Kindergarten } \\
\text { nicht schließen }\end{array}$ & wie Kindergarten \\
\hline $\begin{array}{l}\text { Streptokokken-A- } \\
\text { Angina } \\
\text { Fieber }\end{array}$ & $\begin{array}{l}\text { ja, oral Penizillin V } \\
10 \text { Tage } \\
50000 \text { bis } 100000 \\
\text { E/kg/Tag }\end{array}$ & $\begin{array}{l}\text { a) u. b) ja, Penizillin } \\
\text { oral, } 5 \text { Tage } \\
\text { Dosis: } 50000 \\
\text { E/kg/Tag } \\
\text { c) fakultativ }\end{array}$ & $\begin{array}{l}\text { ja, Penizillin oral, } \\
\text { wenn mehrere } \\
\text { Erkrankungen; } \\
\text { Kindergarten } \\
\text { nicht schließen }\end{array}$ & $\begin{array}{l}\text { wie Kindergarten, } \\
\text { eher fakultativ }\end{array}$ \\
\hline $\begin{array}{l}\text { Streptokokken-A-Träger } \\
\text { ohne Symptome } \\
\text { gesund }\end{array}$ & keine Therapie & keine Therapie & $\begin{array}{l}\text { keine Therapie, } \\
\text { Ausnahme: } \\
\text { Scharlachepidemien } \\
\text { im Kindergarten } \\
\text { Penizillin V oral } \\
5 \text { Tage } \\
50000 \mathrm{E} / \mathrm{kg} / \mathrm{Tag}\end{array}$ & entfällt \\
\hline $\begin{array}{l}\text { Häufige } \\
\text { Scharlachrezidive } \\
\text { mit Streptokokken-A- } \\
\text { Nachweis }\end{array}$ & $\begin{array}{l}\text { ja, Penizillin V (oral) } \\
\text { evtl. } 100000 \mathrm{E} / \mathrm{kg} / \mathrm{Tag}{ }^{1} \\
10 \text { Tage } \\
\text { evtl. i.m. }\end{array}$ & $\begin{array}{l}\text { nur nach Abstrich } \\
\text { a)-c) Penizillin } \\
\text { oral, } 5 \text { Tage }\end{array}$ & entfällt & entfällt \\
\hline $\begin{array}{l}\text { Häufige Anginarezidive } \\
\text { mit Streptokokken-A- } \\
\text { Nachweis }\end{array}$ & $\begin{array}{l}\text { ja, Penizillin V (oral) } \\
\text { evtl. } 100000 \mathrm{E} / \mathrm{kg} / \mathrm{Tag}^{1} \\
10 \text { Tage } \\
\text { evtl. i.m. }\end{array}$ & $\begin{array}{l}\text { nur nach Abstrich } \\
\text { a)-c) Penizillin } \\
\text { oral, } 5 \text { Tage } \\
50000 \mathrm{E} / \mathrm{kg} / \mathrm{Tag} 2\end{array}$ & entfällt & entfällt \\
\hline
\end{tabular}

${ }_{1}^{1}$ Kindergarten- bzw. Schulbesuch frühestens ab 4. Tag nach Therapiebeginn.

2 Eventuell auch anderes Vorgehen (z. B. keine Therapie).

lung bedeutungsvoll, da gleichzeitig therapeutische und prophylaktische (z.B. bei Geschwistern) Maßnahmen getroffen werden müssen (Tabelle 68).

Die Infektiosität bei Scharlach ist auch heute noch hoch. Es besteht immer Endemiegefahr.

Die meisten Menschen erkranken bei wiederholtem Kontakt mit $\beta$-hämolysierenden Streptokokken der Gruppe A nicht mehr unter dem Vollbild des Scharlachs mit Exanthem, sondern lediglich an einer Angina, die jedoch ebenso mit Penizillin behandelt werden muß (Tabelle 68). Allerdings wird derzeit eine Versagerquote für Penizillinpräparate in der Behandlung der Streptokokken-A-Angina mit 20-30\% beobachtet [201].
Die Erkennung von Scharlach wird zusätzlich dadurch erschwert, daß auch Uncharakteristisches Fieber (vgl. B 1.2) mit scarlatiniformem Ausschlag einhergehen kann. Der Hausarzt sollte daher großzügig vom kulturellen Erregernachweis Gebrauch machen!

Zuweilen werden dem Hausarzt Kinder vorgestellt, die eine Abschälung der Haut an Händen und Füßen (Desquamation) aufweisen und bei denen die Begleiter auch bei gezieltester Befragung sich an keine Symptome erinnern können, die an einen „Scharlach“ hätten denken lassen.

Braun sah in seiner Großstadtpraxis zwischen 1944 und 1954 Scharlach bei rund 1,5\%o der Fälle. 1954 bis 1959 deutete sich eine Abnahme an; die 
Tabelle 69. Häufigkeit (Rang) wichtiger Bilder von sog. „Kinderkrankheiten“ in allgemeinmedizinischen Praxen in Österreich ([31] bzw. [37]) und in der Schweiz [151]

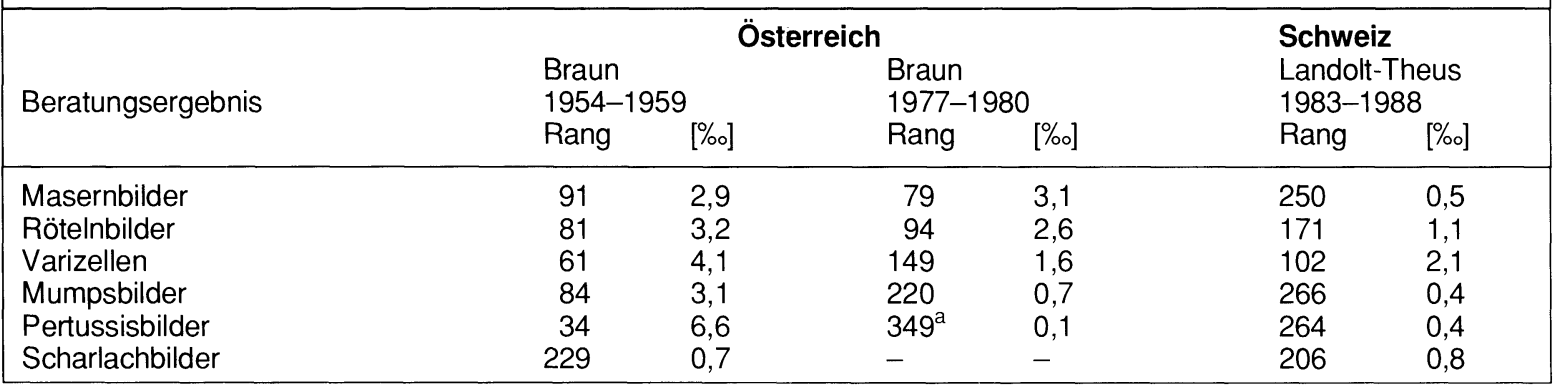

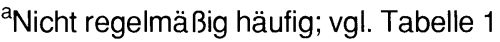

Häufigkeit lag bei $0,74 \%$, also weniger als $1: 1000$ (Rang 229). In den Jahren 1977 bis 1980 (Landpraxis) kam kein einziger Fall mehr vor. Dagegen registrierte der Allgemeinarzt Landolt-Theus Ende der 80er Jahre wieder Scharlachfälle (Tabelle 69).

\subsubsection{Impfungen}

Nach dem jetzigen Stand medizinischer Erkenntnisse sollen und können Kinder und Erwachsene durch aktive Schutzimpfungen vor dem (epidemischen) Ausbruch der meisten Infektionskrankheiten bewahrt werden. Für die Bedürfnisse der Allgemeinpraxis hat sich der Impfplan des Fachverbandes Deutscher Allgemeinärzte (FDA) mod. nach Holzner bewährt (Abb. 96).

\subsection{Gewichtsveränderungen}

Gewichtsveränderungen sind ein objektiver und leicht zu kontrollierender Parameter.

Der einzelne Mensch oder seine Angehörigen vermögen i.allg. Auf- und Abwärtsbewegungen des Gewichts gut abzuschätzen. Allerdings gibt es bei $\mathrm{Ge}$ schwichtskontrollen unter exakten Meßbedingungen für den Patienten wie für den Arzt immer wieder Überraschungen bezüglich des tatsächlichen Gewichts.

Der Hausarzt sollte daher zur regelmäßigen Gewichtskontrolle unter annähernd standardisierten Bedingungen (entkleideter Patient) zu Hause anhalten; ebenso aber sollte das Körpergewicht in der Praxis selbst immer wieder objektiviert werden.

\subsubsection{Gewichtszunahme}

Obwohl Gewichtszunahme in der Bevölkerung eine große Rolle spielt, ist sie nur relativ selten in der Allgemeinpraxis Beratungsursache (BU). Die Klassifizierung erfolgt aufgrund der Relation von Körpergewicht zur Körpergröße.

Wiederholt spricht der Hausarzt bei bestimmten Erkrankungen (z.B. Diabetes, Koxarthrose, Gonarthrose, Hypertonie, Kreuzschmerzen) die Patienten auf ihre Fettleibigkeit (Adipositas) an. Ebenso beteuern diese Menschen immer wieder, daß ihnen ihr Übergewicht selbst unerklärlich sei, da sie wirklich „nichts" essen.

In geeigneten Fällen (z.B. aus psychologischen Gründen - ,ich habe es an den Drüsen“) empfiehlt sich die Handlungsanweisung Nr. 68 (,AdipositasStandard") zur allgemeinmedizinischen programmierten Diagnostik bei uncharakteristischer Gewichtszunahme oder bei dauerndem, starken Übergewicht. Dieses Programm ist so ausgelegt, daß zumindest im Bereich des Möglichen auch die wichtigsten, auf endogene Störungen zurückgehende Fettsuchtformen berücksichtigt werden. Hinweise auf solche Erkrankungen ergeben sich allerdings extrem selten.

\section{Praxisalltag}

Arzt und Patient wissen dabei gleichermaßen gut, daß alle Wege, langfristig zu einer Gewichtsreduktion zu gelangen, recht mühselig und schwierig sind. Alle Frühjahrs-, Fasten- oder Fitneßkuren haben eines gemeinsam: Der Erfolg ist meist nur von kurzer Dauer. Die anfängliche Begeisterung über den ra- 


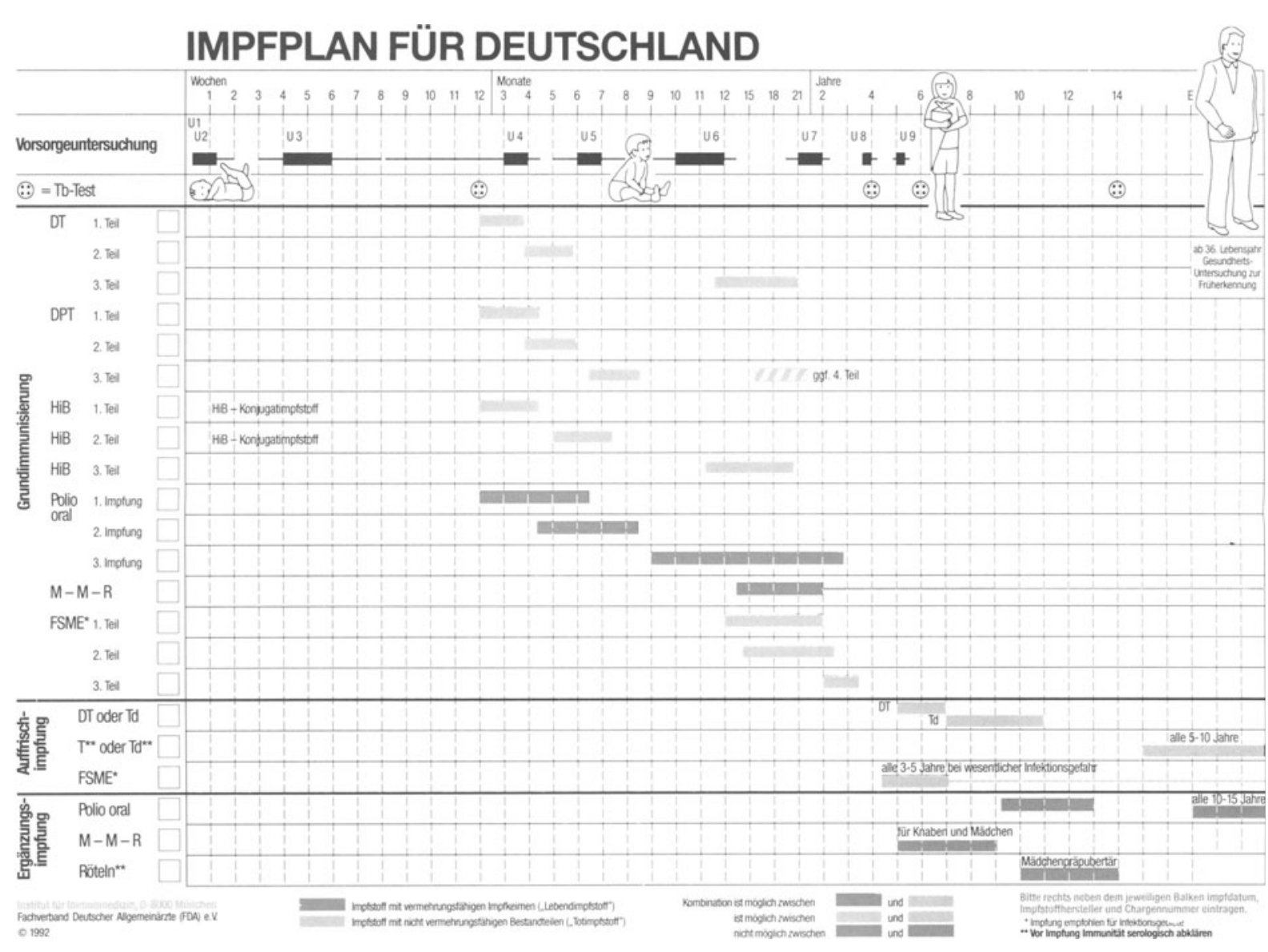

Abb. 96. Impfplan (Grundimmunisierung, Auffrischimpfung, Ergänzungsimpfung) für die Allgemeinpraxis. Impftermine vom Neugeborenen- bis zum Erwachsenenalter unter Bezug zu den gesetzlichen Vorsorgeuntersuchungen [114]

schen Verlust der ersten Pfunde weicht bald der Resignation, wenn die Gewichtsabnahme stagniert oder man gar wieder zunimmt (,Jo-Jo-Effekt“").

Unkontrolliertes E $\beta$ - und Trinkverhalten (Fernsehknabbereien, gewohnheitsmäßiges Naschen, Spätmahlzeiten, schnelles Essen, Heißhunger, alkoholische Getränke) machen auf lange Sicht meist den Vorsatz zum Abspecken zunichte. Ebenso sind eine ungünstige Speisenzusammensetzung (fette Hausmannskost, Kohlenhydratemast) oder Unkenntnis über den Energiegehalt der Nahrungs- und Genußmittel (z.B. von Bier und hochprozentigen alkoholischen oder gesüßten Getränken, von Back- und Bratfetten, von Eiscreme) dazu angetan, eine Gewichtsabnahme zu verhindern.

\section{Hyperphage und hypophage Reaktion}

Seelische und körperliche Reaktionen bestimmen das Appetitverhalten im Sinne von weniger Appetit (hypophage Reaktion) oder mehr Appetit (hyperphage Reaktion) (Abb. 97 und Abb. 98).

Auslöser können sein:

Trauer, Einsamkeit, Ärger, Konflikte, Arbeit, Prüfung, Angst, Langeweile, „Frust“.

Hier kann Essen als Ersatzerlebnis zu „Kummerspeck" führen.

,Jeder Dicke ißt heimlich oder unheimlich, meist beides!“‘ (Franke in [13]). 


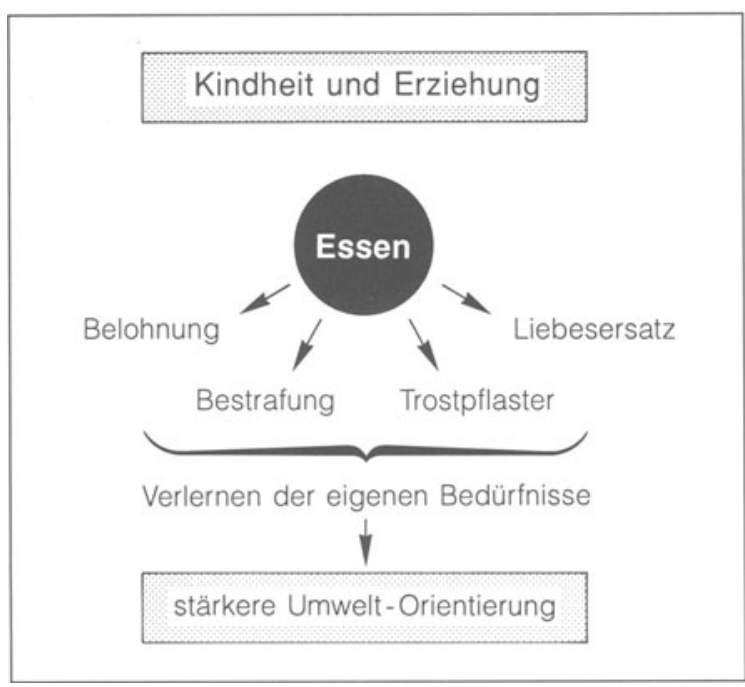

Abb. 97. Ursachen der Elsucht (Hyperphagie) bei Kindern [13]

\section{Diät, Gruppentherapie}

Schier unüberschaubar ist die Zahl der Diäten mit oft wohltönenden Bezeichnungen wie „Hollywood“"-Diät, Buttermilch-Diät, Atkins-Diät etc. Alle diese „Außenseiter"diäten sind durch die Höhe des Eiweiß- und/oder Fettanteils in der Nahrung zuungunsten der Kohlenhydrate charakterisiert.

Das totale Fasten (,Nulldiät“) kann ambulant durchgeführt, aber kaum durchgehalten werden. Es ist darauf zu achten, daß der fastende Patient mindestens 3 l Flüssigkeit pro Tag zu sich nimmt. Der Gewichtsverlust beträgt im Durchschnitt täglich etwa $300-400 \mathrm{~g}$, die Gewichtsabnahme verläuft exponentiell (Hausmann u. Kaffarnik in [139]).

Eine Behandlung adipöser Patienten unter Anleitung eines Therapeuten in Gruppen, die nach kurzer Zeit in Selbsthilfegruppen übergeführt werden können, hat sich bewährt (z.B. Weight-Watchers). Die Verhaltensänderung findet nicht nur aus zeitökonomischen Gründen in Gruppen statt, sondern soll v.a. ermöglichen, daß die Patienten sich gegenseitig, auch außerhalb der Gruppensitzungen, unterstützen. Die Ernährungsgewohnheiten sollen selbst beobachtet und selbst bewertet werden. Der Patient kann z.B. feststellen, von welchen Reizen sein Hungergefühl abhängig ist, wie häufig und wie lange er ißt usw. Die Verhaltensänderung erfolgt in kleinen Schritten; dies

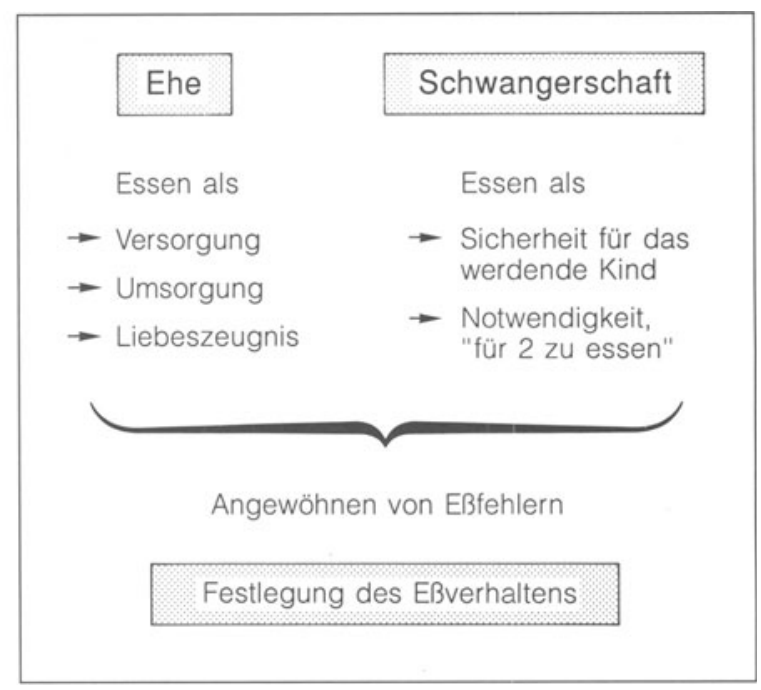

Abb. 98. Ursachen der Eßsucht (Hyperphagie) in Ehe und Schwangerschaft [13]

geschieht deswegen, weil sich die Eßgewohnheiten über viele Jahre hinweg eingeschliffen haben. Plötzlich soll dem Patienten bewußt gemacht werden, daß er alleine es ist, der für den Behandlungserfolg verantwortlich ist [9]. Allzuviel darf aber auch davon nicht erwartet werden. Viele Teilnehmer scheren bald wieder aus.

\subsubsection{Gewichtsabnahme}

Im Gegensatz zur Gewichtsabnahme wird der ungewollte Gewichtsverlust in der Allgemeinpraxis zum diagnostischen Problem. Er muß selbstverständlich immer sehr ernst genommen werden. Bei Gewichtsabnahme ohne sonstige Symptome sollte der Allgemeinarzt seine Beratung mit einer Tabula diagnostica (Programm Nr. 67) starten. Dabei gilt es stets, sich die Abwendbar gefährlichen Verläufe vor Augen zu halten.

Eine Gewichtsabnahme im Senium ist zwar häufig, aber nicht obligat und hält sich in Grenzen von $5-10 \mathrm{~kg}$ [97].

Bei Malignomen, Hyperthyreose, länger dauernden Infekten, Alkoholismus etc. ist Gewichtsverlust ein ,normales“ Symptom.

Gewichtsverlust beim Säugling bedarf einer äuBerst engmaschigen Kontrolle und ist grundsätzlich 
ernst zu nehmen; frühzeitig ist die Teilung der Verantwortung mit dem Spezialisten erforderlich.

\section{Appetitlose Kinder}

Immer wieder sind es die Mütter, die dem Hausarzt „appetitlose Kinder" präsentieren; hier genügt oft 1-2 Tage „schlechtes Essen“, um sie besorgt zu machen. Dabei wird nicht selten die Frage nach „Blutarmut" oder „Vitaminmangel“" aufgeworfen. Ursächlich schuld an der Appetitlosigkeit ist oft genug die Unvernunft der Eltern und/oder der Großeltern oder anderer Haushaltsmitglieder.

Das Körpergewicht muß immer in der Relation zur aktuellen Körpergröße beurteilt werden. Die normale Schwankungsbreite beträgt $10 \%$. Unter Hinweis auf diese biologischen Gegebenheiten ist es in manchen Fällen möglich, die verunsicherte Mutter beruhigt zu entlassen.

Auch wenn sich die Eltern scheinbar unnötig Sorgen machen, muß dennoch gründlich untersucht werden. Bei seelisch und körperlich gesund erscheinenden, angeblich ,appetitlosen“ Kindern empfiehlt sich das Programm Nr. 69 (,Appetitlose-Kinder-Standard").

Der Arzt weiß aus seiner Erfahrung, daß sich das Eßverhalten in den meisten Fällen wieder rasch normalisiert und eine weitere Diagnostik zunächst entbehrlich ist, wenn das ,Zwischendurchfuttern" mit Leckerbissen etc. ein Ende findet. Leider kommt er aber mit Appellen an die Vernunft der Erwachsenen nicht weit, und es bleibt alles beim alten einschließlich der „Appetit-Tropfen“.

\section{Anorexia nervosa, Bulimie}

Scharf abzugrenzen von dem harmlosen Appetitmangel im Kleinkindalter oder von schlechten Eßgewohnheiten ist die Anorexia nervosa (Magersucht) in der Adoleszenz.

Die Bulimie („Ochsenhunger“) leitet sich her von der paroxysmalen und unbeherrschbaren Einverleibung riesiger Nahrungsmengen mit anschließendem provozierten (meist geheim gehaltenen) Erbrechen.

Anorexia nervosa und Bulimie sind Störungen des Eßverhaltens bei jungen, ehedem gesunden Frauen, die von einer geradezu panischen Angst des Dickwerdens erfaßt sind. Beim Syndrom der Anorexia nervosa wird dieses Ziel hauptsächlich durch drastische Einschränkung der Energiezufuhr erreicht, bei der Bulimie wechseln Anwandlungen von Völlerei (,Freßgelage“) mit Erbrechen und exzessivem Laxanzienabusus ab. Der Gewichtsverlust ist bei der Bulimie erfahrungsgemäß nicht sehr groß.

\section{Marasmus}

Die sog. ,Altersschwäche“ mit allgemeinen geistigkörperlichem Kräfteverfall ist durch die (nicht durch Krankheiten erklärte) Reduktion der wichtigsten Körperfunktionen charakterisiert. Die Lebenskraft nimmt unbeeinflußbar über Monate, oft über Jahre bis zum Tod hin, laufend ab. Schließlich geht der Abbauprozeß so weit, daß diese Menschen zu hilflosen Pflegefällen werden. Tritt inmitten eines solchen Abbauprozesses der Tod ein, so ist der Leichenbeschauer häufig außerstande, dafür eine spezielle Krankheit verantwortlich zu machen. Bekanntlich kommen statt dessen die von einzelnen Beschauern in solchen Fällen bevorzugten Begriffe (etwa Herzinfarkt, Lungenembolie) zum Tragen. Auch hierin wirkt sich das wissenschaftliche Vakuum über der angewandten Heilkunde sehr anschaulich aus [35].

\subsection{Fußübel und statische Beschwerden}

Jeder erfahrene Praktiker wird spontan die erhebliche Zahl von Fuß- und statischen Beschwerden bestätigen können, weswegen ihn seine Patienten quer durch alle Altersschichten hindurch konsultieren; dies spiegelt sich auch in Tabelle 70 wider.

Darüber hinaus gibt es eine Fülle weiterer Beratungsprobleme im Fußbereich (die nicht in Tabelle 70 aufgeführt sind), z.B.

- Schwielen, Warzen (vgl. B 7.4),

- bestimmte Verletzungen (vgl. B 4),

- Durchblutungsstörungen (vgl. B 2.1),

- Neuropathien (vgl. B 2.1),

- Engpaßsyndrome (vgl. B 2.1),

- Angeborene Deformitäten etc.

Clavus (Abb. 101a), Unguis incarnatus (Abb. $27 \mathrm{c}$ ) und Dornwarze (Abb. 52) werden auch als die ,kleinen Fußübel " bezeichnet. Wegen ihrer Häufigkeit und der durch sie hervorgerufenen Beschwerden sind sie von großer Bedeutung für die tägliche Praxis. 
Tabelle 70. Häufigkeit (Rang) von bestimmten Beratungsergebnissen im Bereich des Fußes in allgemeinmedizinischen Praxen in Österreich ([31] bzw. [37]), in der Schweiz [151] und in Frankreich/Paris [237]

\begin{tabular}{|c|c|c|c|c|}
\hline \multirow[b]{2}{*}{ Beratungsergebnis } & \multicolumn{2}{|c|}{ Österreich } & \multirow{2}{*}{$\begin{array}{l}\text { Schweiz } \\
\text { Landolt-Theus } \\
\text { 1983-1988 }\end{array}$} & \multirow{2}{*}{$\begin{array}{l}\text { Frankreich } \\
\text { Sourzac/Very } \\
1988-1990\end{array}$} \\
\hline & $\begin{array}{l}\text { Braun } \\
\text { 1954-1959 }\end{array}$ & $\begin{array}{l}\text { Braun } \\
1977-1980\end{array}$ & & \\
\hline Klavi & 104 & 132 & 260 & 190 \\
\hline Füße, kalte & 288 & 135 & 226 & 216 \\
\hline Senkfußbeschwerden & 111 & 139 & 186 & 206 \\
\hline Statische & & & & \\
\hline Beschwerden & 172 & 199 & 166 & 111 \\
\hline Onychogryposis & - & 207 & $452^{a}$ & - \\
\hline Unguis incarnatus & 122 & 211 & 167 & 138 \\
\hline Spreizfüße & 295 & 223 & $386^{a}$ & 114 \\
\hline Kalkaneodynie & 249 & 259 & 143 & 269 \\
\hline Hallux valgus & $307^{a}$ & $303^{a}$ & 177 & 223 \\
\hline
\end{tabular}

${ }^{a}$ Nicht regelmäßig häufig; vgl. Tabelle 1.

Sogenannte „statische Beschwerden“ werden meist im Fuß, in der Wadenmuskulatur oder im Kniegelenk lokalisiert und weniger im ganzen Bein empfunden [194]. Kinder klagen gelegentlich über un-

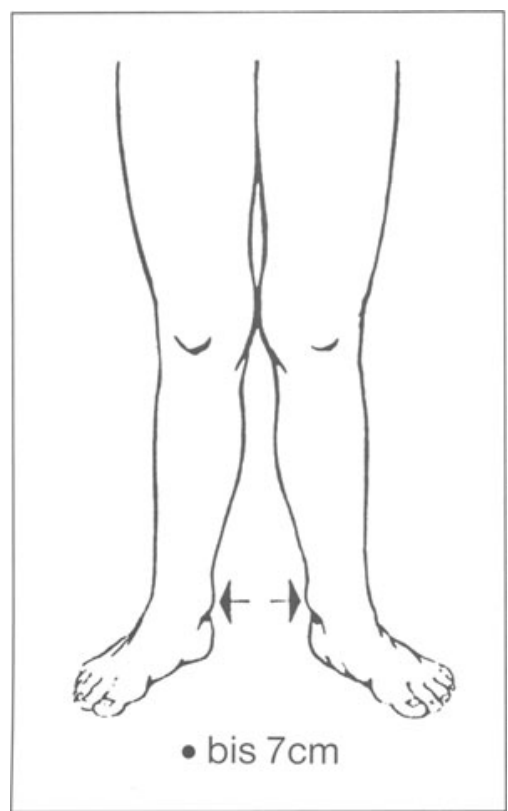

Abb. 99 Innenknöchelabstand bei lose aneinandergelegten Kniegelenken bei Kindern jenseits des 2. Lebensjahres etwa $7 \mathrm{~cm}$. immer pathologisch sind $10 \mathrm{~cm}$ und mehr. Bei adipösen Kindern ist eine Überschreitung von $2-3 \mathrm{~cm}$ möglich [142] charakteristische Beinbeschwerden im Rahmen von länger dauernden Belastungen. Bei Kleinkindern fällt den Eltern manchmal plötzliches Hinken oder Nicht-mehr-laufen-Wollen als Erstsymptom auf (vgl. B 2.5)

Achsenfehlstellungen wie Erkrankungen des Hüftgelenks sollten diagnostisch ausgeschlossen worden sein [91]. Dabei wird der Allgemeinarzt zunächst zu prüfen haben, ob möglicherweise das physiologische X-Bein-Maß (Abb. 99) überschritten ist.

Bevorzugt abendliche oder nächtliche „Wachstumsschmerzen " bei (meist überbehüteten) Kindern können zunächst abwartend offen beobachtet werden, stets den Abwendbar gefährlichen Verlauf (z.B. Osteosarkom, aseptische Knochennekrosen) vor Augen. Der Arzt muß wissen, daß „Wachstum“ nicht schmerzt. Sollten nach 14 Tagen die Schmerzen nicht spontan verschwunden sein, ist spezialistische $\mathrm{Ab}$ klärung erforderlich.

\subsubsection{Klavus}

Hühneraugen (Klavi) (C/D) (Abb. 100 und 101a) können bekanntlich äußerst heftige Schmerzen verursachen. Der Geplagte hat meist schon verschiedene Selbstbehandlungsversuche (Salben, Tropfen, Pflaster), Fußpflegebehandlungen oder Ausschneidungen (Hobel, Rasierklingen) hinter sich, ehe er sich an den Arzt wendet. Häufig findet dieser neben einem 


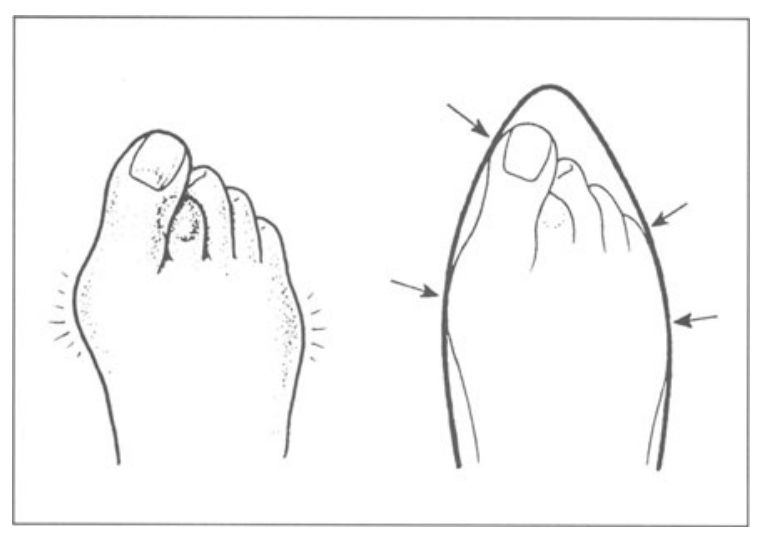

Abb 100. Der breite Vorfuß hat im schmalen Schuh zu wenig Platz, er wird von beiden Seiten gequetscht. Dadurch kommt es zu schmerzhaften Druckstellen am medialen (,Hallux“) oder lateralen Metatarsalköpfchen. Vorn werden die Zehen in den engen Schuhspitzen zusammengepreßt und eingestaucht, wodurch die typische Hammerzehe entsteht [57].

aufgeweichten Hornhautareal auch Anzeichen einer Entzündung. Eine Reizung der darunterliegenden Bursa kann an entsprechenden Stellen vorhanden sein.

Druck und Reibung verursachen stets eine Verhornung der Haut. Sie besteht an der Stelle des größten Druckes, also da, wo dicht unter der Haut ein Knochenvorsprung liegt, z.B. an der Fußsohle, unter dem Metatarsalköpfchen II und/oder III, medial am Metatarsalköpfchen I (sog. „Exostose“ am Hallux valgus), lateral am Metatarsalköpfchen $\mathrm{V}$ (sog. „Exostose“ beim „Digitus V varus“" [Abb. 100], dem Gegenstück des Hallux valgus), an der Spitze der Zehen II-V bei Hammer- oder Krallenzehen oder zwischen zwei kleinen Zehen, wenn Knochenvorsprünge gegeneinander drücken (Interdigitalklavus).

Bei entzündeten Hühneraugen müssen zunächst alle weiteren Reize wie Druck durch falsches Schuhwerk (Abb. 100) oder Manipulationen durch den Patienten unterbleiben; adstringierende, kalte Fußbäder können zunächst als angenehm empfunden werden. Die Therapie der Wahl besteht in Druckentlastung und/oder Ruhigstellung.

Der nicht entzündete Klavus wird bis zum zentralen Pfropf hin (Abb. 101a) schichtweise abgetragen. Das Rezidiv ist vorprogrammiert, wenn weiterhin unpassendes Schuhwerk getragen wird.

Die Hornwarze (Verruca plana) (C/D) (vgl. B 7.4) befindet sich im Gegensatz zum Hühnerauge

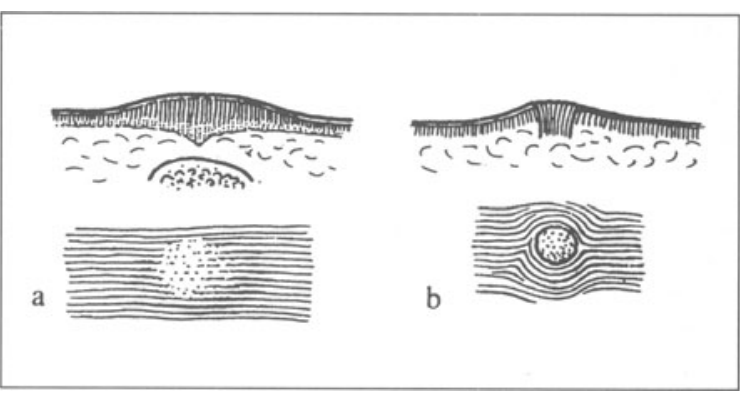

Abb. 101 a,b. Hühnerauge (Klavus) und Hornwarze (Verruca plana) im Querschnitt (oben) und in Aufsicht (unten): a starkt verdickte Hornschicht an der Stelle der größten Belastung, d. h. genau über dem darunter liegenden Knochen. Dort bildet sich mit der Zeit ein Dorn aus verhornter Haut, der schmerzhaft ins Fleisch sticht. b Die Hornwarze liegt in der Regel nicht genau über dem belasteten Knochen, die Hautlinien machen einen Bogen um sie herum. Die Warze selbst besteht aus weichen Papillen mit kleinen schwarzen Stippchen [57]

in der Regel nicht genau über dem belasteten Knochen und ist scharf gegen die Umgebung abgegrenzt (Abb. 101b). Bei ihrer operativen Exzision gibt es anders als bei der schichtweisen Abtragung des Klavus - mitunter nennenswerte Blutungen.

Wie alle Viren braucht das HPV (, human papilloma virus") gesunde Zellen zu seiner Replikation. Zu diesem Zweck baut es sein genetisches Material als gezielte Information in das Genom der Wirtszelle ein und funktioniert sie für sich um.

Der erfolgreiche Abschluß einer Therapie setzt daher die totale Entfernung der Warze als Wirtszellverband und die Vernichtung allen infektiösen Materials von HPV voraus. Das Einfrieren mit flüssigem Stickstoff, Hochfrequenztherapie oder die Vaporisierung mit dem Laserstrahl leisten im Idealfall beides.

Jeder Arzt, der Warzen behandelt, weiß jedoch, daß man mit Rezidiven rechnen muß.

\subsubsection{Kalte Füße}

Die Beratungsursache „kalte Füße“ (A) wird vom Patienten oft eher im Nebensatz erwähnt. Meist befürchtet er eine „Durchblutungsstörung“. In der Regel handelt es sich jedoch um eine Empfindung, von deren Harmlosigkeit der Patient rasch zu überzeugen ist. Selbstverständlich müssen zuvor Abwendbar gefährliche Verläufe, z.B. arterielle Durchblutungsstö- 


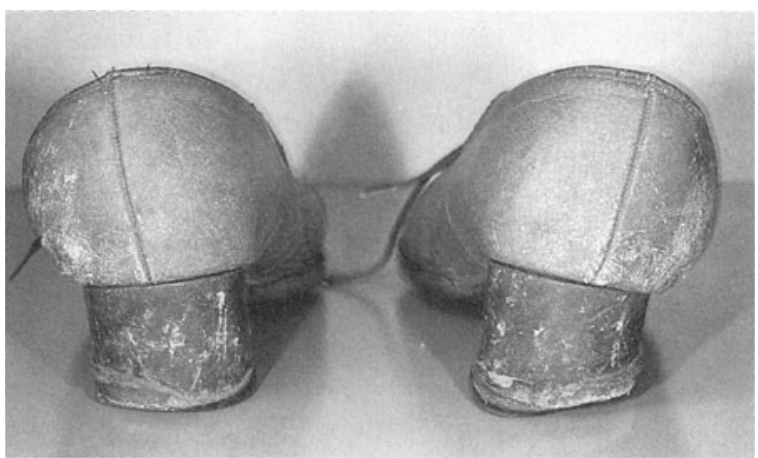

Abb. 102. Schuhinspektion

rungen (vgl. B 12.3.6, Tabelle 66), ausgeschlossen worden sein.

\subsubsection{Senk- und Spreizfüße}

Der Senkfuß (C/D) ist durch Abflachung des medialen Längsgewölbes beim Auftreten charakterisiert. Im Extremfall ist die Längswölbung auch ohne Belastung vollkommen abgeplattet (Plattfu/Pes planus) (C/D).

Nur Füße mit stärkerer Abknickung des RückfuBes sind als Knickfuß (Pes valgus) (C/D) zu bezeichnen. Die Inspektion der (getragenen) Schuhe (Abb. 102) kann gelegentlich wertvolle Hinweise in Diagnostik und Therapie geben. Ohne Inspektion der häufig getragenen Schuhe ist die Untersuchung des Fußes unvollständig.

Spreizfüße verursachen Schmerzen beim Gehen im Bereich der Schwiele unter dem Mittelfußköpfchen II, III und IV. Die Beschwerden sind von Patient zu Patient unterschiedlich. Oft wird versucht, unangenehmen Belastungsdruck durch Abrollen über den Fußaußenrand zu beseitigen; dadurch entstehen dann zusätzlich Schmerzen in den Sprunggelenken.

Patienten mit Senk- und Plattfüßen sind überraschenderweise häufig beschwerefrei. In diesen Fällen ist eine Behandlung entbehrlich [224].

Bei Kleinkindern bis zum 4. Lebensjahr ist der Fuß meist noch flach, die Fettpolsterung der Fußsohle ergibt das Bild eines kindlichen „Plattfußes“; das Fußgewölbe entsteht erst später. Korrigierende Einlagen sind daher zu diesem Zeitpunkt nicht richtig. Der aktive Zehenstand kann den Eltern das normale Wölbungsverhalten demonstrieren.
Barfußgehen ist für die kindliche Fußentwicklung die beste Gymnastik!

Die Schmetterlingsrolle als Zurichtung bei Konfektionsschuhen dient der optimalen Entlastung des schmerzhaften Spreizfußes mit Schwielen und entzündlichen Metatarsalköpfchen, besonders der Zehen II und III.

\subsubsection{Onychogryposis}

Diese - meist erbliche - Nageldeformität (Abb. 103) beginnt nach dem 30.-40. Lebensjahr. Der Patient vermutet oft irrtümlich einen Zusammenhang mit drückendem Schuhwerk. Der Nagel läßt sich in einfacher Weise in örtlicher Betäubung entfernen, er wächst jedoch gleichermaßen deformiert wieder nach. Regelmäßiges Rückzwicken und -feilen hält das Fehlwachstum in Grenzen.

\subsubsection{Kalkaneodynie}

Stechende Schmerzen im Bereich der Ferse beim (morgendlichen) Aufstehen, Verstärkung durch Gehen und Stehen, besonders auf hartem Boden, lassen an einen Fersensporn (C/D) denken. In der Röntgenaufnahme des Fersenbeins im seitlichen Strahlengang findet man zumeist keinen knöchernen Vorsprung, der die Schmerzhaftigkeit (Kalkaneodynie) (A) erklären würde. Auch die Größe eines Sporns (Ex-ostose) korreliert nicht mit dem Beschwerdebild.

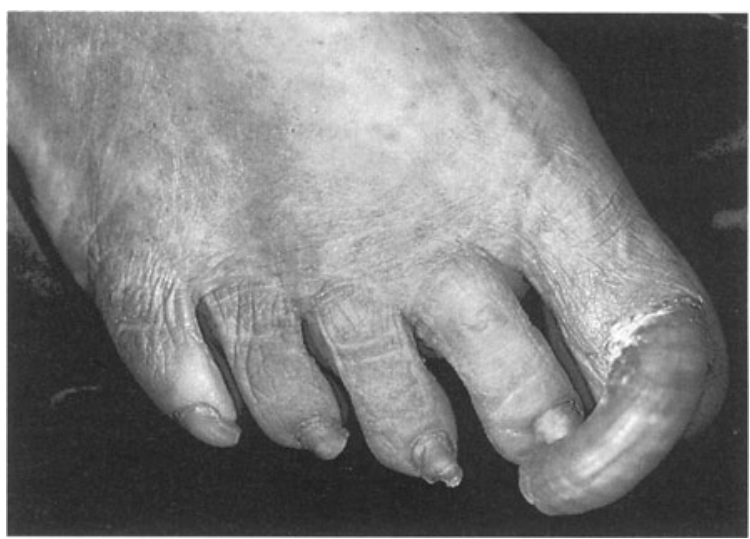

Abb. 103. Vogelkrallenzehe (Onychogryposis - auch: Onychogryphosis) 
Therapeutisch wird zunächst der Schmerzpunkt entlastet, etwa mit einer ringförmigen Polsterung im Schuh, mit Hohllegung in einer Kork-Leder-Einlage oder mittels einer sorgfältig anmodellierten stabilen Metalleinlage.

Einlagen, die wegen uncharakteristischer Tarsalgie verordnet wurden, sollen nicht zu lange getragen werden.

\subsubsection{Hallux valgus}

Der Hallux valgus (Ballenwinkel) (C/D) ist bei Frauen weit verbreitet, doch macht er in den meisten Fällen wenig Beschwerden. Enge, spitze Schuhe spielen eine wesentliche Rolle bei der Deformierung des Fußes.

Durch die Fehlstellung der Großzehe kommen die kleinen Zehen in Raumnot, werden ihrerseits deformiert und geraten oft über oder unter die Großzehe (Abb. 100). Beides kann ebenfalls schmerzhaft sein.

\subsection{Kropf und Schilddrüsenüberfunktion}

Spätestens dann, wenn bei Heranwachsenden ein seit längerer Zeit bestehender, geringfügig verdickter Hals an Größe noch zunimmt, drängen die Angehörigen auf eine hausärztliche Abklärung dieses „Blähhalses“. In der Regel handelt es sich um eine euthyreote Adoleszentenstruma, bei der eine direkte Diagnostik ausreicht.

Die Vergrößerung der Schilddrüse (Kropf, Stru$m a)(C / D)$ stellt in Jodmangelgebieten eine häufige Beratungsursache dar. Extrem ausgeprägte Kröpfe bei Erwachsenen sind in der Sprechstunde heute eine Rarität geworden, da die Patienten i. allg. frühzeitig eine Behandlung erhalten.

Grundsätzlich ist die Beurteilung der Funktion der Schilddrüse von der Beurteilung des Organs zu unterscheiden. Bei Strumen gilt die diagnostische Sorge - neben einer möglichen Malignität - der routinemäßigen Exklusion einer Hyperthyreose (C/D). Legen der Aspekt eines Patienten und sein Verhalten zusammen mit den geklagten Beschwerden nahe, $\mathrm{da} ß$ eine Schilddrüsenüberfunktion zugrunde liegen könnte, dann ist zur initialen Diagnostik das Programm Nr. 78 (,Schilddrüsenüberfunktions-Standard") anzuwenden.
„Hyperthyreose“ ist eine zusammenfassende Bezeichnung für verschiedene, in der Praxis überwiegend sehr seltene Krankheitsformen mit unterschiedlicher Pathogenese:

- Hyperthyreosen vom Typ des M. Basedow,

- Hyperthyreosen bei autonomen Adenomen, bei Malignomen, bei Entzündungen der Schilddrüse,

- Hyperthyreosis facticia bei Überdosierung mit Schilddrüsenhormonpräparaten,

- Hyperthyreose durch Jodapplikation (meist jodhaltige Kontrastmittel): Struma basedowicata (Jod-Basedow),

- thyreotoxische Krise (Basedow-Koma).

Nicht selten läßt sich bei älteren Menschen eine zunächst unklare Tachykardie durch eine aufgedeckte Hyperthyreose, z.B. auf dem Boden eines autonomen Adenoms, erklären.

Andererseits sind viele der bei Hyperthyreose vorkommenden Mißempfindungen auch bei vegetativ Stigmatisierten (vgl. B 11.2) zu finden:

Unruhe, Reizbarkeit, Zittern, Herzrasen, Herzklopfen, Schwitzen, Haarausfall.

Die klassische Merseburger Trias (Tachykardie, Struma, Exophthalmus) ist selten.

Beim Anschein einer Hyperthyreose sollte auch gezielt nach eingenommenen Medikamenten (z.B. jodhaltige Präparate, östrogenhaltige Antikonzeptiva) gefragt werden, da diese einen Einfluß auf die Schilddrüsenfunktion bzw. Entwicklung einer Struma haben und die Schilddrüsenlaborwerte beeinflussen können.

\subsection{Gutartige Neubildungen}

Bei anscheinend gutartigen Neubildungen reicht -im Gegensatz zur umfangreichen Diagnostik bei der Möglichkeit eines Malignoms - für gewöhnlich die direkte Diagnostik (vgl. B 7.1, 7.9, 7.16.1, 8, 8.5.2, $8.6,9.12,9.17 .8,12.2 .4,12.8$ ) aus, so bei Bildern von

- Ganglien,

- Lipomen,

- Atheromen,

- Gefäßnävi,

- Chalazien,

- Granulomen etc. 
Selbstverständlich sind tastbare Knoten (z.B. in der Brust, im Adnex- und Uterusbereich) solange als potentiell bösartig anzusehen, bis nicht das Gegenteil (z.B. histologisch) bewiesen wurde.

\subsubsection{Knoten in der Brust}

Bei über $80 \%$ aller Brustkarzinome werden die Knoten heute von den Patientinnen selbst entdeckt. Frauen, die meist zufällig einen solchen Knoten in der Brust (C/D) finden (Abb. 104), sind aufs äußerste beunruhigt und suchen unverzüglich den Arzt auf. Nicht selten wird ein Zusammenhang mit einem Trauma (z.B. Stoß, Kneifen) vermutet. Der Hausarzt palpiert beide Mammae, die Axillen sowie die Lymphabflußgebiete sorgfältig und überträgt meist durch sofortige Überweisung die Verantwortung für das weitere diagnostische und therapeutische Vorgehen den Spezialisten.

Als Mastopathie bezeichnet man mehr oder weniger schmerzhafte Knotenbildungen in den Mammae, die bevorzugt präklimakterisch auftreten.

Was wie eine Mastopathie aussieht, kann sehr wohl ein Mammakarzinom sein.

Solitäre Brustknoten müssen aus diagnostischen, therapeutischen, daneben aber auch aus psychologischen Gründen so rasch als möglich exstirpiert und histologisch untersucht werden [238].

Zur frühen Aufdeckung eines Mammakarzinoms gehören die Selbstkontrolle der Brust nach jeder Menstruation und eine jährliche Kontrolle durch den Hausarzt [238].

\subsubsection{Gynäkomastie}

Die meist sichtbaren, berührungsempfindlichen und druckschmerzhaften Knoten im Brustwarzenbereich, vorwiegend bei Knaben in der Pubertät, beunruhigen die Betroffenen ebenso wie die Eltern (Angst vor Brustkrebs). Der Arzt hat es am häufigsten mit einer (physiologischen) Gynäkomastie (C/D) des Adoleszenten zu tun. Die Knoten können ein- oder beidseitig auftreten. Selbstverständlich muß zum Ausschluß eines Abwendbar gefährlichen Verlaufs örtlich sowie im Bereich der Hoden gründlich untersucht werden. Der Hausarzt kann die Eltern beruhigen, da sich die Knoten gewöhnlich binnen einiger Wochen

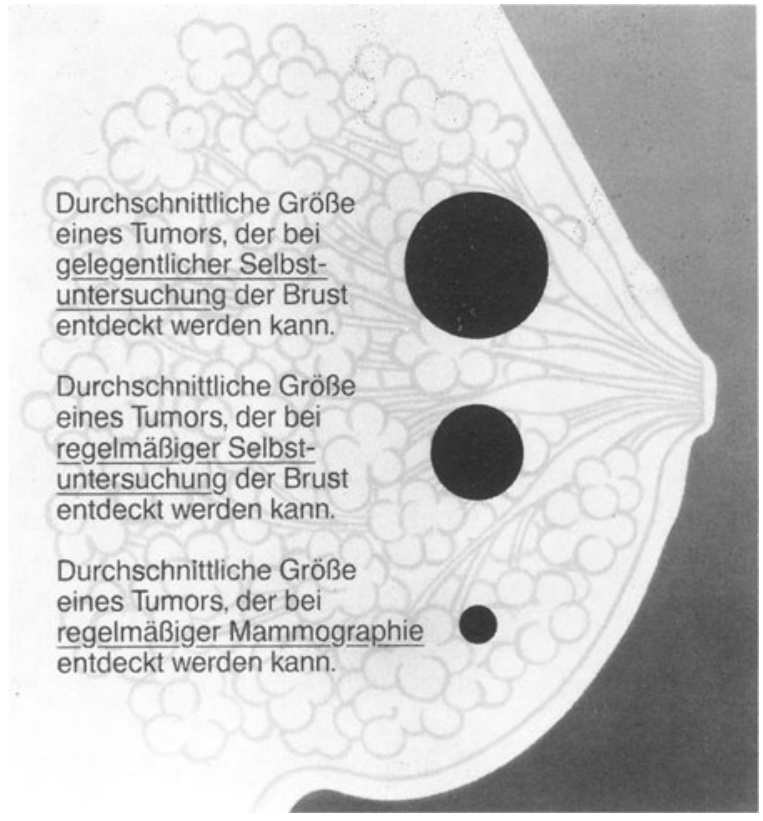

Abb. 104. Wertigkeit verschiedener Untersuchungsmethoden beim Screening auf Brustkrebs [16]

spontan zurückbilden. Selten bleiben sie länger als ein Jahr bestehen.

Es gibt keine sichere medikamentöse Therapie. Sexualhormone sind ohne Wirkung [120]. Bei ausgeprägten und/oder persistierenden Brustdrüsenschwellungen bleibt meist nur die operative Behandlung.

Die neonatalen Brustdrüsenvergrößerungen bei beiden Geschlechtern sind harmlos und bilden sich ohne Therapie rasch zurück [91].

Überzählige Brustwarzen und Brustdrüsen (Polythelie/Polymastie) gelten vielfach als eine harmlose Anomalie (Abb. 105). Oft findet der Arzt beiläufig im Rahmen einer körperlichen Untersuchung solche Drüsen. Dabei sollte bedacht werden, daß überzählige Brustwarzen mit renogenitalen Dysplasien korreliert sein können [272].

\subsubsection{Lymphomata}

Normalerweise sind Lymphknoten nicht oder kaum palpabel. Ob palpable Lymphknoten Bedeutung gewinnen oder nicht, hängt von ihrer Anzahl, Größe, Begrenzung, Konsistenz, Verschieblichkeit, Schmerz- 


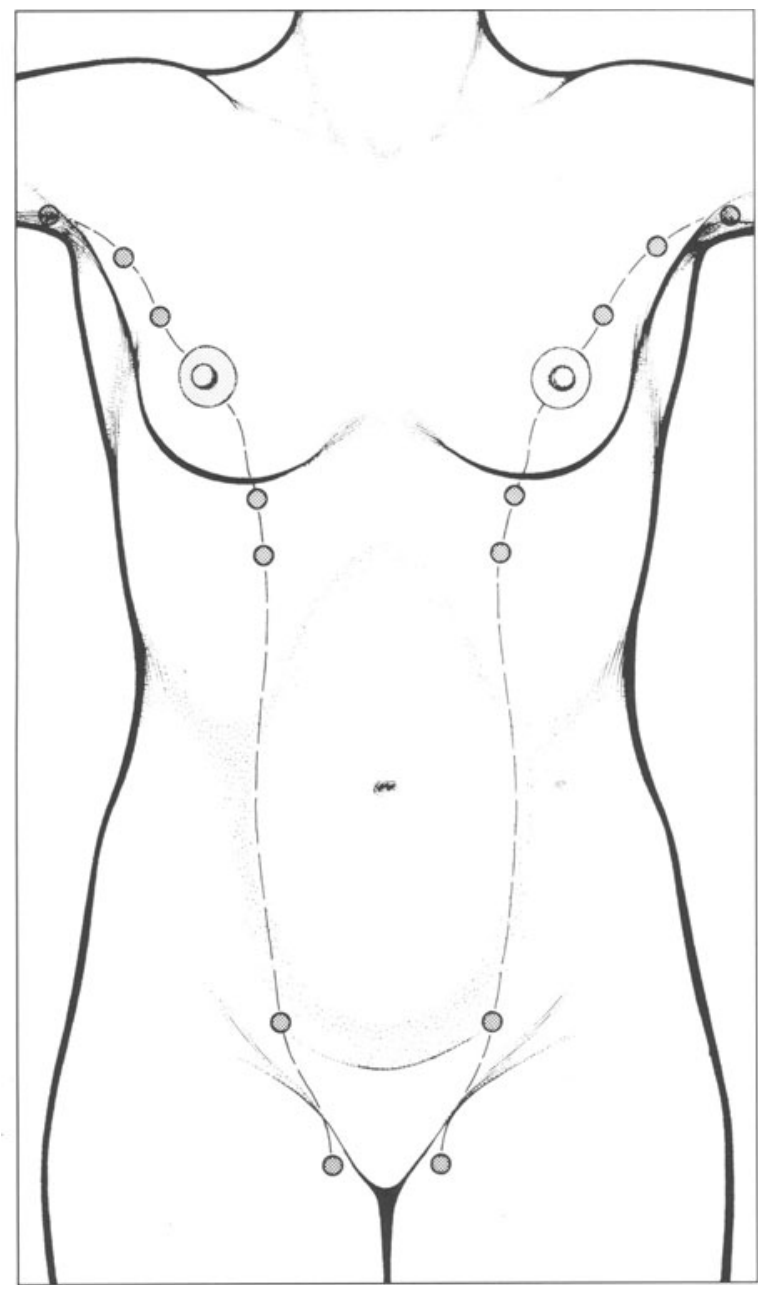

Abb. 105. Überzählige Brustdrüsen treten im Verlauf der embryonalen Milchleiste von der Achsel bis zur Leistenbeuge, vorwiegend auf der linken Seite, auf.

haftigkeit sowie von der Lokalisation und vom Alter des Patienten ab.

In der Allgemeinpraxis überwiegen einseitige, kaum imponierende, wenig dolente Schwellungen im oberen vorderen Halsbereich.

In der Pubertät nehmen Zahl und Größe der Lymphknoten zu. Sie lassen sich nicht nur im Rahmen charakteristischer Krankheitsbilder, wie etwa Röteln oder Masern (vgl. B 12.5), palpieren.

Auch beim Uncharakteristischen Fieber (UF) (vgl. B 1.2) kommt es manchmal zu nennenswerten
Lymphdrüsenschwellungen, etwa im oberen vorderen Halsbereich. Im Rahmen von Infektionen aufgetretene Lymphdrüsenvergrößerungen bilden sich fast immer spontan innerhalb von 2-3 Wochen zurück.

Einzelne solcher Drüsenvergrößerungen können jedoch noch wochenlang nach Abklingen der fieberhaften Erkrankung bestehen bleiben. Ähnliches gilt für Residuen nach pyogenen Infekten an der Haut.

Generelle und indolente (oder kaum dolente) Vergrößerungen der Lymphdrüsen lassen an Malignome (besonders Leukämie), Lues, AIDS usw. denken.

Die Lokalisation der vergrößerten Lymphknoten kann dabei gelegentlich diagnostisch hilfreich sein. Eine posteriore aurikuläre Adenopathie weist auf Röteln hin. In der Leiste oder im Kieferwinkel werden nicht selten vom Patienten selbst oder bei Routineuntersuchungen Lymphdrüsenvergrößerungen gefunden; sie sind meist ohne Bedeutung. Deckt bei indolenten Lymphknoten die Diagnostik nichts weiter auf, dann wird als Beratungsergebnis ,Uncharakteristische Lymphdrüsenvergrößerung (A)“ klassifiziert. Bedenklicher können Lymphomata in der Achsel, in der Supraklavikulargrube oder in der Ellenbeuge sein [145].

Sehen isolierte Schwellungen genauso aus wie Lymphomata, so müssen durchaus nicht vergrößerte Lymphdrüsen vorliegen; der Arzt sollte bei Anschwellungen in der Hals- oder Inguinalgegend auch mit Vortäuschungen, etwa durch Zysten oder Hernien (vgl. B 6.7) rechnen, obwohl diese selten sind.

Beim Anschein von uncharakteristischen, isolierten, einzelnen oder multiplen, kaum dolenten oder indolenten, vergrößerten Lymphknoten empfiehlt sich das Programm Nr. 77 (,Lymphknoten-Standard“).

Für schmerzende Lymphdrüsenschwellungen, die über 1 Woche bestehen und bei denen sonstige Krankheitszeichen fehlen, wurde das Programm Nr. 21 (,Lymphadenitis-Standard“) entwickelt (vgl. hierzu auch B 3.9).

Schmerzhafte, derbe Lymphknotenschwellungen, v.a. im Zervikalbereich, und körperliche Abgeschlagenheit legen den Verdacht auf eine Lymphadenopathie in Folge eines Protozoeninfekts mit Toxoplasma gondii nahe. Der entsprechende serologische Befund bringt Klarheit.

„Steinharte" Lymphomata lassen sogleich an Krebs denken. Sie sind ebenfalls nicht ,uncharakteristisch“. Solche offensichtlich metastatischen Lymph- 


\begin{tabular}{|c|c|c|c|c|}
\hline \multirow[b]{2}{*}{$\begin{array}{l}\text { Beratungsergebnis } \\
\text { (BE) }\end{array}$} & \multicolumn{2}{|c|}{ Österreich } & \multirow{2}{*}{$\begin{array}{l}\text { Schweiz } \\
\text { Landolt-Theus } \\
\text { 1983-1988 }\end{array}$} & \multirow{2}{*}{$\begin{array}{l}\text { Frankreich } \\
\text { Sourzac/Very } \\
1988-1990\end{array}$} \\
\hline & $\begin{array}{l}\text { Braun } \\
\text { 1954-1959 }\end{array}$ & $\begin{array}{l}\text { Braun } \\
1977-1980\end{array}$ & & \\
\hline Bursitis acuta & 176 & 167 & 158 & 189 \\
\hline Hygrome, chron. Bursitis & 255 & 170 & $287^{a}$ & 222 \\
\hline Tendovaginitis & 155 & 177 & 50 & 90 \\
\hline Ganglion & 130 & 190 & 163 & 182 \\
\hline Epikondylitis humeri & 123 & 231 & 57 & 105 \\
\hline
\end{tabular}

${ }^{a}$ Nicht regelmäßig häufig; vgl. Tabelle 1

knoten präsentieren sich als indolent, regional begrenzt, mit dem umgebenden Gewebe verbacken und unbeweglich. Für die Diagnostik dieser Befunde ist der Einsatz des Programms Nr. 77 nicht gedacht.

Die Indikation zur diagnostischen Lymphdrüsenexstirpation und feingeweblichen Untersuchung stellt der Allgemeinarzt in Zusammenarbeit mit dem Spezialisten. Dabei wird man zweckmäßigerweise zervikale oder supraklavikuläre Lymphknoten herausnehmen, da axilläre und inguinale Lymphknoten z.B. durch Infekte unspezifisch verändert sein können. Bei $40 \%$ der Patienten liefert jedoch auch die Lymphknotenbiopsie keine exakte Diagnose [105].

\subsection{Bursitis, Hygrom, Tendovaginitis, Ganglion, Epikondylitis}

In diesem Abschnitt werden jene Beratungsergebnisse zusammengefaßt, die bestimmte akute oder chronische Beschwerden und/oder Krankheitszeichen im Bereich gelenknaher Strukturen betreffen (Tabelle 71).

\subsubsection{Bursitis acuta}

Eine Schleimbeutelentzündung bzw. -reizung (Bursitis acuta bzw. subacuta) (C) wird an der ersten ärztlichen Linie v.a. an den Ellenbogen (Bursitis olecrani) und an den Knien (Bursitis praepatellaris) beobachtet. Typisch ist eine auffallende, abgegrenzte und meist wenig schmerzhafte Schwellung. Kinder und alte Leute sind erfahrungsgemäß höchst selten betroffen.

Eitrige Bursitiden entstehen beispielsweise im Anschluß an eine traumatische Eröffnung der Bursa.

\subsubsection{Bursitis chronica}

Wiederholte, meist geringfügige Traumatisierungen führen nicht selten zu einer chronischen (sterilen) Entzündung (Bursitis chronica) (C) (,Studentenellenbogen"). Es gibt jedoch immer wieder Fälle, bei denen sich der Patient an keinerlei Ursache für seine Schleimbeutelschwellung erinnern kann.

Mit einer großkalibrigen Kanüle läßt sich in der hausärztlichen Praxis die Punktion rasch und einfach durchführen. Die Beschaffenheit des Punktats (z.B. putride, serös, sanguinolent) kann einen Hinweis auf die Ursache der Reizung geben. Nicht immer ist es jedoch möglich, Punktat zu gewinnen (z.B. nach Einblutung). Eine kurzfristige Ruhigstellung des betroffenen Gelenks ist angezeigt, besonders nach zuvor durchgeführter Punktion.

Die chronische Bursitis praepatellaris tritt meist bei Patienten mit kniender Beschäftigung auf (Fliesenleger, Pflasterer) und kann von einem Kniegelenkerguß in der Regel gut unterschieden werden. Nach Punktion des Schleimbeutelergusses lassen sich manchmal reiskornartige Verdickungen palpieren.

Im Rahmen einer chronischen Polyarthritis (vgl. B 2.6) oder einer Gicht (vgl. Zusatzfragen „Hyperurikämie, Arthritis urica, Gicht" auf S. 64) können gelegentlich entzündliche Veränderungen der Schleimbeutel am Ellenbogen und am Knie auftreten. Für zahlreiche chronische Bursitiden gibt es jedoch keine Erklärung.

\subsubsection{Hygrom}

Dauerhafte Druckbelastung des Schleimbeutels (chronische Bursitis - vgl. B 12.10.2) kann zu einem schwielenartig verdickten, z.T. mehrkammerigen 
Hygrom mit gelegentlichem Einschluß („Reiskorn“) führen. Analoge Auftreibungen können auch von den Sehnenscheiden ausgehen (z.B. Hygroma carpale).

\subsubsection{Tendovaginitis}

Unter den akuten Tendovaginitiden klassifiziert der Arzt in der Praxis am häufigsten das Bild einer Paratenonitis crepitans.

Bei diesem Krankheitsbild liegt eine entzündliche Veränderung des Sehnengleitgewebes in einem Bereich vor, in dem die Sehnenscheiden nicht entwikkelt sind, wie beispielsweise die Streck- und Beugesehnen der Finger proximal des Handgelenkes, die Strecksehnen der Zehen, die Sehne des M. tibialis anterior sowie die Achillessehne.

Betroffen sind meist Patienten mit Überbeanspruchung der Hand, z.B. Landwirte, Forstarbeiter, Sekretärinnen, Fließbandarbeiter und Sportler. Die Behandlung ist in der Regel konservativ, die Ruhigstellung steht im Vordergrund der Maßnahmen.

Ein typisches Beispiel für eine stenosierende Sehnenscheidentzündung (Tendovaginitis stenosans) ist der schnellende Finger (auch „Triggerfinger"). Die konservativen Maßnahmen führen häufig zum Erfolg. Ansonsten besteht die Behandlung in einem kleinen Eingriff (Spaltung der verengten Sehnenscheide in Lokalanästhesie) [280].

Der Rang des Beratungsergebnisses „Tendovaginitis" (C) hat im allgemeinmedizinischen Krankengut der 80er und frühen 90er Jahre deutlich zugenommen (Tabelle 71).

\subsubsection{Ganglion}

Ganglien sind häufige, von Gelenken, Sehnenscheiden oder Bursen ausgehende prallelastische Gebilde bzw. zystische Geschwulstbildungen. Sie werden im Volksmund auch als „Überbeine“ bezeichnet.

\subsubsection{Epikondylitis}

Der „Tennisellenbogen“ (Epicondylitis humeri radialis) (C) ist in der Allgemeinpraxis weniger ein diagnostisches als vielmehr ein therapeutisches Problem. Auch der Rang des Beratungsergebnisses
„Epikondylitis“ hat wie das BE „Tendovaginitis“ (vgl. B 12.10.4) im allgemeinmedizinischen Krankengut der 80er und frühen 90er Jahre deutlich zugenommen (Tabelle 71).

Meist klagen die Patienten über schmerzhafte Bewegungseinschränkungen im Ellenbogengelenk, bevorzugt bei Drehbewegungen des Unterarmes bzw. bei Greifbewegungen der Finger (z.B. beim Tennisspielen, Auswringen eines Putzlappens, Umgang mit Schrauenzieher, Öffnen eines Schraubdeckels, Schreiben).

\subsection{Anämie}

Meist sind es Frauen, die befürchten, eine „Blutarmut" (Anämie) zu haben. Oftmals werden Blässe oder ein längerer Krankenhausaufenthalt, allgemeine Müdigkeit und nachlassende Leistungen mit einem „Eisenmangel“" in Verbindung gebracht. Ebenso kommen auch Mütter zum Arzt, denen bei ihren Kindern Blässe und Ringe unter den Augen auffallen, oder Leute, denen von der Umgebung die Blässe auf den Kopf zugesagt und eine Blutuntersuchung empfohlen wurde.

Mit einfachen diagnostischen Mitteln (z.B. beginnend mit der Beurteilung der Konjunktivaldurchblutung) läßt sich in der Praxis feststellen, ob und ggf. in welchem Ausmaß eine Anämie vorliegt.

Fiel anamnestisch, physikalisch und im Routinelabor nichts Besonderes auf und ließen sich auch bei entsprechender Indikation - endoskopisch, mit bildgebenden Verfahren usw. weder eine Blutungsquelle im allgemeinen, noch ein Malignom im speziellen nachweisen, so wird der Arzt die Programmierte Handlunganweisung Nr. 81 zur allgemeinmedizinischen redundanten Diagnostik bei uncharakteristischer Anämie („Anämie-Standard“) einsetzen. Dieses Programm ist als Teil einer systematischen Weiterbeobachtung zu verstehen. Es dient aber ebenso der Beruhigung der Patientengruppe.

Eine trotz Durchuntersuchung unklar bleibende, nennenswerte Anämie ist so lange auf ein (okkultes) Malignom verdächtig, bis nicht das Gegenteil bewiesen wurde [42]. 


\section{Thematik des Fachgesprächs}

\begin{abstract}
Aufgabe
Besprechen Sie die in der Übersicht 43 aufgeführten Beratungsergebnisse ,Sonstige Beschwerden und Erkrankungen" anhand der nachfolgenden Fragen und der bei den entsprechenden Beratungsergebnissen aufgeführten Zusatzfragen!
\end{abstract}

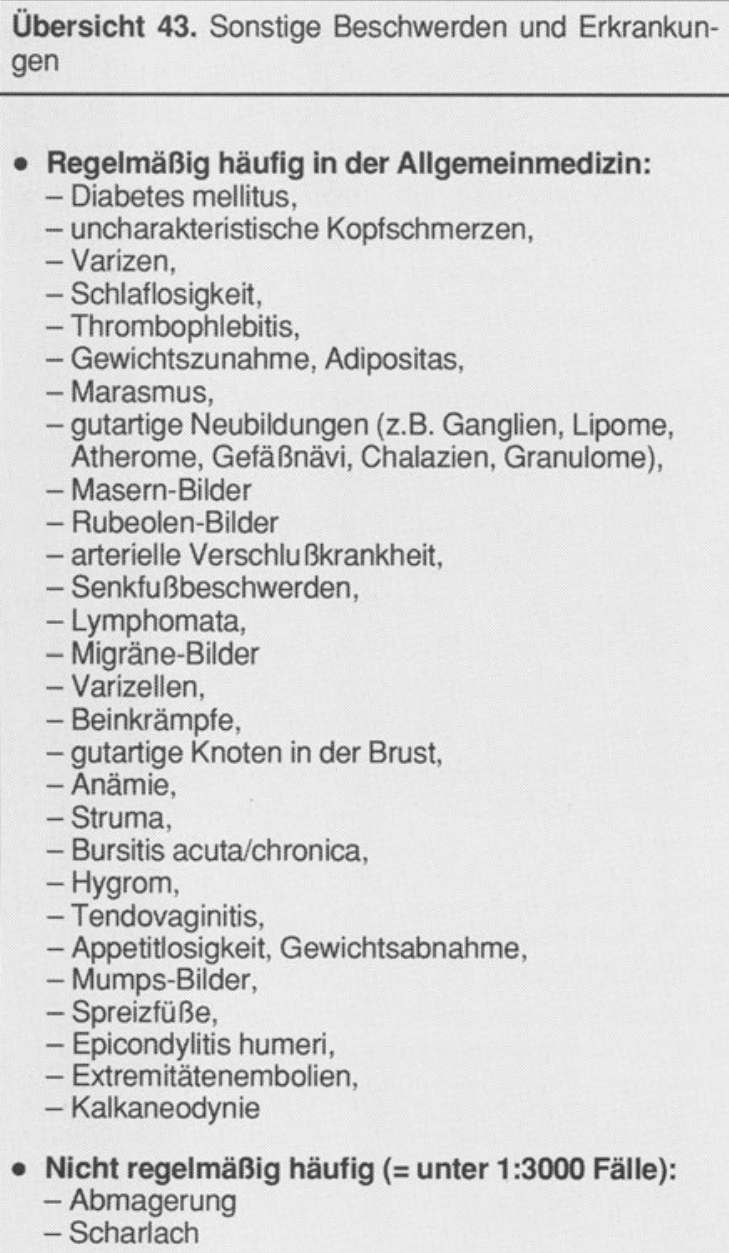

- Regelmäßig häufig in der Allgemeinmedizin:

- Diabetes mellitus,

- uncharakteristische Kopfschmerzen,

- Varizen,

- Schlaflosigkeit,

- Thrombophlebitis,

- Gewichtszunahme, Adipositas,

- Marasmus,

- gutartige Neubildungen (z.B. Ganglien, Lipome, Atherome, Gefäßnävi, Chalazien, Granulome),

- Masern-Bilder

- Rubeolen-Bilder

- arterielle Verschlußkrankheit,

- Senkfußbeschwerden,

- Lymphomata,

- Migräne-Bilder

- Varizellen,

- Beinkrämpfe,

- gutartige Knoten in der Brust,

- Anämie,

- Struma,

- Bursitis acuta/chronica,

- Hygrom,

- Tendovaginitis,

- Appetitlosigkeit, Gewichtsabnahme,

- Mumps-Bilder,

- Spreizfüße,

- Epicondylitis humeri,

- Extremitätenembolien,

- Kalkaneodynie

- Nicht regelmäßig häufig (= unter 1:3000 Fälle):

- Abmagerung

- Scharlach

Fragen

„Sonstige Beschwerden und Erkrankungen“"

1. Ungefähre Häufigkeit in der Allgemeinpraxis.

2. Überlegungen zur Klassifizierung.

3. Bevorzugte Altersgruppe, bevorzugtes Geschlecht.

4. Notwendigkeit, Dringlichkeit und Zumutbarkeit des Hausbesuchs bei „Kinderkrankheiten“.

5. Vermutete Ursache/Auslöser (auch Beruf/Freizeit)/Disposition.

6. Patientenklage bzw. Klage der Angehörigen (,Was klagt der Patient? Angst vor?").

7. Kontaktfragen (,Was fragt der Arzt?").

8. Selbstmaßnahmen (,Was hatte der Patient bereits unternommen?").

9. Erster Eindruck des Arztes/(Lokal)befund (,Was sieht der Arzt?“).

10. Untersuchungstechniken in der Allgemeinpraxis (,Was prüft der Arzt? Welche apparative und laborchemische Diagnostik setzt er ein?").

11. Spezielle Techniken (,Welche Untersuchungen im spezialistischen Bereich veranlaßt der Arzt?").

12. Falsifizierung/Exklusion: „Es sieht so aus wie (z.B. Coma diabeticum) ..., aber was ist es wirklich (z.B. Intoxikation bei Suizidversuch)?"“.

13. Beispiele für Abwendbar gefährliche Verläufe („Fallstricke“), z.B. Erstfeststellung eines Knotens in der Brust.

14. Sinnvolle Dokumentation (,Was notiert der Arzt?").

15. Behandlung durch den Allgemeinarzt:

- Empfehlungen an den Patienten/die Eltern (,Was rät der Arzt?“) (z.B. Bettruhe, Lagerung, Schuhwerk, Diät, Freizeit und Fitneß);

- lokal (z.B. Verbände, Einlagen, Schuhzurichtung, Ruhigstellung);

- systemisch; 
- abwartendes Offenlassen (,Wie lange zuwarten?");

- Notwendigkeit und Dringlichkeit der Überweisung zum Spezialisten und der Einweisung ins Krankenhaus.

16. Notwendigkeit und Intervalle zur Wiederbestellung des Patienten.

17. Arbeits- und Schulbefreiung, Rückstellung vom Schul- und Vereinssport.

18. Erörterung der Reiseproblematik im Hinblick auf Kinderkrankheiten, Diabetes mellitus und Venenleiden.

\section{Zusatzfragen „Diabetes mellitus“}

- Wann kann man aufgrund laborchemischer Ergebnisse von einem Diabetes mellitus sprechen?

- Vorgehen bei Kindern/Jugendlichen/Erwachsenen/bei Menschen im Senium mit positivem Harnzucker und pathologisch erhöhten Blutzuckerwerten.

- Grundzüge der Diabetesdiagnostik:

postprandiale Blutzuckerbestimmung, Bestimmung des Urinzuckers (Störung durch hohe Harnsäure, Ascorbinsäure, nitritbildende Bakterien möglich), Azetonnachweis.

- Glukosetoleranztest:

Zwei-Stunden-Wert über $200 \mathrm{mg} \%$ sicher pathologisch, zwischen 140 und $200 \mathrm{mg} \%$ Hinweis auf prädiabetische Stoffwechsellage; Bedeutung von Glykohämoglobin (HbA $1 \mathrm{c})$ ?

- Grundzüge einer Diät bei übergewichtigen, älteren Patienten mit leichtem Diabetes (Altersdiabetes Typ II):

z.B. Kalorien- und Fettreduktion, Vermeidung von raffiniertem Zucker, Vermeidung von Mehlspeisen, vermehrt ballaststoffreiche, langsam resorbierbare Nahrungsmittel wie geschrotetes Roggenbrot, Berücksichtigung des Gesamtenergiegehalts der Lebensmittel in Speisen und Getränken.

- Stellenwert der einzelnen Energieträger in der Diabetesdiät:

- Fett $(60 \mathrm{~g} / \mathrm{Tag}): 1 / 3$ als Brotaufstrich, $1 / 3$ zum Kochen, $1 / 3$ als verstecktes Fett;

- eiweißhaltige Nahrungsmittel (für magere Produkte keine Beschränkungen!);

- Kohlenhydrate (grundsätzlich verboten: alle zuckerhaltigen Nahrungsmittel und Getränke: laut Kostplan erlaubt: alle Getreideprodukte also auch Teigwaren, ferner Kartoffeln und Obst).
- Stellenwert von Honig in der Diabetesdiät?

- Beispiel für sinnvolle Verteilung des Gesamtkalorienbedarfs von $2000 \mathrm{kcal} / \mathrm{Tag}$ : Kohlenhydrate (200-250 g), Eiweiß (75-100 g) und Fett (75$90 \mathrm{~g})$.

- Definition einer Broteinheit (BE), Problematik der Diätberechnung nach BE (,Kohlenhydrataustauschtabelle").

- Stellenwert von Ballaststoffen, von „freien“ kohlenhydrathaltigen Nahrungsmitteln, Zuckeraustauschstoffen wie Sorbit und Fruktose, Diabetikerdiätmitteln.

- Beispiele für die unterschiedliche Resorptionsgeschwindigkeit der Kohlenhydrate in den einzelnen Nahrungsmitteln (,glykämischer Index“).

- Abstimmung zwischen Insulintherapie und Kost: Erstellen eines Tageskostplanes für einen jugendlichen, schlanken, körperlich schwer arbeitenden Typ-I-Diabetiker, der 2 mal täglich spritzt (Abb. 106): Zahl der BE (z.B. 20 BE), Häufigkeit der Mahlzeiten (6- bis 7 mal), Kohlenhydratanteil der Zwischenmahlzeiten (nicht wesentlich weniger Kohlenhydrate als in den Hauptmahlzeiten!). Beachte: Spätmahlzeit!

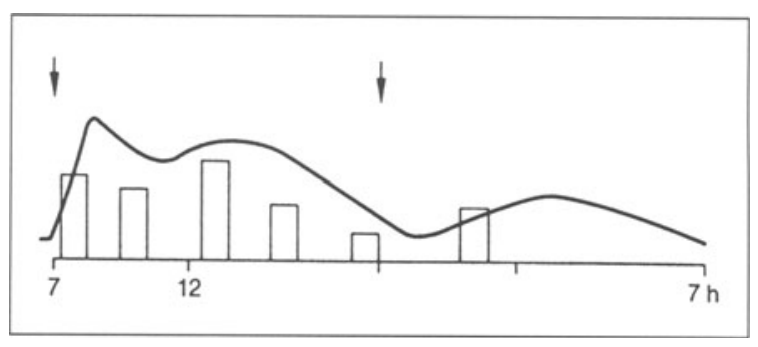

Abb. 106. Insulinämie und Verteilung der Kohlenhydrate über den Tag bei Behandlung mit einer Mischung von Normalinsulin und Verzögerungsinsulin morgens und Verzögerungsinsulin allein am Abend. Bei Patienten, die 2 mal am Tag Insulin spritzen, besteht zwischen den Mahlzeiten immer eine ausgeprägte Hyperinsulinämie. Daher sollten 6-7 mal den Blutzucker steigernde $\mathrm{KH}$ gegessen werden. $(\downarrow=$ Insulininjektionen; [12])

Diabetiker, die vor jeder Hauptmahlzeit Normalinsulin (Altinsulin) injizieren (Abb. 107), können - im Unterschied zu den Diabetikern, die 2 mal Verzögerungsinsulin spritzen (Abb. 106), in den meisten Fällen auf Zwischenmahlzeiten verzichten. 


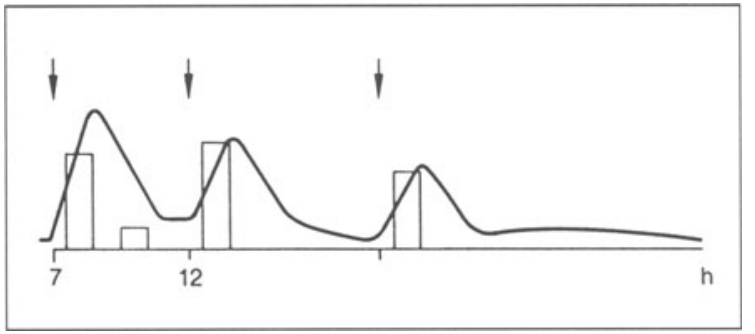

Abb. 107. Insulinämie und Verteilung der Kohlenhydrate über den Tag bei Injektion von Normalinsulin 3 mal am Tag. Für diese Patienten genügen meistens die Hauptmahlzeiten. ( $\downarrow$ = Insulininjektionen; [12])

- Erstellen eines Tageskostplanes für eine erheblich übergewichtige 60jährige Frau (Typ II b), die mit oralen Antidiabetika (Glibenclamid 3,5 mg 2/0/1 Tbl.) nicht mehr ,,ausreichend“ eingestellt ist: BE (z.B. 12 BE), Gesamtkalorien (z.B. $1200 \mathrm{kcal}$ ), Diskussion der Medikamentendosis (Reduktion wegen Hyperinsulinämie!), Diskussion der Gabe von Biguaniden.

- Realistische Einstellung auf Broteinheiten unter Alltagsbedingungen (nicht unter $12 \mathrm{BE}$ !).

- Essensintervalle (3 mal große Mahlzeiten oder 6 mal kleine Mahlzeiten?).

- Diabetesdiät und Alkoholzufuhr (Achtung: Hoher Energiegehalt von Alkohol $=7 \mathrm{kcal} / \mathrm{g} ; 0,51$ deutsches Bier enthält ca. 1,5 BE und erhöht den Blutglukosespiegel um ca. $50 \mathrm{mg} \%$; 1 Glas Wein hat $80 \mathrm{kcal}$ ). Beschränkung des Alkoholkonsums pro Tag auf höchstens $20 \mathrm{~g}(0,51 \mathrm{Bier}=140 \mathrm{kcal})$ bis $30 \mathrm{~g}(1 / 41 \mathrm{Wein}=210 \mathrm{kcal} ;[13])$.

\section{Hypoglykämiegefahr bei übermäßigem Alkoholkon-} sum ${ }^{12}$.

- Tip: Den Diabetiker bei Alkoholkonsum zusätzlich Kohlenhydrate essen lassen!

- Hyperglykämiegefahr durch chronischen Alkoholmißbrauch: Entzündliche Veränderungen der Bauchspeicheldrüse, dadurch Behinderung der Insulinfreisetzung; Insulinwirkung am Muskel wird abgeschwächt. Verschiedene alkoholische Zube-

\footnotetext{
${ }^{12}$ Alkohol - auch in kleinen Mengen genossen - kann die Zuckerbereitstellung in der Leber blockieren, die Entleerung des gefüllten Magens verzögern sowie die Kohlenhydratresorption im resorptionsbereiten Dünndarm abschwächen [13]
}

reitungen enthalten Zucker, Malz und Stärke (Kohlenhydrate!).

- Erörterung von Compliance-Problemen unter Alltagsbedingungen in Abhängigkeit von Lebensalter und Diabetestyp.

- Vorteile und Problematik von Diabetikernährmitteln. (Beachtung der Broteinheiten und des häufig hohen Fettgehaltes!).

- Besprechen möglicher Ursachen für „Diätversagen": z.B. Eßsucht (Hyperphagie, geleugnete Diätfehler).

- Mögliche diabetogene Medikamente (z.B. Glukokortikoide, Thiazide/Esidrix ${ }^{\circledR}$, Saltucin ${ }^{\circledR}$, Propranolol/Dociton ${ }^{\circledR}$, Guanethidin, Diazoxid/Hypertonalum ${ }^{\circledR}$ ).

- Orale Antidiabetika:

- Glukosidasehemmer wie Arcabose (Glucobay ${ }^{\circledR}$ ): Verzögerung des Kohlenhydratabbaus (Einnahme mit den ersten Bissen der Mahlzeit!), Verlangsamung der Glukoseaufnahme ins Blut. In Kombination mit Sulfonylharnstoffen Senkung der Blutzucker- und Hämoglobin$\left(\mathrm{HbA}_{1}\right)$-Werte.

- Sulfonylharnstoffe (z.B. Tolbutamid/Rastinon. Glibenclamid/Eugucon ${ }^{\circledR} N$ :

Wirkungsweise (Senkung des Blutzuckerspiegels durch Stimulation der Insulinsekretion, Erhöhung der Insulinrezeptoren in der Peripherie), Indikationen (z.B. nicht übergewichtige [!] Typ-II-b-Diabetiker).

Merke: Bei übergewichtigen Diabetikern nicht zu früh Sulfonylharnstoffe einsetzen. Kombinierbarkeit (z.B. mit Insulin oder Biguanid), Kontraindikationen (z.B. Ketoazidose, Schwangerschaft, fortgeschrittene Niereninsuffizienz), Tagesdosis (Tolbutamid 0,5-2,0 g; Glibenclamid 2,5-15 mg), Wirkungsstärke (Tolbutamid schwach, Glibenclamid stark), Arzneimittelinterferenzen bei Einnahme von Sulfonamiden, Analgetika, Antiphlogistika.

- Biguanidderivate (Metformin/Glucophage ${ }^{\circledR}$ retard):

Wirkungsweise (Steigerung der Insulinempfindlichkeit, verzögerte Glukoseresorption, gesteigerter Glukoseverbrauch der Skelettmuskulatur), Indikation (übergewichtige Diabetiker mit Sekundärversagen gegen Sulfonylharnstoffe), Kontraindikationen (z.B. einge- 
schränkte Leber- und Nierenfunktion, über 65jährige, undisziplinierte Diabetiker), wichtige unerwünschte Wirkung (Laktatazidose: Letalität etwa $50 \%$ !, häufig gastrointestinale Symptome).

- Insuline:

Einteilung nach dem Wirkungsprofil (Normaloder Altinsuline; Routine-, Intermediär- oder Depotinsuline; Mischinsuline; Langzeit- oder Basisinsuline; Insuline für Spezialanwendungen wie Pumpen- und Injektoreninsuline).

Biosynthetisches Humaninsulin ist hoch gereinigt, daher weitgehend frei von antigenen Begleitproteinen; daneben auch Extrakte aus Rinder- und Schweinepankreas, Dosierung (optimale Insulindosierung im Einzelfall nicht vorhersehbar; Bedarf von vielen Faktoren abhängig wie Diabetestyp, Anpassung an den Blutzucker, Stoffwechsellage, Injektionsort, Injektionshäufigkeit, Injektionsareale), Resorption bei s.c.-Injektion (am schnellsten in der Bauchhaut, am langsamsten in Oberschenkel und Gesäß, mittlere Resorption an den Oberarmen).

- Antidiabetika und Eßabstand:

Bei Insulinen zwischen 15 und 60 min (abhängig vom Wirkstoff), bei Tabletten (z.B. Euglucon ${ }^{\circledR}$ ) unmittelbar vor den Mahlzeiten (bei Tagesdosis von max. 3 Tbl. erfolgt Standardverteilung: 2 Tbl. vor dem Frühstück, 1 Tbl. vor dem Abendessen).

- Überlegungen zur Kontrolle bei medikamenten-/ insulinpflichtigen Diabetikern:

z.B. Kontrollintervalle durch den Patienten von Blut- und Urinzucker, Kontrollintervalle durch den Arzt, Hypo- und Hyperglykämien als Akutkomplikationen, Urinkontrolle auf Azeton, Gewichtskontrollen.

- Diabetes und Schwangerschaft:

Achtung: Risikoschwangerschaft!

- Gestationsdiabetes:

Entwicklung und erstmalige Feststellung in der Schwangerschaft (ca. 2-4 von 100 schwangeren Frauen meist am Ende des zweiten Drittels der Schwangerschaft).

- Diabetes und Familienplanung (Erblichkeit beim Typ I viel geringer als beim Typ II).

- Diabetische Spätschäden (Kombination von Angio- und Neuropathien an Prädilektionsstellen wie Niere, Retina, Füße).
- Beratungsproblem „Füße des Diabetikers“ (vgl. B 3.6 und 3.6.2):

z.B. Trophik gestört? Claudicatio? Fehlende Fußpulse? Hypästhesie? abgeschwächter PSR? Hühneraugenpflaster? Schuhwerk? - Empfehlungen zum vorsichtigen Nagelschneiden, Vermeidung von Bagatellverletzungen, Warnung vor Heizkissen/Wärmflaschen; weiterführende Diagnostik wie Ultraschalldoppler.

- Bild einer Hypoglykämie:

z.B. Warnsymptome wie Zittern, Schweißausbrüche, Heißhunger, Leeregefühl im Kopf, Bauch; Alarmzeichen wie Bewußtseinsverlust, Krampfanfall, Halbseitenlähmung, Kollaps;

Ursachen:

z.B. zuviel Insulin, zu viele Tabletten, zuwenig BE, zuviel Bewegung, zuviel Alkohol, Wachstumsschub, Suizidabsicht;

Therapie bei Warnzeichen:

Zuckerzufuhr, bei Alarmzeichen (Gabe von 20-50 $\mathrm{ml}$ 40\%iger Glukose i.v.! Reaktion für gewöhnlich prompt, sollte spätestens nach $10-20$ min erfolgen).

Die probatorische Gabe von Glukoselösung beim hypoglykämischen Koma ohne vorherige Sicherung der „,Hypoglykämie“" (Blutzuckerwerte unter $50 \mathrm{mg} \%$ sind beweisend !) ist obsolet [187]!

- Bild einer Hyperglykämie:

z.B. Frühzeichen der Entgleisung, wie trockener Mund, Polyurie, Schwächegefühl, Appetitlosigkeit, Erbrechen und Übelkeit, Atemnot und Kurzatmigkeit, vermehrtes Durstgefühl, Azetonurie, Blutzuckerwerte über $350 \mathrm{mg} / \mathrm{dl}$; Ursachen, z.B. Adrenalinausstoß durch Streß, Infektion, Diätfehler, Hypoglykämiegegenregulation.

- Diskussion der Notwendigkeit einer Klinikeinweisung.

- Indikationen für Überweisung zum Augenarzt (Retinopathie, grauer Star).

- Indikation für Überweisung zum Neurologen (Poly-und Mononeuropathie).

- Verstärkung des Risikoprofils bei Vergesellschaftung von Diabetes mit z.B. Übergewicht, Koronarerkrankung, peripheren arteriellen Durchblutungsstörungen, Fettstoffwechselstörungen, Gicht, mehrfache Aborte. 
- Diabetes und Führerschein:

Diabetiker mit Neigung zu schweren Stoffwechselentgleisungen mit Hypoglykämie und Hyperglykämien sind zum Führen von Fahrzeugen aller Klassen ungeeignet. Zuckerkontrollintervalle nach verkehrsmedizinischen (nicht nach allgemeinärztlichen!) Kriterien: diätbehandelte Diabetiker spätestens alle 12 Wochen durch den Arzt; oral behandelte Diabetiker spätestens alle 6-8 Wochen durch den Arzt; insulinbehandelte Diabetiker spätestens alle 4-6 Wochen durch den Arzt [160].

- Diskussion der Berufswahl:

Einschränkungen bei z.B. Arbeiten mit Absturzgefahr, Tätigkeit an laufenden Maschinen, bei beruflicher Personenbeförderung, bei berufsmäßigem Waffengebrauch, bei verantwortlichen Überwachungsfunktionen.

- Erörterung der Insulinpumpenbehandlung: Grundsätzlich kann jeder Patient mit Insulinmangel mit kontinuierlicher s.c.-Insulininfusion behandelt werden. Therapieversuch sinnvoll, wenn keine ausreichend guten Ergebnisse mit der Injektionstherapie zu erzielen, multiple Injektionen täglich zu aufwendig sind oder flexiblere Gestaltung der Insulintherapie erforderlich ist. Zwischenmahlzeiten nicht erforderlich. Achtung: Nur bei verläßlichen Patienten!

\section{Zusatzfragen „Uncharakteristische Kopfschmerzen" und ,Migräne“}

- Beispiele für die vielfältigen Gründe von Kopfschmerzen/Migräne, wie familiäre Disposition, Gemütsverfassung, Persönlichkeitsstruktur, soziale Konflikte, Streß, toxische Einwirkungen am Arbeitsplatz, Fernsehen, Schlafmangel, sexuelle Überaktivität, Medikamente (Nitrate, Nifedipin, Pille), Genußmittelexzesse, hoher Blutdruck, sklerotische Gefäßveränderungen, Epilepsie, vertebragene Ursachen, Glaukom, Muskelspannung (,tension-headache“), Höhendruck (Föhn), hormonelle Schwankungen, Infekte.

- Nahrungs- und Genußmittel als mögliche Auslöser einer Migräneattacke:

z.B. gegorene Speisen (reich an Tyramin), Schokolade (enthält Phenyläthylamin), ,orientalisches Essen" (Mononatrium-Glutamat/MNG in der Sojasauce), alkoholische Getränke (reich an Histamin), Speiseeis (Kältereiz), Zitrusfrüchte, Käse
(Tyramin), „heiße Würstchen“ (Nitritgehalt im Pökelfleisch).

- Abwendbar gefährliche Verläufe bei Kopfschmerz (z.B. schwere Sinusitis, Meningitis, Enzephalitis, Gehirntumor, Subarachnoidalblutung, Glaukom, hypertensive Krise, Riesenzellarteriitis Horton).

- Selbstmaßnahmen und Ratschläge für den Patienten: z.B. Kontrolle der Luftfeuchtigkeit im Raum, entspannende Übungen, Konfliktbewältigung, Gefäßtraining (kalte Duschen, Schwimmen, Sport).

- Nichtmedikamentöse Behandlung: z.B. SchulterNacken-Massage, Krankengymnastik, therapeutische Lokalanästhesie (TLA), Akupunktur.

- Grundzüge der medikamentösen Behandlung von „Uncharakteristischen Kopfschmerzen“ (z.B. peripher wirkende Analgetika wie Parazetamol (z. B. benuron ${ }^{\circledR}$ ), Azetylsalizylsäure (Aspirin ${ }^{\circledR}$ ), Metamizol (Novalgin ${ }^{\circledR}$ ), Propyphenazon, nichtsteroidale Antirheumatika wie Ibuprofen (Indikation, Dosierung für Säuglinge/Kleinkinder/Schulkinder/Erwachsene, Nebenwirkungen, Kontraindikationen, Problematik von Kombinationspräparaten und Abusus).

- Kopfschmerz im Kindesalter (z.B. durch Refraktionsanomalien, behinderte Nasenatmung, familiäre Konflikte, sonstige familiäre Belastung, Schulkonflikte), Problematik der Deutung von „Kopfschmerzen“ bei Kindern.

- Prophylaktische, medikamentöse Behandlung der Migräne (z.B. niedrig dosierte $\beta$-Blocker, Mutterkornalkaloide, trizyklische Antidepressiva, Clonidin, Antihistaminika). Merke: Zurückhaltung mit Analgetika! Cave: Sucht! Ergotismus!

- Sofortmaßnahmen bei Migräneanfall [z.B. Ruhe und Reizabschirmung, Sedierung, Mutterkornalkaloide, Antiemetika, Analgetika, ggf. Sumatrip$\tan \left(\operatorname{Imigran}{ }^{\circledR}\right)$ als selektiver Serotoninagonist; enterale oder parenterale Medikation?]. Auch eigene praktische Erfahrungen!

\section{Zusatzfragen „Varizen“}

- Mögliche Ursachen (z.B. familiäre Disposition, Schwangerschaften, sitzende und stehende Tätigkeit, Adipositas, statische Fehlfunktionen).

- Diagnostik in der Allgemeinpraxis: Veränderung der Hautfarbe (z.B. Pigmentflecke, Blauverfärbung), Veränderungen der Form, Ödem (?), Palpa- 
tion der muskelhaltigen Beinabschnitte am stehenden oder hängenden Bein (Hauttemperatur? Gewebsturgor? Muskeltonus? Gefäßveränderungen? Statische Veränderungen an Fuß- und Kniegelenk? Druckschmerzpunkte?), Abtasten der Leistengegend, Prüfungen der Venenklappenfunktion. Trendelenburg-Test ${ }^{13}$, Perthes-Test. ${ }^{14}$

- Weiterführende Maßnahmen im spezialistischen Bereich, z.B. Ultraschalldoppler (USD), DuplexVerfahren, Lichtreflexionsrheographie (LRR), Phlebographie.

- Indikationen zur Phlebographie, z.B. vor operativer Behandlung von Varizen, bei Ulcus cruris, zum Nachweis einer Varikozele, bei Verdacht auf akute Phlebothrombose.

- Ratschläge für Beinleidende:

z.B. Hochlagern der Beine (Fußkeil im Bett), keine einengenden Hüftgürtel oder Socken, Gefäßtraining durch kaltes Duschen, aktivierendes Muskeltraining, Vermeiden von heißen Bädern, Sonnenbädern, Thermalbädern, Fangopackungen, Vermeidung bzw. Bekämpfung von Übergewicht.

- Konservative Therapie durch den Arzt:

Kompressionsverband, Gummistrümpfe, Korrektur von Fußübeln, Varizensklerosierung.

- Kompressionsverband als dosierte Kompression auf Gewebe und Venen: Embolieschutz, Entstauung, Prophylaxe.

- Verbandarten:

Nichtnachgiebige Verbänd (z.B. Idealbinde, Zinkleimverband, Dauerbinde, textilelastische Kurzzugbinden); Charakteristikum: geringer Anlagedruck, hoher Arbeitsdruck. Elastische Verbände (z.B. Gummibinde, Pflasterbinde, Langzugbinden); Charakteristikum: hoher Anlagedruck, geringer Arbeitsdruck.

\footnotetext{
${ }^{13}$ Trendelenburg-Test: Anlegen eines Stauschlauches in Horizontallage nahe der V.-saphena-magna-Mündung am Oberschenkel des erhobenen Beines. Patient steht dann auf. Füllen sich jetzt die Varizen unterhalb der Staubinden innerhalb von ca. $15 \mathrm{~s}$ rasch wieder auf, so sind die Klappen der Vv. perforantes insuffizient.

${ }^{14}$ Perthes-Test: Legt man am stehenden Patienten eine Stauung am Oberschenkel an und läßt den Patienten umhergehen, so müssen sich die gestauten Krampfadern entleeren, wenn die tiefen Venen in ihrer Funktion nicht beeinträchtigt sind. Bleibt die Krampfaderstauung oder nimmt sie unter Schmerzen sogar zu, ist ein Verschluß der tiefen Venen anzunehmen.
}

- Verbandstechnik.

- Indikationen für nichtnachgiebige Verbände: alle akuten, subakuten und chronischen Thrombosen und Phlebitiden der oberflächlichen und tiefen Venen, alle Stauungen beim postthrombotischen Syndrom, alle Ulcera cruris mit begleitender Phlebitis, Stauungsdermatosen im nicht nässenden Stadium (Verband mit Kurzzug- (ideal-) binden kann über Nacht angelegt bleiben).

- Indikationen für elastische Verbände:

Behandlung von Ulcera cruris ohne Begleitphlebitis und der chronischen venösen Stauung leichten bis mittleren Grades, nach Verödung von Varizen, Prophylaxe und Nachbehandlung von Venenerkrankungen (Achtung: Gummibinden nachts abnehmen!).

- Gegenindikationen für Kompressionsverbände: Arterielle Verschlußkrankheiten (AVK) im Stadium II bis IV.

- Indikation für Gummistrümpfe: Nachsorge, in geringerem Umfang Prophylaxe. Achtung: Keine Gummistrumpfverordnung bei akuten und subakuten Erkrankungen der Venen!

- Beispiel für die Musterverordnung von Gummistrümpfen:

„1 Paar Kompressionsstrümpfe Klasse II (nach Maß?/Konfektion?), Unterschenkellänge, Fußspitzen offen, wegen postthrombotischem Syndrom“.

- Diskussion sog. „Venenmittel“ als „Ödemprotektiva" (häufige Inhaltsstoffe: Roßkastanienextrakt Aescin, Bioflavonoide, besonders Rutin: Wirkung auf die gestörte Kapillarpermeabilität?).

- Diskussion von heparin- oder hirudinhaltigen Salben (antithrombotischer Effekt?).

- Diskussion des Einsatzes von niedrig dosierten Depot-Heparinen in der Allgemeinpraxis.

- Diskussion der Varizensklerosierung und der Varizenoperation.

- Daran denken: Schmerzen im Kniegelenk, ähnlich den arthrotischen Schmerzen, können auch durch Varizenkonvolute bedingt sein (Arthralgia phlebopathica). Lokale Verödung kann Besserung erbringen.

\section{Zusatzfragen „Muskelkrämpfe/Krampi““ und ,Beinkrämpfe“‘}

- Überlegungen zur Ätiologie (meist nicht venös, sondern neuromuskulär bedingt). 
- „,burning feet“ (brennendes Gefühl an den Fußsohlen, das durch Wärme verstärkt wird) und ,restless legs": Ausschluß einer Neuropathie und eines Tarsaltunnelsyndroms (TTS)!

- Behandlungsvorschläge, z.B. Magnesium, Chinin.

\section{Zusatzfragen ,Arterielle Verschlußkrankheit, Extemitäten-Embolien“", „M. Raynaud“"}

- Mögliche Ursachen und Risikofaktoren, z.B. allgemeine Arteriosklerose (Arteriosclerosis obliterans), arterielle Hypertonie, Diabetes mellitus, Hyperlipidämie, Nikotingenuß, Adipositas, Hyperurikämie.

- Gezielte körperliche Untersuchung: Pulspalpation, Auskultation der großen Gefäßstämme.

- Apparative (spezialistische) Diagnostik:

Ultraschalldopplermessungen, Oszillographie, Rheographie, Angiographie.

- Therapeutische Prinzipien:

Allgemeine Maßnahmen: Flüssigkeitszufuhr; Ausschalten der Risikofaktoren; intensives Gehtraining, Förderung der Kollateralisation, Lagerungsübungen nach Ratschow, Hämodilution (durch Aderlaß Senkung des Hämatokrits auf Werte um $40 \%)$.

Gezielte Maßnahmen, z.B. Medikamente, Operationen (z.B. Bypass-Verfahren, Thrombendarteriektomie/TEA), lumbale Sympathektomie, perkutane Angioplastik mittels Ballonkatheter nach Dotter.

- Diskussion der Behandlung mit sog. „,vasoaktiven" Medikamenten:

Gefäßerweiternde Mittel? Beispiele (Pentoxiphyllin/Trental ${ }^{\circledR}$, Buflomedil/Bufedil ${ }^{\circledR}$, Naftidrofuryl/Dusodril ${ }^{\circledR}$ ), Rheologika? Beispiele (z.B. Dextran 40/Rheomacrodex ${ }^{\circledR}$ ), Thrombozytenaggregationshemmer? Beispiel (Azetylsalizylsäure/Aspirin $\left.^{\circledR}\right)$, Antikoakulation? Dicumarol-Prophylaxe mit Marcumar ${ }^{\circledR}$ ?

- Aufklärung des Patienten:

Gefährlichkeit von Bagatellverletzungen, Nagelpflege, drückender Schuh. Cave: Unterkühlung/ Überwärmung!

- Diskussion von Methoden außerhalb der Schulmedizin wie Sauerstoffbehandlung, Schlangengifttherapie (Hypofibrinogenierung).

\section{Zusatzfragen ,Akuter Verschluß einer Extremitätenarterie“"}

- Mögliche Ursachen im Bereich des Herzens, z.B. Klappenfehler mit Vorhofflimmern, absolute Arrhythmie, Zustand nach Herzinfarkt, Herzklappenersatz.

- Therapeutische Sofortmaßnahmen außerhalb der Klinik:

Schmerzbekämpfung intravenös (z.B. Dolantin ${ }^{\circledR}$, Fortral $^{\circledR}$ ), evtl. Schockbekämpfung, Tieflagerung der Extremität zur Verbesserung des Perfusionsdruckes, Wattepolsterung zur Vermeidung von Auskühlung und von Drucknekrosen, Heparin (z.B. Liquemin ${ }^{\circledR}$ ) 10000 IE i.v.

Achtung: Heparindosis und Injektionszeitpunkt auf dem Einweisungsschein vermerken! Cave: Intramuskuläre Injektionen!

\section{Zusatzfragen ,Schlaflosigkeit““}

- Mögliche Ursachen:

Situationsbedingte Faktoren, wie Streß (z.B. wegen Scheidung, Todesfall, Ärger), Fernsehen, Kaffee, zuviel Alkohol, Schichtdienst, Wetterfühligkeit, Zeitverschiebung bei Flugreisen, ungewohnte Sinneseindrücke, Geräusche, Helligkeit; somatische Einflüsse (z.B. Schmerzen, Hypoglykämie, Herzinsuffizienz, tachy- oder bradykarde Herzrhythmusstörungen, pulmonale Störungen); psychische Störungen (z.B. Depression, Multiinfarktsyndrom); Medikamente (z.B. $\beta$-Blocker), koffeinhaltige Präparate, bestimmte Antidepressiva.

- Allgemeine Behandlungsmaßnahmen:

z.B. Aufklärung (Ziel: Patient muß lernen, mit seiner spezifischen Schlafveranlagung fertig zu werden), Einübung von Schlafritualen (,Schäfchenzählen"), Schlafhygiene (z.B. niedrige Raumtemperatur, kühle Bettwäsche, harte Schlafstätte), Autogenes Training (AT), Respiratorisches Feedback (RFB) nach Leuner.

- Notfalltherapie der Schlafmittelvergiftung durch den Primärarzt:

Stabilisierung von Atmung und Kreislauf, Atropininjektion (1 mg i. m.), peripherer Venenzugang, ggf. Asservation des Medikamentes.

ABC-Schema:

$\mathbf{A}=$ Atemwege freimachen und freihalten .

$\mathbf{B}=$ Beatmen (Atemspende, ggf. Intubation). 
$\mathbf{C}=$ Circulation (bei Herzstillstand externe Herz massage und Beatmung; Volumensubstitution mit Volumenersatzmittel/Elektrolytlösungen über Venenverweilkanülen.

\section{Zusatzfragen „Bilder von Masern, Röteln, Varizellen, Mumps, Scharlach"“}

- Erster Eindruck bei Bild von Masern: ,,verrotzt verheult - verschwollen - Schafshusten“.

- Aktive und/oder passive Immunisierung gegen Polio, Diphtherie, Pertussis, Tetanus, Haemophilus influenzae B (HiB), Mumps, Masern, Röteln, Influenza, Hepatitis A und B, Varizellen: bei Kindern und Erwachsenen, Indikationen, Kontraindikationen, Begleiterscheinungen/Nebenwirkungen. Impfintervalle, Kombinationsimpfstoffe (z.B. MMR, Td).

- Erstellen eines konkreten Impfplanes für das Säuglings-, Kleinkindes-, Vorschul- und Schulalter, ggf. unter Berücksichtigung der Zuordnung zu den Terminen für die gesetzlichen Kindervorsorgeuntersuchungen.

- Notwendige Labordiagnostik und Aufdeckung möglicher Komplikationen bei Bildern von Masern, Röteln, Varizellen, Mumps und Scharlach. (Bei Scharlach routinemäßig Urinstatus 2-3 Wochen nach Auftreten des Exanthems kontrollieren!).

- Andere Erkrankungen durch Streptokokken der Gruppe A (Erysipel, Streptokokkenangina). Andere Antibiotika zum primären Einsatz bei Streptokokkenangina als Alternative zur primären Penizillingabe (Cephalosporine).

- Immunstatus nach Rötelninfektion bzw. -impfung: Titer von 1:8 und 1:16 fraglich bzw. schwach-positiv. Bei Titer von 1:32 und höher kann Immunität angenommen werden.

- Behandlungsansätze und -notwendigkeiten bei „Kinderkrankheiten“: extern-antipruriginös, physikalisch, antipyretisch, Chemotherapeutikum bei Grunderkrankung und/oder Komplikation, Bettruhe, Schul- und Sportbefreiung, allgemeine Ratschläge wie Verdunkelung des Zimmers, Fernsehund Leseabstinenz.

\section{Zusatzfragen „Übergewicht““}

- Ursachen der Adipositas: soziale, psychische, kulturelle und genetische Einflüsse.
- Patientenberatung im Hinblick auf eine mögliche Gewichtszunahme beim Aufhören mit dem Rauchen sowie bei Einnahme bestimmter Medikamente (Östrogene, Psychopharmaka, Kortison).

- Problematik von Adipositas und Diabetes mellitus: Hyperinsulinämie (Übergewichtsdiabetes Typ II mit Insulinüberschuß). Cave: Gabe von Sulfonylharnstoffen $(\mathrm{SH})$ statt Gewichtsreduktion. SH führen zur Insulinreaktivierung mit Appetitsteigerung.

- Methoden der Gewichtsreduktion:

Diät bzw. Umstellung des Eßverhaltens (unter regelmäßiger Gewichtskontrolle), körperliche Betätigung, Medikamente (Appetitzügler: amphetaminähnliche Substanzen; Schilddrüsenhormone), in verzweifelten Fällen operativ: Jejunoileostomie.

- Diätetische Maßnahmen: 5 oder 6 möglichst gleichkalorische kleine Mahlzeiten, nichts außer der Reihe essen, Weglassen von Alkoholika, Nüssen, Süßigkeiten u.a., Vermeidung von schnell mobilisierbaren Kohlenhydraten (überschießende Insulinsekretion mit anschließendem Blutzuckerabfall mit nachfolgendem Hungergefühl), Reduktion der Nahrungszufuhr auf $1200 \mathrm{kcal} /$ Tag.

- Broca-Index:

Sollgewicht $(\mathrm{kg})=$ Größe $(\mathrm{cm})-100$

Idealgewicht: Sollgewicht $-10 \%$ bei Männern/ $-15 \%$ bei Frauen.

$\bullet$

Zusatzfrage ,Appetitlose Kinder“

- Mögliche Ursachen:

Falsche Ansichten der meist übertrieben ängstlichen Mütter, Großmütter und anderer Pflegepersonen (individuelles Eßbedürfnis des Kindes); zu viele kalorienhaltige Getränke. Eßzwang verstärkt die Essensverweigerung.

\section{Zusatzfragen}

\section{„Anorexia nervosa““ und „Bulimie“}

- Anorexia nervosa:

Bevorzugtes Lebensalter (vor oder kurz nach der Pubertät bis vor dem 25. Lebensjahr), Geschlecht (nahezu regelmäßig Frauen), Gewichtsverlust (mindestens 25\% des ursprünglichen Körpergewichts), charakteristisch: Amenorrhöe, Obstipation. 
- Bulimie:

Variante der Anorexia nervosa? Gewichtsdefizit meist nicht mehr als 15\% des Idealgewichts. Menstruation in der Hälfte der Fälle vorhanden.

- Diskussion der Behandlung von Anorexie und Bulimie:

Stationär oder ambulant? Familientherapie, Verhaltenstherapie, Psychotherapie.

\section{Zusatzfragen ,Statische Beschwerden“}

- Mögliche Störfaktoren, z.B. verschiedene (echte) Beinlängendifferenz, Valgus - oder Varusstellung im Kniegelenk, Fußgewölbe? Schuhkontrolle (einseitig) abgelaufene Absätze und Sohlen (auBenüberlagerter Fuß).

- Beispiele für aseptische Knochennekrosen im Beinbereich: M. Perthes, M. Osgood-Schlatter, M. Kienböck.

\section{Zusatzfragen ,Klavus“ und „Callositas“}

- Behandlung von Hühneraugen:

Konservativ, z.B. mittels Filzringen, Salizylpflaster, -lösungen, Tragen von Sandalen; operativ wie Abhobeln, Exzision des Klavus, Resektion des unter der Druckstelle liegenden Knochenvorsprungs.

- Vorfußschwielen:

Entstehungsmechanismus (Druck!); Behandlung, z.B. Abhobeln der Schwielen, salizylharnstoffhaltige Salben, Korrektur der Fehlbelastung des Fußgewölbes durch Einlagen in Langform mit Entlastung an den Druckstellen.

\section{Zusatzfrage ,Kalte Füße“}

- Diskussion möglicher Zusammenhänge zwischen „kalten Füßen“ und vegetativer Dysregulation oder mit dem Beruf, ferner mit Mykosen, Warzen, Katarrhen der oberen Luftwege und der Blase.

\section{Zusatzfragen}

\section{„Senk-, Spreiz- und Knickfüße“}

- Aktive Maßnahmen bei mangelhafter Fußwölbung, v.a. bei Kindern/Jugendlichen: Fußgymnastik, Barfußlaufen, Zehengreifübungen, Zehengang.

- Verordnung von Einlagen und Schuhzurichtungen bei Kindern und Erwachsenen.

Andere Indikationen: Insuffizienz der Bein- und
Rückenmuskulatur, Varikosis; Einlagenmaterialien (Kunststoff, Kork, Metall z.B. Aluminium, V2A-Stahl, mit oder ohne Lederbeschichtung, mit oder ohne Supinationskeilen und Fersenbettung), Formulierung der Rezeptur.

- Diskussion der Notwendigkeit von Konfektionsoder Maßverordnung bei Einlagenversorgung.

- Geeignetes Schuhwerk für Einlagenversorgung: Mehrösige Schnürschuhe, Konfektionsschuhe zur Einlagenmessung mitbringen!

- Bei Knickfüßen aktives Muskeltraining u.a. durch Tragen von Holzsandalen.

- Hinweise für den Kauf von Kinderschuhen: Bewegliche Sohlen für Kinderschuhe, keine Einengung des Vorfußes durch modisches Schmalhalten der Schuhe, Zehenfreiheit, Vermessung des Kinderfußes beim Schuhkauf nach dem „WeitenMaß-System“(WMS-Schuhe).

- Indikation für die Versorgung mit orthopädischem Schuhwerk:

z.B. Ausgleich von Beinverkürzungen über $3 \mathrm{~cm}$, Stützung sämtlicher Fußgewölbe, Zustand nach Frakturen im Fußbereich (z.B. Fersenbeinbruch); Kooperation mit dem Spezialisten beispielsweise bei angeborenen Fußfehlbildungen (z.B. Klumpfuß).

\section{Zusatzfragen „Hallux valgus“}

- Ideales Schuhwerk:

Besonders vorne weite Schuhe, seitlich ausgeweitetes Oberleder, offene Schuhe wie Sandalen.

- Behandlung durch Schutzkissen, Hallux-Bandage, Operation (erhebliche Komplikationsrate, oft schlechte Spätresultate!)

\section{Zusatzfragen}

\section{„Kropf und Schilddrüsenüberfunktion“}

- Mögliche Ursachen für einen Kropf:

sog. Kropfgebiete (von Nord nach Süd zunehmender Jodmangel in der Nahrung; relativer Jodmangel in der Schwangerschaft); hormonelle Umstellung (Pubertät, Gravidität, Menopause); Jodbedarf der embryonalen Schilddrüse ab der 10.-12. Schwangerschaftswoche; familiäre Disposition.

- Tägliche Jodzufuhr bei gesunder Schilddrüse: 150-200 mg/Tag (WHO).

- Jodprophylaxe: 5 g Jodsalz verhilft zu etwa $100 \mu \mathrm{g}$ Jod; besonders jodhaltig: Seefisch (z.B. Schellfisch, 
Seelachs, Scholle); 2 mal frischer Seefisch pro Woche beugt möglichem Jodmangel vor; Jodtabletten zu 100-150 $\mu \mathrm{g}$ Jod/Tag.

- Mögliche Komplikationen einer Jodprophylaxe: Induktion einer Hyperthyreose (selten), Auslösen einer echten Jodallergie (absolute Rarität).

- Schilddrüsendiagnostik und Wertigkeit einzelner Methoden:

Gezielte Befragung, Palpation, Halsumfangsmessung, Ultraschalluntersuchung, Szintigraphie, Punktionszytologie, Ösophagusbreischluck unter Röntgenkontrolle; In-vitro-Diagnostik: z.B. TSH, fT 3-RIA, fT 4-RIA.

- Symptome, die an eine Schilddrüsenüberfunktion denken lassen.

- Definition von „heißen Knoten“ (= überaktive autonome Adenome mit vermehrter Anreicherung der Radioaktivität im Szintigramm), von „kalten Knoten" (= gutartige Gewebsanteile, selten bösartige Veränderungen des Schilddrüsengewebes).

Definition der Autonomie: Hormonproduktion unabhängig vom Bedarf des Organismus und von der hypophysären, hypothalamischen Regulation.

Autonomes Adenom: Die autonomen Zellen sind in einem Verband zusammengefaßt.

Disseminierte Autonomie (nur im Jodmangelgebiet!): autonome Zellen sind diffus über die Schilddrüse verteilt.

Dekompensiertes autonomes Adenom: Hormonproduktion findet nur im autonomen Adenom statt. Das paranoduläre Gewebe ist vollständig supprimiert und szintigraphisch nicht darstellbar.

- Therapie der Jodmangelstruma: Jodid bis zu $500 \mu \mathrm{g} / \mathrm{Tag}$, Schilddrüsenhormone (T4-Präparate), Strumaresektion, Radiojodtherapie (angezeigt bei jodavider, kleiner, diffuser Struma oder bei Kontraindikation für Operation).

- Therapie der euthyreoten Struma: Jodid mindestens über $200 \mu \mathrm{g} / \mathrm{Tag}$, L-Thyroxin (z. B. Euthyrox ${ }^{\circledR}$ ), Operation, Radiojodtherapie. Sporadische Struma (bei der Jod nicht die Ursache ist): Jodbehandlung nicht möglich, dagegen LThyroxin, Operation, Radiojodtherapie.

- Einnahmemodus von Schilddrüsenhormonpräparaten:

ggf. schleichende Dosierung (zwingend erforderlich bei Patienten mit KHK), Steigerung in wöchentlichen Abständen bis zur Tageshöchstmenge.
Mögliche Nebenwirkungen bei Überdosierung: Tremor, Tachykardie, Hyperhidrosis.

Achtung: Verstärkung der Wirkung von Antikoagulanzien!

- Therapie der Hyperthyreosen:

Medikamentöse Behandlung mit antithyreoidalen Substanzen wie Carbimazol/Carbimazol ${ }^{\circledR}$ Henning, Thiamazol/Favistan ${ }^{\circledR}$; Operation (bei Patienten z.B. mit Autonomie in einer vergrößerten Schilddrüse); Radiojodtherapie (Mittel der Wahl z.B. bei Automatie, Rezidiven nach Operation, Kontraindikation für Operation).

- Verlaufskontrolle der hormonellen Strumatherapie: Alle 6-12 Monate körperliche Untersuchung (Tastbefund, Halsumfang, Puls, Gewicht etc.), ggf. Sonogramm, Bestimmung des $\mathrm{T}_{3}$-Spiegels im Serum, TSH (Beachte: letzte Tabletteneinnahme am Vortag!), ggf. weiterführende Diagnostik, wenn Verdacht auf Schilddrüsenhormonüberdosierung oder thyreoidale Autonomie besteht, die durch das Schilddrüsenhormonpräparat demaskiert wurde: TRH-Test, Szintigramm etc.

- Operationsindikationen beim Kropf: Strumagröße (Stadium II nach vergeblichem konservativen Behandlungsversuch mit Schilddrüsenhormon, Stadium III), Strumafolgen (Einengung von Trachea, von Ösophagus und/oder Gefäßen), Malignitätsverdacht. Primär kein Alterslimit!

- Betreuung von Patienten nach Strumaresektion: Substitution in den ersten 6 Monaten post operationem mit 75-100 $\mu \mathrm{g} / \mathrm{Tag}$ L-Thyroxin. Nach weiteren 6 Monaten 4wöchiger Auslaßversuch mit Organ- und Funktionskontrolle. Bei Hypothyreoseneigung lebenslange Substitution von Schilddrüsenhormon, alternativ lebenslange Rezidivprophylaxe mit $200 \mu \mathrm{g} / \mathrm{Tag}$ Jodid.

\section{Zusatzfragen „Knoten in der Brust"}

- Bei Inspektion und Palpation zu beachten:

Brustwarzen, Warzenhof, Hautveränderungen, Hautverfärbung, verstärkte Venenzeichnung, Sekretion.

- Instruktionen zur Selbstuntersuchung der weiblichen Brust:

Nach dem 20. Lebensjahr $1 \mathrm{mal}$ im Monat am Ende oder nach der Periode, Untersuchung bei nasser Haut (z.B. beim Duschen), systematischer Untersuchungsgang unter Berücksichtigung aller 
Quadranten, Untersuchung vor dem Spiegel, Untersuchung im Sitzen und im Liegen.

- Beispiele für spezialistische Untersuchungsmethoden und Diskussion ihrer diagnostischen Wertigkeit:

Mammographie, Thermographie, Feinnadelpunktionszytologie, Pneumomammographie, Galaktographie, Probeexzision.

- Konservative Behandlung bei gutartigen Brustveränderungen (Mastodynie, Mastopathie):

Nichthormonell wie kühlende Salben und Umschläge, Pflanzenextrakte (z.B. Mastodynon ${ }^{\circledR}$ ), Diuretika, Methylxanthin-Entzug (Kaffee, Tee, Schokolade), Vitamin $B_{1}$, Vitamin E, Akupunktur. Hormonell wie lokale Gestagene (z.B. Progestogel $\left.^{\circledR}\right)$, Prolaktinhemmer (Pravidel $\left.{ }^{\circledR}\right)$, Minipille (z.B. Microlut ${ }^{\circledR}$ ).

- Indikationen zur (regelmäßigen) Mammographie: Anamnestisches Risiko, Alter über 50 Jahre, vorausgehendes Karzinom der anderen Seite; aber auch beim geringsten Verdacht auf eine Neubildung, bei psychischer Unsicherheit, bei sehr großen und schlecht palpierbaren Mammae.

Beachte: Mammographie aus Beurteilungsgründen möglichst postmenstruell durchführen!

\section{Zusatzfragen ,Mammakarzinom“}

- Suspekte sichtbare und tastbare Veränderungen, die an ein Mammakarzinom denken lassen:

Unterschiedliche Bewegungen der Brüste beim Anheben beider Arme, einseitig eingezogene Brustwarze, einseitige Sekretion aus der Brustwarze, Einziehung oder Vorwölbung der Haut, Auftreten einer ,Apfelsinenhaut“ in einem abgrenzbaren Bezirk, Rötung und Schwellung der Haut, verstärkte Gefäßzeichnungen, ekzematöse Veränderungen von Mamille und Areolabereich, unterschiedliche Konsistenz der Brüste, umschriebene Induration, tastbare regionale Lymphknoten (axillär, supra- und infraklavikulär), geringe Verschieblichkeit eines tastbaren Knotens, Größenzunahme eines bekannten Knotens, Fixierung des Knotens unter der Haut oder auf dem Pektoralismuskel.

- Charakterisierung:

frühzeitig metastasierender Tumor, häufiges Karzinom der Frau, bei kleinem Knoten von 1-2 cm bereits $20-40 \%$ okkulte Fernmetastasen, Metasta- sierung bevorzugt in Knochen, Lungen, Leber, Gehirn und kontralaterale Brust.

- Diskussion eines möglichen Zusammenhangs von Mammakarzinom und Pille (derzeit umstritten).

- Psychische Stadien eines möglichen Krankheitsverlaufes bei Krebskranken:

Angst - Rationalisierung - Verdrängung - kontraphobische Abwehr - Verleugnung - Depression - Aggression und Projektion - Schuld Abhängigkeit und Autonomie - Wiederbelebung guter innerer Erfahrungen - innerseelische Spaltung [180].

\section{Zusatzfragen „Gynäkomastie“}

- Physiologische Gynäkomastie: bei Neugeborenen, Adoleszenten, alten Menschen.

- Beispiele für pathologische Gynäkomastie: vermehrte Östrogenbildung wie bei Hodentumoren, Lungenkarzinom, Lebererkrankungen; $\mathrm{Ne}$ benwirkung bestimmter Medikamente in der Langzeitbehandlung (wie z.B. Östrogene bei Männern, Spironolacton, Cimetidin, INH, Digitalis, Rauwolfia-Präparate).

- Untersuchungsschritte bei Adoleszentengynäkomastie:

Messung der Hoden (Orchidometrie), Palpation der Hoden, Untersuchung der Schambehaarung.

- Diagnostik bei Gynäkomastie im Erwachsenenalter: Fragen nach Medikamenten, Alkohol; Hodenuntersuchung (Tumor?), Abklärung der Leberfunktion; evtl. weitere Diagnostik im spezialistischen Bereich.

\section{Zusatzfragen „Lymphomata“}

- Kontaktfragen, z.B. nach Verletzung, Insektenstich, Tierkontakt, Umgebungsinfektionen, Vita sexualis, berufliche Tätigkeit.

- Einsatz und Aussagekraft bestimmter Laboruntersuchungen wie BKS, Leukozyten, Hb, Differentialblutbild; Komplementbindungsreaktionen, z.B. auf Mononukleose, Toxoplasmose, Röteln; Sternalpunktion.

- Diagnostische Rückschlüsse aus der Lokalisation vergrößerter Lymphknoten:

z.B. retroaurikulär im Rahmen einer exanthematischen Erkrankung: Röteln, Masern;

auffallende bilaterale Vergrößerung im vorderen 
Halsbereich: Mononukleose (Pfeiffersches Drüsenfieber), Toxoplasmose.

Unilateral supraklavikulär: Malignom im Thorax oder im Abdomen; linksseitig lokalisierter supraklavikulärer Lymphknoten („Virchow-Drüse“): Mammakarzinom, intraabdominelle Tumoren, v.a. von Magen, Ovarien, Hoden und Nieren; axillär: Mammakarzinom; kubital beidseits: sekundäre Lues; inguinal: venerische Infektionen wie primäre Lues, Lymphogranuloma venereum, Weicher Schanker, ferner Anus-, Rektum-, Prostata-, Vulva-, Hodenkarzinom;

meist unilateral am Hals: maligne Lymphome (M. Hodgkin, Non-Hodgkin-Lymphome). Achtung: Jeder „Tumor" am Hals ist - abgesehen von einer eindeutig harmlosen Struma - bis zum Beweis des Gegenteils als bösartig anzusehen!

\section{Zusatzfragen „Bursitis acuta“ und „Bursitis chronica“"}

- Behandlung der akut-eitrigen Bursitis olecrani nach vorausgegangener vergeblicher Ruhigstellung, einschließlich Umschlägen: Inzision und Drainage, nach Abheilung wird eine Bursektomie empfohlen.

- Vorgehen bei der chronischen Form: wiederholte Punktionen; ggf. Ruhigstellung; Injektion kleiner Steroiddosen möglich; ggf. Bursektomie.

- Beispiele für weitere praxisrelevante Bursitiden, z.B. B. praepatellaris, B. trochanterica (vgl. Abb. 8 in B 2.2).

- Therapeutisches Vorgehen bei Bursitis im Bereich des Fußes über Skelettvorsprüngen, z.B. Hallux valgus, Fußrist, Haglund-Exostose des Fersenbeins:

Ruhigstellung, entzündungshemmende Lokalbehandlung, Wechsel der Sportart, anderes Schuhwerk, Druckentlastung.

\section{Zusatzfragen ,Tendovaginitis“}

- Lokalisation von Insertionstendopathien und $\mathrm{Zu}$ sammenhang mit sportlichen Aktivitäten: Rotatorenmanschette (Wurf); Achillessehne (Lauf, Sprung); oberer und unterer Patellapol (Sprint, Sprung, Volleyball, Basketball); Adduktoren (Fußball); Ellenbogen (Tennis); Plantarfaszie am Fuß (Lauf).

- Spontanrupturen der Sehnen durch degenerative Veränderungen im Sehnengewebe oder nach Kor- tisonanwendung, z.B. Achillessehne, lange Bizepssehne, Sehnen im Handbereich.

- Therapie der akuten Form:

Eisbeutel, Antiphlogistika, Ruhigstellung, Aufklärung über Zusammenhang mit Sport und Arbeitsplatz.

- Therapie der chronischen Form:

Wärme, funktionelle Verbände, physikalische Therapie, Antiphlogistika, u.U. operative Spaltung des Paratenons; ferner Ausgleich von Fehlformen und fehlerhaften Bewegungsabläufen (Einlagenversorgung, Längenausgleich, Schuhzurichtung durch Absatzerhöhung bei Achillessehnenbeschwerden).

Cave: Kortisoninjektionen im Bereich von Achillessehne und Ligamentum patellae!

\section{Zusatzfrage „Ganglion“}

- Therapie der Wahl:

Operative Entfernung (Achtung: hohe Rezidivquote).

\section{Zusatzfragen „Epicondylitis humeri radialis und ulnaris"}

- Schilderung des Untersuchungsganges (Berührungs- und Druckempfindlichkeit an den Epikondylen, Verstärkung der Schmerzen beim kräftigen Faustschluß und bei der Dorsalextension des Handgelenks gegen Widerstand).

- Mögliche Ursachen, z.B. einseitige körperliche Belastung am Gebrauchsarm (z.B. bei Tennisspielern radialseits, bei Golfern ulnarseits).

- Thrapiemaßnahmen:

z.B. temporäre Schonung (evtl. Ruhigstellung), Kataplasmen, lokale Infiltration, elektrophysikalische Therapie, Krankengymnastik und Massagen auch im Schulter-Nacken-Bereich, ggf. Epikondylititsbandage, z. B. n. Beige, Vermeidung der belastenden Bewegungsmuster, als Ultima ratio Hohmann-Diszision (Trennung der Streck- bzw. Beugesehnen am Epikondylus: dadurch Muskelverkürzung).

\section{Zusatzfragen „Anämie““}

- Ursachen der Anämie:

Verlust an Erythrozyten (akute oder chronische Blutungen), verminderte Erythrozytenproduktion (Eisenmangelanämie, aplastische Anämie), ge- 


\begin{tabular}{|c|c|c|c|c|c|c|c|}
\hline \multicolumn{2}{|c|}{ Blutkörperchen } & \multicolumn{2}{|c|}{ Erwachsene } & \multicolumn{2}{|c|}{ Kinder } & \multicolumn{2}{|c|}{ Säuglinge } \\
\hline \multicolumn{2}{|c|}{ Erythrozyten $/ \mathrm{mm}^{3}$} & \multicolumn{2}{|c|}{$\begin{array}{l}\text { Oَ 4,5-6 Mio. } \\
\text { o 4,1-5,4 Mio. }\end{array}$} & \multicolumn{2}{|c|}{ 4,5-5,5 Mio. } & \multicolumn{2}{|l|}{6 Mio. } \\
\hline \multicolumn{2}{|c|}{ Thrombozyten $/ \mathrm{mm}^{3}$} & \multicolumn{2}{|c|}{$200000-300000$} & \multicolumn{2}{|c|}{$200000-470000$} & \multicolumn{2}{|c|}{$200000-470000$} \\
\hline \multicolumn{2}{|c|}{ Leukozyten $^{a}$} & \multicolumn{2}{|c|}{$\begin{array}{l}4000-9000 / \mu \mathrm{l} \\
4-9 \mathrm{G} / \mathrm{l}\end{array}$} & \multicolumn{2}{|c|}{$\begin{array}{l}8000-12000 / \mu l \\
8-12 \mathrm{G} / \mathrm{l}\end{array}$} & \multicolumn{2}{|c|}{$\begin{array}{l}9000-15000 / \mu l \\
9-15 \mathrm{G} / \mathrm{l}\end{array}$} \\
\hline \multirow{6}{*}{ 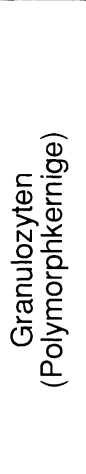 } & & {$[\%]$} & absolut & {$[\%]$} & absolut & {$[\%]$} & absolut \\
\hline & Neutrophile & $55-70$ & $\begin{array}{l}2200-6300 / \mu l \\
2,2-6,3 \mathrm{G} / \mathrm{l}\end{array}$ & $35-70$ & $\begin{array}{l}2800-8400 / \mu l \\
2,8-8,4 \mathrm{G} / \mathrm{l}\end{array}$ & $25-65$ & $\begin{array}{l}2250-9750 / \mu l \\
2,25-9,75 \mathrm{G} / \mathrm{l}\end{array}$ \\
\hline & Stabkernige & $3-5$ & $\begin{array}{l}120-450 / \mu \mathrm{l} \\
0,12-0,45 \mathrm{G} / \mathrm{l}\end{array}$ & $0-10$ & $\begin{array}{l}-1200 / \mu l \\
-0,12 \mathrm{G} / \mathrm{l}\end{array}$ & $0-10$ & $\begin{array}{l}-1500 / \mu \mathrm{l} \\
-0,15 \mathrm{G} / \mathrm{L}\end{array}$ \\
\hline & Segmentkernige & $50-70$ & $\begin{array}{l}2000-6300 / \mu l \\
2-6,3 \mathrm{G} / \mathrm{l}\end{array}$ & $25-65$ & $\begin{array}{l}2000-7800 / \mu \mathrm{l} \\
2-7,8 \mathrm{G} / \mathrm{l}\end{array}$ & $22-65$ & $\begin{array}{l}2250-9750 / \mu l \\
2,25-9,75 \mathrm{G} / \mathrm{l}\end{array}$ \\
\hline & Eosinophile & $2-4$ & $\begin{array}{l}80-360 / \mu \mathrm{l} \\
0,08-0,36 \mathrm{G} / 1\end{array}$ & $1-5$ & $\begin{array}{l}80-600 / \mu 1 \\
0,08-0,6 \mathrm{G} / \mathrm{l}\end{array}$ & $1-7$ & $\begin{array}{l}90-1050 / \mu \mathrm{l} \\
0,09-1,05 \mathrm{G} / \mathrm{l}\end{array}$ \\
\hline & Basophile & $0-1$ & $\begin{array}{l}-90 / \mu \mathrm{l} \\
-0,09 \mathrm{G} / \mathrm{l}\end{array}$ & $0-1$ & $\begin{array}{l}-120 / \mu \mathrm{l} \\
-0,12 \mathrm{G} / \mathrm{l}\end{array}$ & $0-2$ & $\begin{array}{l}-300 / \mu \mathrm{l} \\
-0,03 \mathrm{G} / \mathrm{l}\end{array}$ \\
\hline \multirow{2}{*}{ 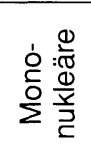 } & Monozyten & $2-6$ & $\begin{array}{l}80-540 / \mu \mathrm{l} \\
0,08-0,54 \mathrm{G} / \mathrm{l}\end{array}$ & $1-6$ & $\begin{array}{l}80-720 / \mu 1 \\
0,08-0,72 \mathrm{G} / \mathrm{l}\end{array}$ & $7-20$ & $\begin{array}{l}630-3000 / \mu l \\
0,63-3,0 \mathrm{G} / /\end{array}$ \\
\hline & Lymphozyten & $25-40$ & $\begin{array}{l}1000-3600 / \mu l \\
1-3 \mathrm{G} / \mathrm{l}\end{array}$ & $25-50$ & $\begin{array}{l}2000-6000 / \mu \mathrm{l} \\
2-6 \mathrm{G} / \mathrm{l}\end{array}$ & $20-70$ & $\begin{array}{l}1800-10500 / \mu \mathrm{l} \\
1,8-10,5 \mathrm{G} / \mathrm{l}\end{array}$ \\
\hline
\end{tabular}

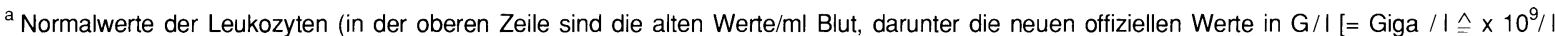
Blut] angegeben: \%-Werte sollen durch Anteil ersetzt werden, d.h. $50 \% \bumpeq 0,5)$

steigerter Erythrozytenabbau (hämolytische Anämie)

- Laborbasisdiagnostik:

Hämoglobin (sicherheitshalber Doppelansatz!); bei Hb-Verminderung: Erythrozyten + Leukozyten + Hämatokrit + Stuhl auf okkultes Blut sowie $\mathrm{HbE}+\mathrm{MCHC}$ aus den Grunddaten ${ }^{15}$

- Beispiele für Eisenmangelanämie:

Blutverluste (häufig menstruell, gastrointestinal, Blutspenden); gesteigerter Eisenbedarf (Schwangerschaft, Stillzeit, Wachstumsalter); ungenügende Eisenzufuhr mit der Nahrung; perniziöse Anämie (z. B. nach abgebrochener Behandlung mit Vitamin $\left.\mathrm{B}_{12}\right)$.

\footnotetext{
$\overline{\frac{\mathrm{Hb}(\mathrm{g} \%)}{\text { Ery (Mio.) }}} \times 10=\mathrm{HbE}$ (Normalbereich $\left.27-32 \mathrm{pg}\right)$

$\frac{\mathrm{Hb}(\mathrm{g} \%)}{\mathrm{Hk}(\text { Vol.- } \%)} \times 100=\mathrm{MCHC}($ Normalbereich $30-36 \%)$
}

- Deutlich erhöhte Retikulozytenwerte beim unbehandelten Patienten:

Hinweis auf hämolytische Anämie (Zahl der Retikulozyten im peripheren Blut als Maß für die erythropoetische Aktivität des Knochenmarks).

- Prinzip des Blutausstrichs (Differentialblutbild) (Tabelle 72):

Beurteilung und Bestimmung des Prozentanteils der einzelnen Leukozytenarten (neutrophile Granulozyten; jugendliche, stabkernige, segmentkernige Granulozyten; eosinophile Granulozyten; basophile Granulozyten; sowie der Monozyten und Lymphozyten) nach spezieller Färbung (meist n. Pappenheim). Zur Ausstrichdifferenzierung gehört auch die Beurteilung der Erythrozyten in Bezug auf Größe, Form, Farbe, abnorme Formen und Einschlüsse. Das gleiche gilt für die Thrombozyten.

- Resorbierbarkeit von zweiwertigen (Ferro-) und dreiwertigen (Ferri-)Eisensalzen. Ferrisalze für die perorale Therapie von Eisenmangelzuständen oh- 
ne Bedeutung wegen mangelhafter Resorption durch die Darmschleimhaut.

Bewährt: Ferroverbindungen mit Zusatz von Askorbinsäure (z.B. Eryfer $\left.{ }^{\circledR}\right)$. Einnahme auf nüchternen Magen. Patient auf mögliche Magenunverträglichkeit und schwarzen Stuhl hinweisen.

- Problematik der parenteralen Eisentherapie mit dreiwertigen Eisenverbindungen:

Reizung der Gefäßwände durch die intravenöse Injektion (Thrombophlebitis, akute Vergiftungssymptome wie Kopfschmerzen, Hitzegefühl, Übelkeit, Erbrechen, Herzschmerzen, evtl. Kollaps!); bräunliche Verfärbung der Haut an der Injektionsstelle bei intramuskulärer Gabe.

Merke: Intravenöse Eisenanwendung ausschließlich, wenn perorale Eisentherapie wirkungslos bleibt!

- Seltene Indikation für parenterale Eisenzufuhr: manche Darmerkrankungen (z.B. Kolitis).

- Indikationen für die (ambulante) Transfusionstherapie:

chronische normovolämische Anämien mit Hypoxiesymptomen, chronische aplastische Symptome, maligne Systemerkrankungen des hämatopoetischen Systems, hereditäre und erworbene korpuskuläre hämolytische Anämien, palliative Therapie, Strahlentherapie. Vollblut nur bei Hypovolämie, sonst Erythrozytenkonzentrate.

- Diskussion der Eigenblutgabe zur Vermeidung von Fremdbluttransfusionen (Vermeidung HIVkontaminierter Blutkonserven, Hepatitis, Zytomegalie, Krebs).

Indikationen: z.B. elektive Eingriffe. Eigenblutspenden in mehreren Etappen bereits Wochen vor dem Operationstermin organisieren! Gleichzeitige Eisengabe!

- Beispiele für Krankheiten, die typischerweise mit einer Anämie einhergehen können: chronische Polyarthritis (c.P.), Urämie, Leberzirrhose.

- Medikamente, die Leukopenien auslösen können: z.B. Zytostatika, Analgetika, Thyreostatika, Antikonvulsiva, Antirheumatika.

- Eosinophilie als Hinweis auf allergische Ätiologie (Medikamente, Asthma, Heuschnupfen) und parasitäre Erkrankungen (z.B. Würmer).

Das Ausmaß der Eosinophilie ist kein Indikator für die Krankheitsaktivität! 